UC-25 - Metals, Ceramics, and Materials TID-4500 (29th ed.)

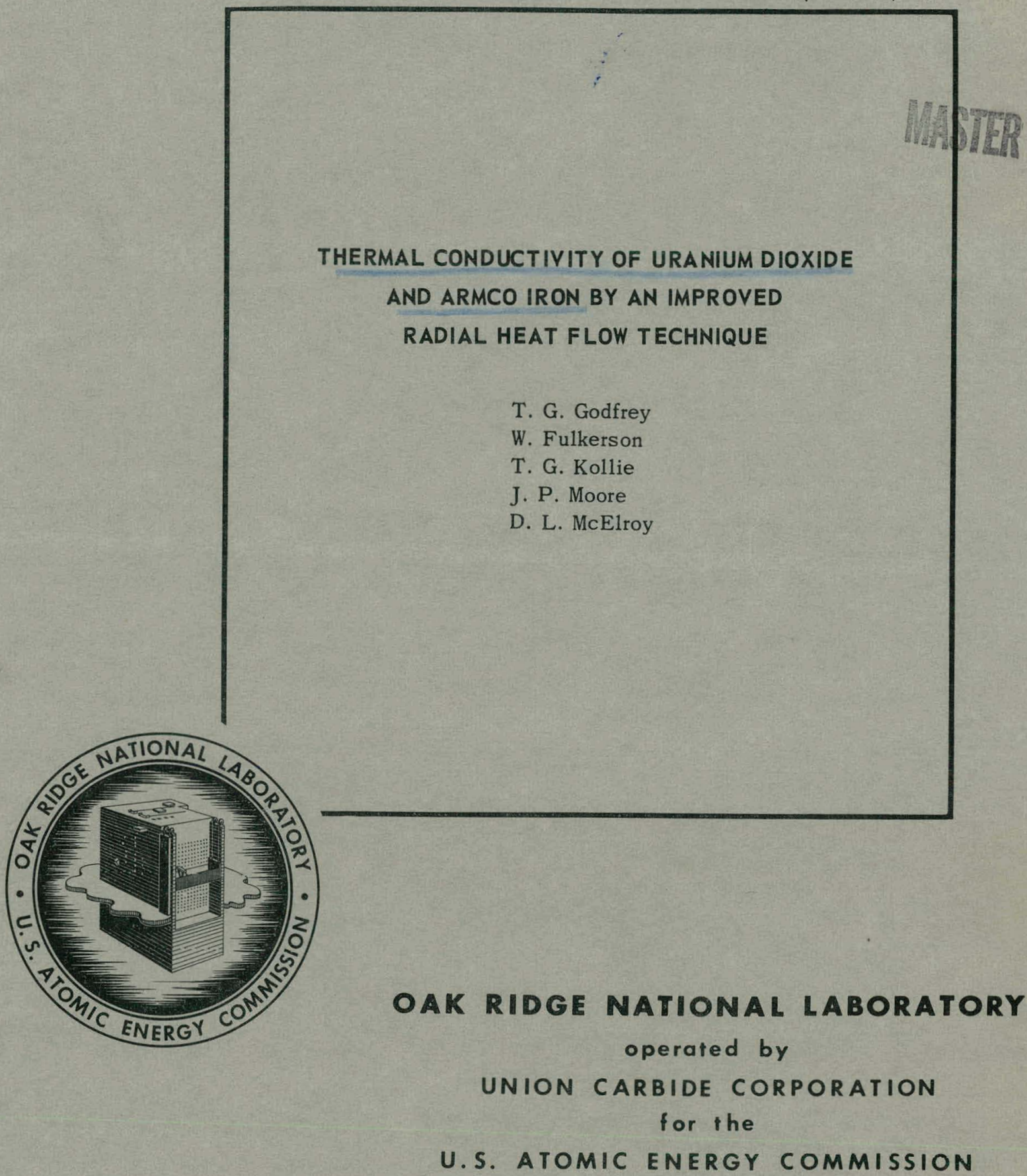




\section{DISCLAIMER}

This report was prepared as an account of work sponsored by an agency of the United States Government. Neither the United States Government nor any agency Thereof, nor any of their employees, makes any warranty, express or implied, or assumes any legal liability or responsibility for the accuracy, completeness, or usefulness of any information, apparatus, product, or process disclosed, or represents that its use would not infringe privately owned rights. Reference herein to any specific commercial product, process, or service by trade name, trademark, manufacturer, or otherwise does not necessarily constitute or imply its endorsement, recommendation, or favoring by the United States Government or any agency thereof. The views and opinions of authors expressed herein do not necessarily state or reflect those of the United States Government or any agency thereof. 


\section{DISCLAIMER}

Portions of this document may be illegible in electronic image products. Images are produced from the best available original document. 
Printed in USA. Price: $\$ 1.75$ Available from the

Office of Technical Services

U. S. Department of Commerce

Washington 25, D. C.

\section{LEGAL NOTICE}

This report was prepared as an account of Government sponsored work. Neither the United States, nor the Commission, nor any person acting on behalf of the Commission:

A. Makes any warranty or representation, expressed or implied, with respect to the accuracy, completeness, or usefulness of the information contained in this report, or that the use of any information, apparatus, method, or process disclosed in this report may not infringe privately owned rights; or

B. Assumes any liabilities with respect to the use of, or for damages resulting from the use of any information, apparatus, method, or process disclosed in this report.

As used in the above, "person acting on behalf of the Commission" includes any employee or contractor of the Commission, or emplayee of such contractor, to the extent that such employee or contractor of the Commission, or employee of such contractor prepares, disseminates, or provides access to, any information pursuant to his employment or contract with the Commission, or his employment witlı such controctor. 
ORNL-3556

Contract No. W-7405-eng-26

METALS AND CERAMICS DIVISION

THERMAL CONDUCTIVITY OF URANIUM DIOXIDE AND ARMCO IRON BY AN IMPROVED RADIAL HEAT FLOW TECHNIQUE
T. G. Godfrey
W. Fulkerson
T. G. Kollie
J. P. Moore
D. L. McElroy

JUNE 1964

\footnotetext{
OAK RIDGE NATIONAL LABORATORY

Oak Ridge, Tennessee

operated by

UNION CARBIDE CORPORATION

for the

U.S. ATOMIC ENERGY COMMISSION
} 


\section{THIS PAGE}

\section{WAS INTENTIONALLY LEFT BLANK}




\section{CONTENTS}

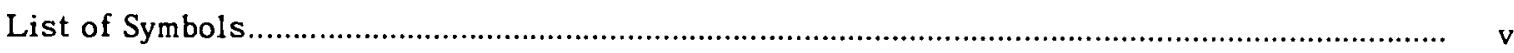

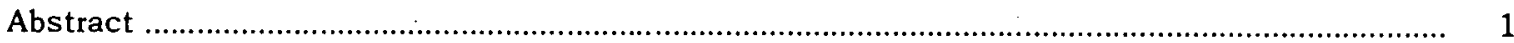

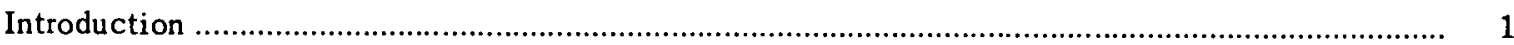

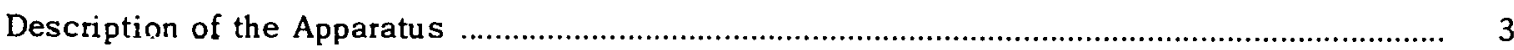

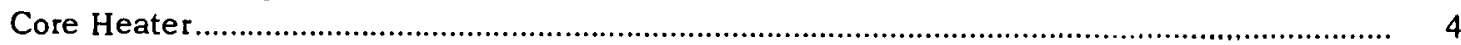

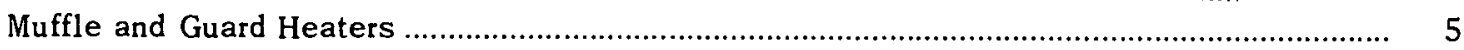

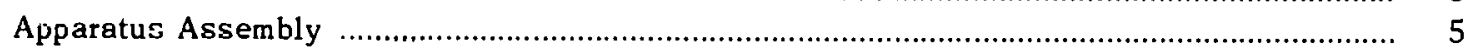

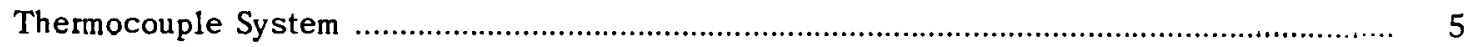

Power and Temperature Control Systems .............................................................. 8

Method of Operation and Data Analysis ............................................................................. $\quad 9$

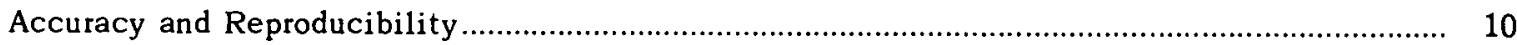

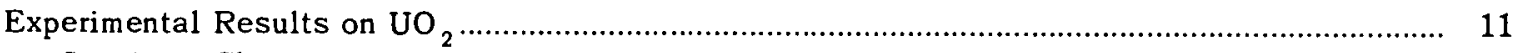

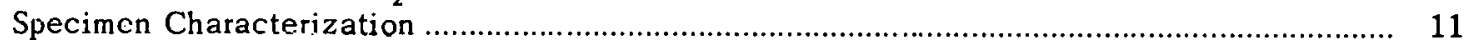

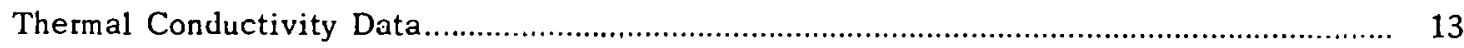

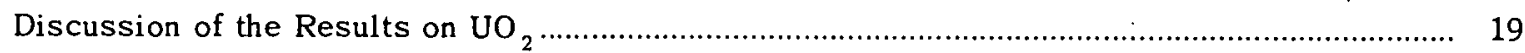

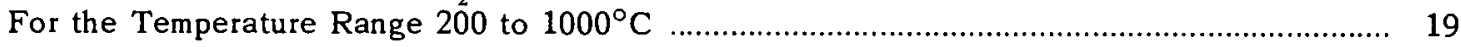

Derivation of an Expression for Thermal Resistance .................................................... 19

Calculation of Debye Characteristic Temperature ................................................... 21

Impurity Scattering Cross-Section Estimation ............................................................. 21

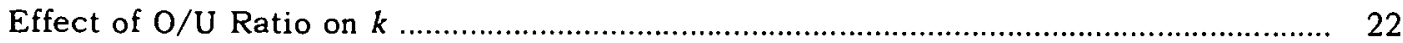

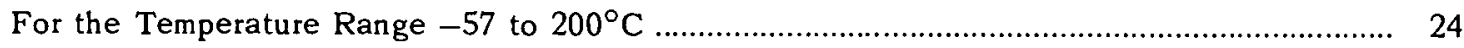

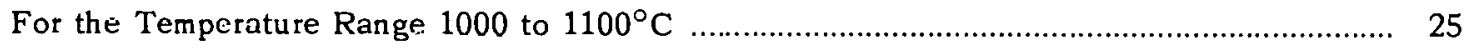

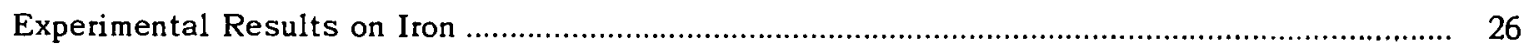

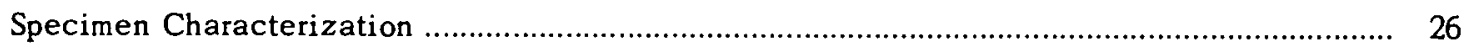

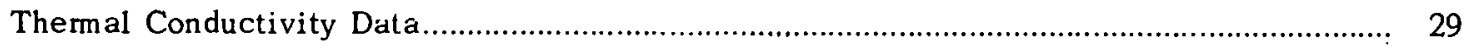

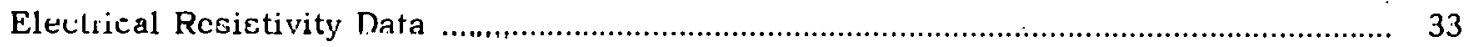

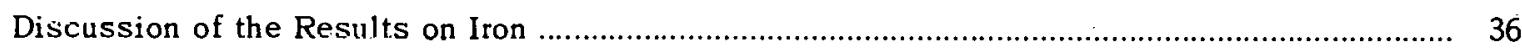

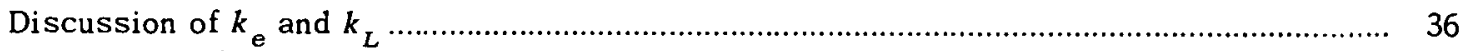

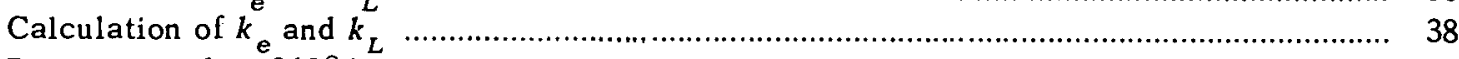

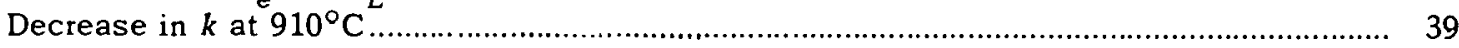

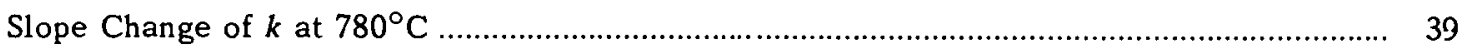

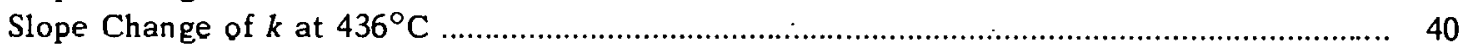

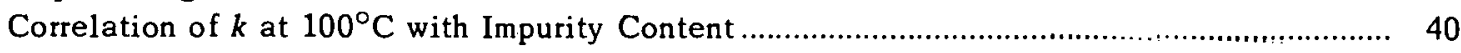

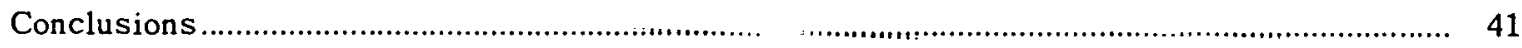

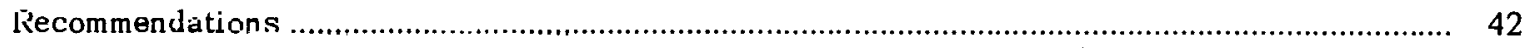

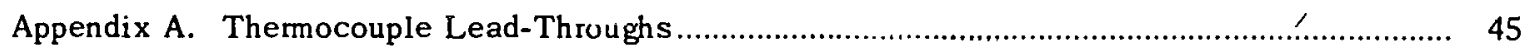

Appendix B. Determinable Errors for the Radial Heat Flow Apparatus................................... 47 
Appendix C. Thermocouple-Immersion-Depth Test

Appendix D. $\mathrm{UO}_{2}$ Thermal Conductivity Data ...................................................................... 51

Appendix E. Armco Iron Thermal Conductivity and Thermal Diffusivity Data............................ 55

Appendix F. Determinate Errors in Electrical Resistivity Measurements .................................. 59

Appendix G. Electrical Resistivity Data for Armco Iron ........................................................ 60

Appendix H. Electrical Resistivity Data of $\mathrm{Pt}$ vs Pt-10\% Rh ............................................. 61

Appendix I. Sample Data Sheets and Calculations ............................................................. 62 
$A$ See Eq. $4, \mathrm{~cm}^{\circ} \mathrm{K} \mathrm{w}^{-1}$

$A^{*}$ Cross-sectional area, $\mathrm{cm}^{2}$

a A constant defined by Eq. $16, \mathrm{w} \mathrm{cm}^{-1}{ }^{\mathrm{K}_{\mathrm{K}}}{ }^{-1}$

$B$ See Eq. 4, cm/w

$b$ A constant defined by Eq. 16, unitless

$C_{V}$ Heat capacity at constant volume, wsec ${ }^{9} \mathrm{~K}^{-1} \mathrm{~g}$-mole $\mathrm{e}^{-1}$

$C_{p}$ Heat capacity at constant pressure, wsec ${ }^{0} \mathrm{~K}^{-1} \mathrm{~g}$-mole ${ }^{-1}$

$C_{1}$ A constant defined by Eq. 27, $\mu \mathrm{ohm}-\mathrm{cm}$

$\mathrm{C}_{2}$ A constant defined by Eq. $27, \mu \mathrm{ohm}-\mathrm{cm} /{ }^{\circ} \mathrm{K}$

$\mathrm{C}_{3}$ A constant defined by Eq. 27., $\mu \mathrm{uhm}-\mathrm{cm} /{ }^{\circ} \mathrm{K}^{3}$

$c_{V}$ Specific heat at constant volume, wsec ${ }^{0} \mathrm{~K}^{-1} \mathrm{~cm}^{-3}$

$c_{P} \quad$ Specific heat at constant pressure $w \sec { }^{C^{-1}} \mathrm{~g}^{-1}$

$E$ Modulus of elasticity, dynes $/ \mathrm{cm}^{2}$

$E_{G} \quad$ Forbidden band gap, ev

e Electronic charge, coulombs

$h$ Planck's constant, $6.628 \times 10^{-34} \mathrm{wsec}^{2}$

$\bar{l} \quad$ Average electric current, amp

k. Total thermal conductivity, $\mathrm{w} \mathrm{cm}^{-1}{ }^{\mathrm{K}^{-1}}$

$k_{u} \quad$ Reciprocal of $R_{u}$, the thermal resistance due to umklapp processes, $w \mathrm{~cm}{ }^{1} \mathrm{~K}^{-1}$

$k_{0} \quad$ See Eq. $17, \mathrm{w} \mathrm{cm}^{-1} \circ_{\mathrm{K}^{-1}}$

$k_{L} \quad$ Lattice portion of the thermal conductivity, $\mathrm{w} \mathrm{cm}^{-1}{ }^{\mathrm{O}^{-1}}$

$k_{\mathrm{e}}$ Electronic portion of the thermal conductivity, $\mathrm{w} \mathrm{cm}^{-1} \mathrm{~K}^{-1}$

$k$ Boltzmann's constant, $1.38 \times 10^{23}$, wsec/ $/{ }^{2}$

$L$ Theoretical value of the Wiedemann-Franz-Lorenz constant, $2.45 \times 10^{-8} \mathrm{w}$-ohm $/{ }^{\circ} \mathrm{K}^{2}$

$L^{*} \quad$ Length hetween voltage taps, $\mathrm{cm}$

$\bar{l}_{i} \quad$ Average phonon mean free path, $\mathrm{cm}$

$\bar{l}_{u}$ Average phonon mean free path due to umklapp processes, $\mathrm{cm}$

$\bar{\ell}_{I}{ }_{I} \quad$ Average phonon mean free path due to phonon impurity interaction, $\mathrm{cm}$

$M \quad$ Mass per atom, $\mathrm{g}$

$N_{i} \quad$ Concentration of impurities of type " $i$, , number $/ \mathrm{cm}^{3}$

$n$ A constant in Eq. 16, unitless

$Q \quad$ Heat flow rate, w

$R \quad$ 'Thermal resistance, em $\mathrm{K} \mathrm{w}^{-1}$

$R_{u \text {. }} \quad$ Thermal resistance due to umklapp processes, $\mathrm{cm}{ }^{\mathrm{K}} \mathrm{w}^{-1}$

$R_{I} \quad$ Thermal resistance due to impurity scattering, $\mathrm{cm} * \mathrm{~K} \mathrm{w}^{-1}$

$r$ Radial position in a specimen relative to the cylindrical axis, $\mathrm{cm}$

$r_{1}$ Radial position of inside thermocouples, $\mathrm{cm}$

$r_{2}$ Radial pusition of the outside thermorouples, $\mathrm{cm}$

$S$ Seebeck coefficient, $\mu \mathrm{v} /{ }^{\circ} \mathrm{K}$ 
$T \quad$ Absolute temperature, ${ }^{\circ} \mathrm{K}$

$t$ Temperature, ${ }^{\circ} \mathrm{C}$

$V$ Molar volume, $\mathrm{cm}^{3} / \mathrm{g}$-mole

$\bar{V}_{1} \quad$ Average thermocouple emf of thermocouples at radius $r_{1}$

$\bar{V}_{2}$ Average thermocouple emf of thermocouples at radius $r_{2}$

$\bar{v}$ Average phonon velocity, $\mathrm{cm} / \mathrm{sec}$

a Thermal diffusivity, $\mathrm{cm}^{2} / \mathrm{sec}$

$a_{v}$ Volume thermal expansion coefficient, ${ }^{\circ} \mathrm{K}^{-1}$

$a_{L}$ Linear thermal expansion coefficient, $\mathrm{K}^{-1}$

$\triangle \quad$ A symbol representing a finite change

$\delta$ Cube root of the volume per atom, $\mathrm{cm}$

$\epsilon$ Determinahle error, unitlc3s

$\gamma \quad$ Gruneisen constant defined by Eq. 11, unitless

$\kappa$ Isothermal compressibility, $\mathrm{rm}^{3} / \mathrm{wsec}$

$n \quad 3.141 .6$

$\rho \quad$ Electrical resistivity, $\mu$ ohm-cm

$\rho_{0} \quad$ A constant defined by Eq. $31, \mu$ ohm $-\mathrm{cm}$

$\rho^{*}$ Density, $\mathrm{g} / \mathrm{cm}^{3}$

$\sigma \quad$ Electrical conductivity, $\mu \mathrm{ohm}-\mathrm{cm}^{-1}$

$\sigma_{e}$ The portion of the electrical conductivity due to electrons, $\mu \mathrm{ohm}-\mathrm{cm}^{-1}$

$\sigma_{h}$ The portion of the electrical conductivity due to holes, $\mu \mathrm{ohm}-\mathrm{cm}^{-1}$

$\sigma_{i}$ Scattering cross section of " $i$ " type impurity; $\mathrm{cm}^{2}$

$O_{D}$ Debye temperature, $u_{K}$

$\Omega \quad$ Electrical resistance, ohms 


\title{
THERMAL CONDUCTIVITY OF URANIUM DIOXIDE AND ARMCO IRON BY AN IMPROVED RADIAL HEAT FLOW TECHNIQUE
}

\author{
T. G. Godfrey, W. Fulkerson, T. G. Kollie, J. P. Moore, and D. L. McElroy
}

\begin{abstract}
.
A description of an improved radial heat flow technique for measuring the thermal conductivity of solids in the range -57 to $1100^{\circ} \mathrm{C}$ is presented. The technique yielded results with a probable accuracy of $\pm 1.5 \%$ and a reproducibility of $\pm 0.1 \%$ in this range. Meaningful measurements were limited to $1100^{\circ} \mathrm{C}$ by Pt vs Pt-10\% Rh thermocouple instability, although the apparatus was structurally sound to $1400^{\circ} \mathrm{C}$. The thermal conductivity of polycrystalline $\mathrm{UO}_{2}$ was measured from -57 to $1100^{\circ} \mathrm{C}$ and reveals a maximum in $k$ near room temperature caused by the decrease of the lattice specific heat. The thermal resistance, $1 / k$, shows a linear dependence with temperature from 200 to $1.000^{\circ} \mathrm{C}$, which is expected for an insulator well above its Debye temperature. The slope of the $1 / k$-temperature plot is $0.0223 \mathrm{~cm} / \mathrm{w}$, and this is independent of impurity content, although the intercept is sensitive to impurity content. The thermal conductivity of polycrystalline Armco iron was measured between 100 and $1000^{\circ} \mathrm{C}$ and was found to be within \pm 2 to $3 \%$ of the best values reported in the literature. The temperature dependence of the thermal conductivity of iron is largely controlled by the electronic contribution, which was deduced from electrical conductivity measurements. The thermal conductivity of iron can be represented by four linear equations for the temperature ranges 0 to 436,136 to 786,786 to 910 , and 910 to $1000^{\circ} \mathrm{C}$. A slope change of $30 \%$ at $436^{\circ} \mathrm{C}$ may be coupled to a minimum in the thermoelectric power of iron near this temperature. A minimum in the thermal conductivity occurs near $786^{\circ} \mathrm{C}$ and is associated with the Curie transformation. A $4 \%$ decrease in the thermal conductivity was observed at the $\alpha-\gamma$ transformation $\left(910^{\circ} \mathrm{C}\right)$, and this is associated with a change in the lattice contribution to the total thermal conductivity.
\end{abstract}

\section{INTRODUCTION}

The first objective of this work was to develop apparatuses and techniques capable of producing very accurate thermal conductivity values for solid specimens between room temperature and $1400^{\circ} \mathrm{C}$. A second goal was to study materials of nuclear and scientific interest to learn about the heat-transfer mechanisms controlling thermal conductivity, $k$.

There is no universal thermal conductivity method which is applicable for use for all solid specinens at all temperatures. For this reason a number of overlapping methods are necessary to measure $k$ over a wide spectrum of specimens and temperatures. The radial heat flow apparatus described here is one such method which Powell ${ }^{1}$ developed in 1939 to measure $k$ of Armco iron. It is an absolute method and is capable of very good accuracy. For this reason

\footnotetext{
${ }^{1}$ R. W. Powell, "Further Measurements of the Thermal and Electrical Conductivity of Iron at High Temperatures." Proc. Phys. Soc. (Loridnn) 51, 407 (1939).
} 
the present apparatus was developed to measure materials which can be used as standards in checking the accuracy of other methods under development. The method has disadvantages in that large specimens are required and that measurements at a given temperature normally require 8 hours.

The versatility and accuracy of the radial heat flow apparatus were demonstrated by measurements on two widely different materials, $\mathrm{UO}_{2}$ and Armco iron. Uranium dioxide is a semiconductor with a low thermal conductivity, whereas iron is a metal with a high thermal conductivity. Both of these materials have been measured extensively by other investigators and thus afford ample grounds for comparison. However, accurate measurements of the thermal conductivity of both materials are of scientific interest to enable the differentiation of the various heat transfer mechanisms operative in these two materials. In fact, there is a heated debate ${ }^{2-7}$ about whether or not $k$ of UQ, reactnr fupl elements inrirases di prory higli lemperatures and about what mechanisms could cause such an increase. The debate can be settled only by good high-temperature measurements. In addition, recent data tạken hel lnwi rogm tomperature by Béthoux, Thomas, and Weil ${ }^{8}$ show that $k$ of $\mathrm{UO}_{2}$ has two local maxima - one at about $300^{\circ} \mathrm{K}$ and another at about $10{ }^{\circ} \mathrm{K}$. This shape of the thermal conductivity-temperature curve is related to the antiferromagneticparamagnetic transition at about $30^{\circ} \mathrm{K}$ (ref 8 ). This effect was also verified qualitatively by a group at CEN. ${ }^{9}$ In light of this information, a much closer scrutiny of the thermal conductivity of $\mathrm{UO}_{2}$ at room temperature and below was in order.

Armco iron is considered by many to be a thermal conductivity standard, and Powel1 ${ }^{10}$ recently reviewed the published data. This review shows that below $600^{\circ} \mathrm{C}$ the data spread is about $4 \%$ but becomes progressively larger at higher temperatures, amounting to $42 \%$ at $900^{\circ} \mathrm{C}$. Because of the spread, more accurate high-temperature measurements are needed. In addition, there is considerable uncertainty about the effect of the ferrnmagnetic-paramannelic transition and the ay pliase lransformation on the thermal conductivity sn that additional medsurements at these temperatures are of interest.

\footnotetext{
${ }^{2}$ J. L. Bates, "Thermal Conductivity of UO ${ }_{2}$ Improves at High Temperature," Nucleonics 19(6), 83 (1961).

${ }^{3} \mathrm{D}$. Wiedenbaum, High Performance UO $\mathrm{O}_{2}$ Program - Quarterly Progress Report No. 8, January-March 1963 , GEAP-3771-8 (Apr. 15, 1963), ser 4. pp 1n-11.

'J. A. L. Robertson et al., "Temperature Distribution in $\mathrm{UO}_{2}$ Fuel Elements," J. Nucl. Mater, 7(3), 21854 (1962).

${ }^{5}$ I. Cohen, B. Lustman, and J. E. Eichenberg, Measurement of the Thermal Condirctivity of Mctal-Claul Uranium Oxide Rods Durine Irradiation, WA PD-228 (August 1960).

${ }^{6}$ A. J. Anthony, C. E. Burdg, and R. J. Sanderson, "Out-of-Pile Thermal Testing of UO 2 Fuel Elements," Trans. Am. Nucl. Soc. 5(1), 236.(1062).

${ }^{7}$ M. F. Lyons et al., "UO 2 Thermal Conductivity at Elevated Temperatures," Trans. Am. Nucl. Soc. 6(1), 152 (1963).

${ }^{8} \mathrm{O}$. Béthoux, P. Thomas, and L. Weil, "Conductibilite thermique de $\mathrm{UO}_{2}$ a basse temperature," Compt. Rend. 253(19), 2043-45 (1961).

${ }^{9}$ Minutes of Ceramic Fuels Meeting Held in Brussels, 3-5 Oct., 1962, Euratom-United States Joint Research and Development Board, TID-7666 and EUR/C/4936 62e, p 20.

${ }^{10}$ R. W. Powe11, "Armco Iron as a Thermal Conductivity Standard. Part I, Review of Published Data," p 454 in Progress in Intemational Research on Thermodynamic and Transport Properties (ed. by Joseph F. Mesi and Donald H. Tsai), The American Society of Mechanical Engineers and Academic Press, New York, 1962.
} 
For iron, much of the heat is transported by electrons, so measurements of electrical conductivity are helpful in evaluating thermal conductivity behavior. Therefore supplementary electrical conductivity measurements were made on this material.

The following sections contain extensive descriptions of the experimental apparatus and techniques as well as a detailed characterization of the specimens tested. These were included to allow critical evaluation of this work.

\section{DESCRIPTION OF THE APPARATUS}

The present radial heat flow apparatus was designed to produce a measurable outward radial heat flow in a cylindrical specimen consisting of a stack of disks, several of which are instrumented with thermocouples to determine the radial temperature gradient. Each specimen disk had a central $5 / 8$-in. hole, and the heat flow was generated by an axial core heater carefully positioned in this hole. The overall temperature of the specimen was maintained by an enclosing cylindrical

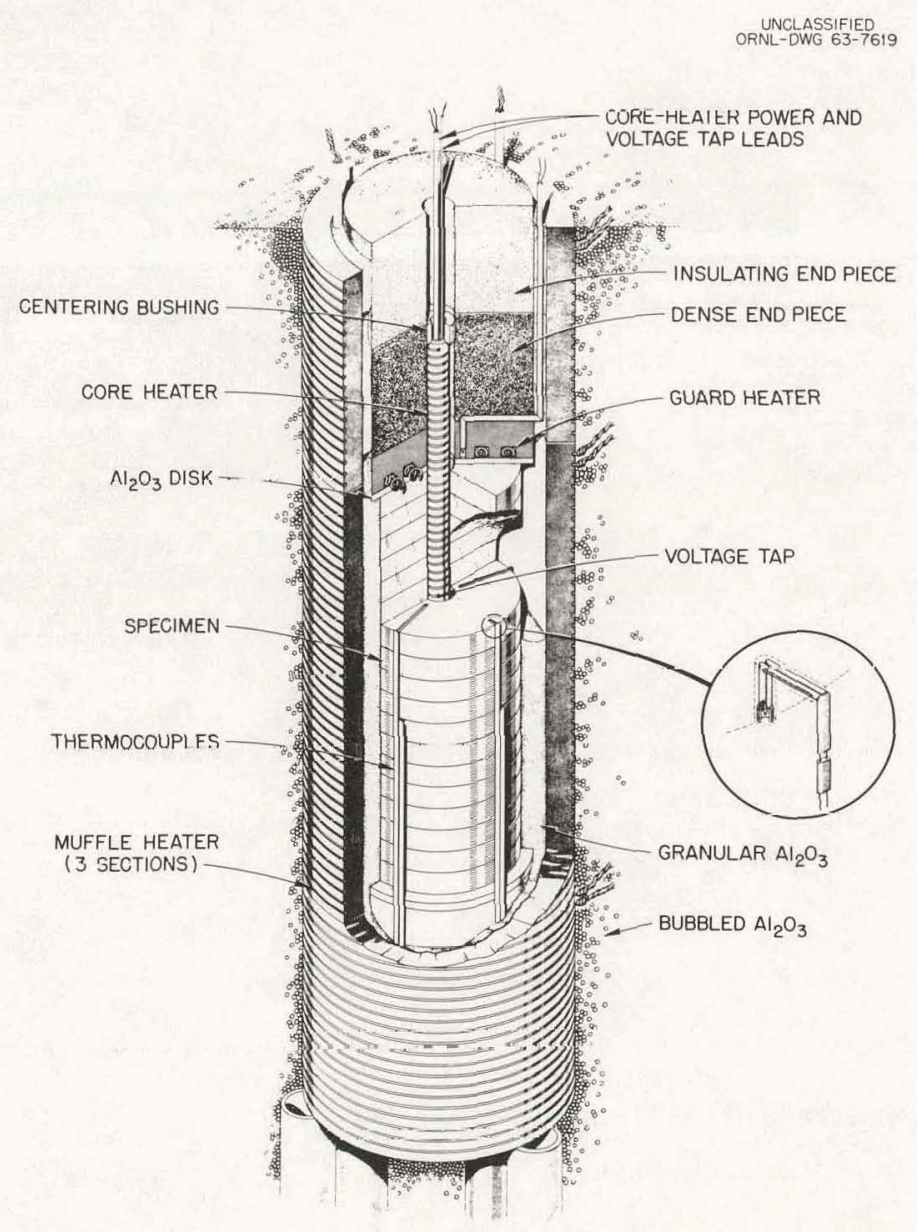

Fig. 1. Schematic Drawing of Apparatus. 
muffle heater. Radial heat flow was ensured by the use of end guard heaters and also by adjusting the power to the separately wound end sections of the muffle heater. To protect the specimen from oxidation, the apparatus was contained in a water-cooled brass chamber under $1 \mathrm{~atm}$ of helium which was $99.999 \%$ pure. To prevent convection currents and to minimize radiation losses, the annuli between the specimen and the muffle heater and between the specimen and the core heater were filled with granular alumina. For thermal insulation the space outside the muffle heater was filled with bubbled alumina. Figure 1 is a schematic drawing of the apparatus. Figures $2(a)$ and $2(b)$ show the apparatus in stages of assembly.

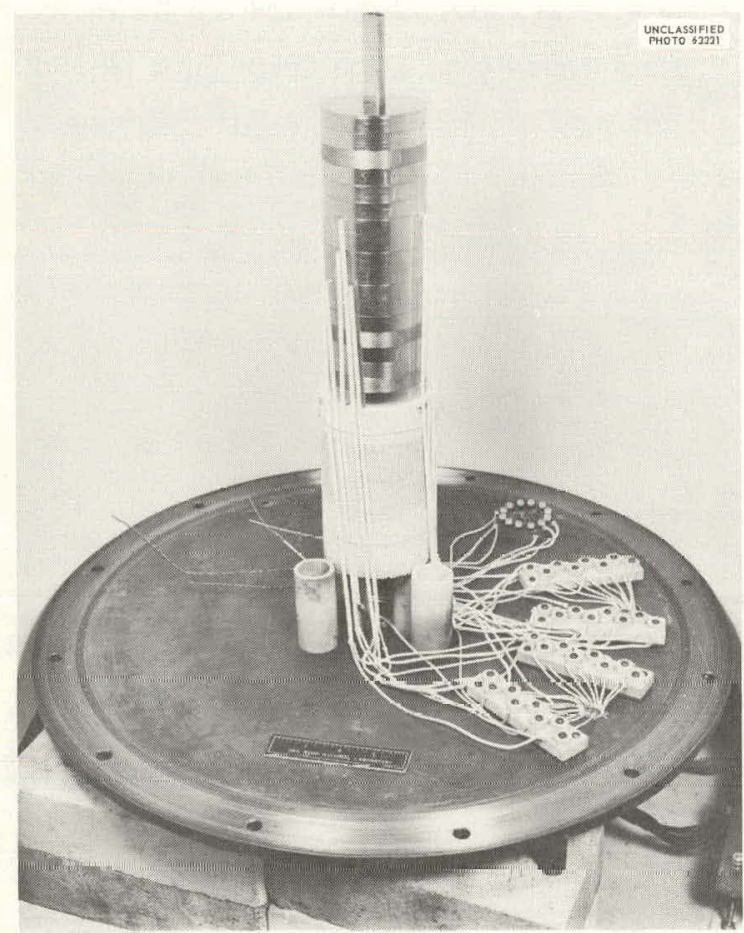

Fig. 2(a). Armco Iron Specimen Disks in the Radial Heat Flow Apparatus, Showing the Thermocouples, the Bottom Guard Heater, the Bottom Insulating Pieces, and the Thermocouple Connection Blocks. The brass axial rod is an assembly aid.

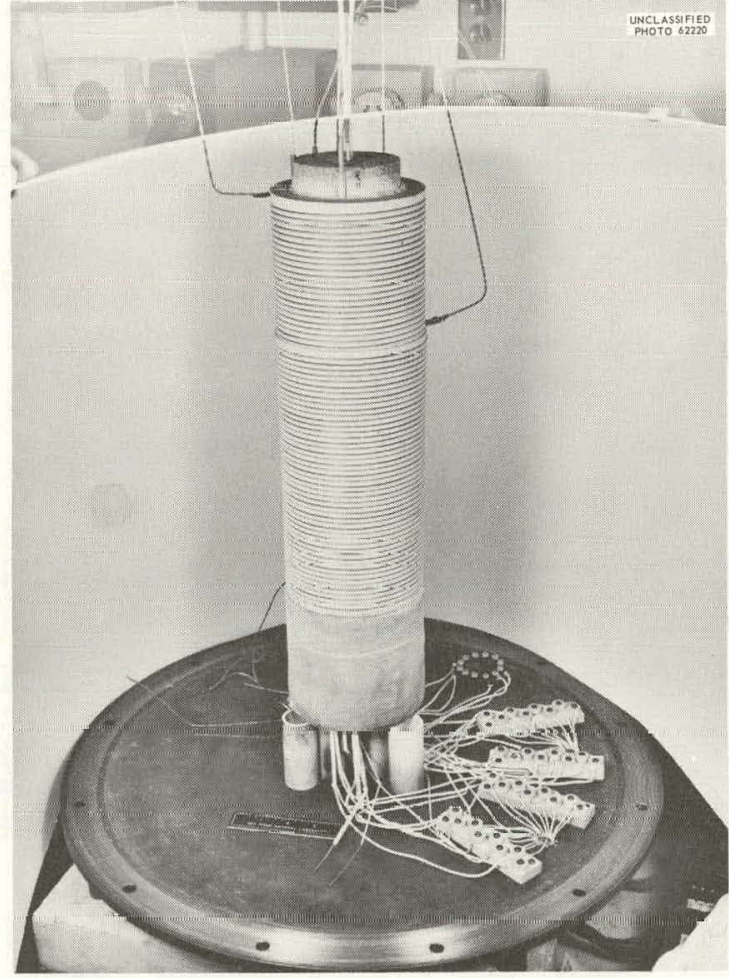

Fig. 2(b). Radial Heat Flow Apparatus, Showing the Three Independent Sections of the Muffle Heater in Place.

\section{Core Heater}

The core heater was made by winding a double strand of 0.020 -in.-diam Pt-10\% Rh wire on a 3/8-in.-OD, 15-in.-long Coors AD-99 alumina tube grooved 9 turns per inch. Two small holes were drilled exactly $3 \mathrm{in}$. apart in the center section of the tube. These holes accommodated the $0.020-$ in. $\mathrm{Pt}-10 \% \mathrm{Rh}$ voltage taps which were tweezer-welded to both heater wires. The voltage taps 
and the input power leads were connected to 12-gage copper wires just inside the water-cooled brass shell. These and all other power leads passed through the shell by means of large Kovar seals.

\section{Muffle and Guard Heaters}

The muffle assembly consisted of a 10-in. center section and two 5 -in. end sections, as shown in Fig. 2. Each section consisted of a 5-in.-OD $\times$ 4-in.-ID McDaniel high-purity alumina tube which was grooved 5 turns per inch to accommodate a bifilar winding of 0.047 -in.-diam molybdenum wire. The end guard heaters were 1 -in.-thick $3 \frac{1}{2}$-in.-OD spirally grooved alumina disks. A coiled winding of 0.040-in.-diam molybdenum wire was cemented into the spiral groove with alumina cement. A $\frac{1}{8}$-in.-thick $3 \frac{1}{2}$-in.-OD Coors AD-99 alumina disk separated each end guard heater from the specimen stack. The end guard heaters were backed by two $2 \frac{1}{2}$-in.-thick $3 \frac{1}{2}$-in.-OD alumina pieces, as shown in Fig. 1. The inside piece was cut from a dense $99 \%$ alumina brick, and the second, from a bubbled alumina brick. The end guard heaters, alumina disks, and backup pieces were suitably drilled to accommodate the core heater and its lead wires.

\section{Apparatus Assembly}

In assembling the apparatus, the specimen stack together with associated end pieces was built around a $\frac{5}{8}$-in. alignment rod to ensure axial symmetry between all components. As the stacking proceeded, the various measuring planes were instrumented with thermocouples as described below. After the top guard heater and backup pieces were in place, the alignment rod was removed and replaced by the core heater which was aligned axially by close-fitting alumina bushings contained in the top and bottom dense brick. Figure 2(a) shows the Armco iron specimen with the alignment rod still in place. When the stack assembly was completed, the muffle furnace sections were lowered over it, and granular alumina was poured into the annulus between the specimen and the muffle and between the specimen and the core heater. The water-cooled chamber was lowered into position, power and voltage connections were made, and the chamber was filled with bubbled alumina.

\section{Thermocouple System}

Several of the specimen disks were instrumented with thermocouples which were fitted into 0.063-in.-diam holes drilled in the disks perpendicular to the radial direction. The thermocouple wires extended out of the specimen stack through shallow grooves in the measuring planes. Figure 3 shows the thermocouple groove and hole arrangement for the measuring planes of the iron and $\mathrm{UO}_{2}$ specimens. For $\mathrm{UO}_{2}$ there were three measuring disks, each containing four $3 / 8$-in.-deep thermocouple wells - two at an inside radius of $0.450 \mathrm{in}$. and two at an outside radius of 1.375 in. These measuring disks were placed in the central 3 in. of the stack with two noninstrumented disks between each pair of measuring planes. For the iron there were two 1-in.-thick measuring 


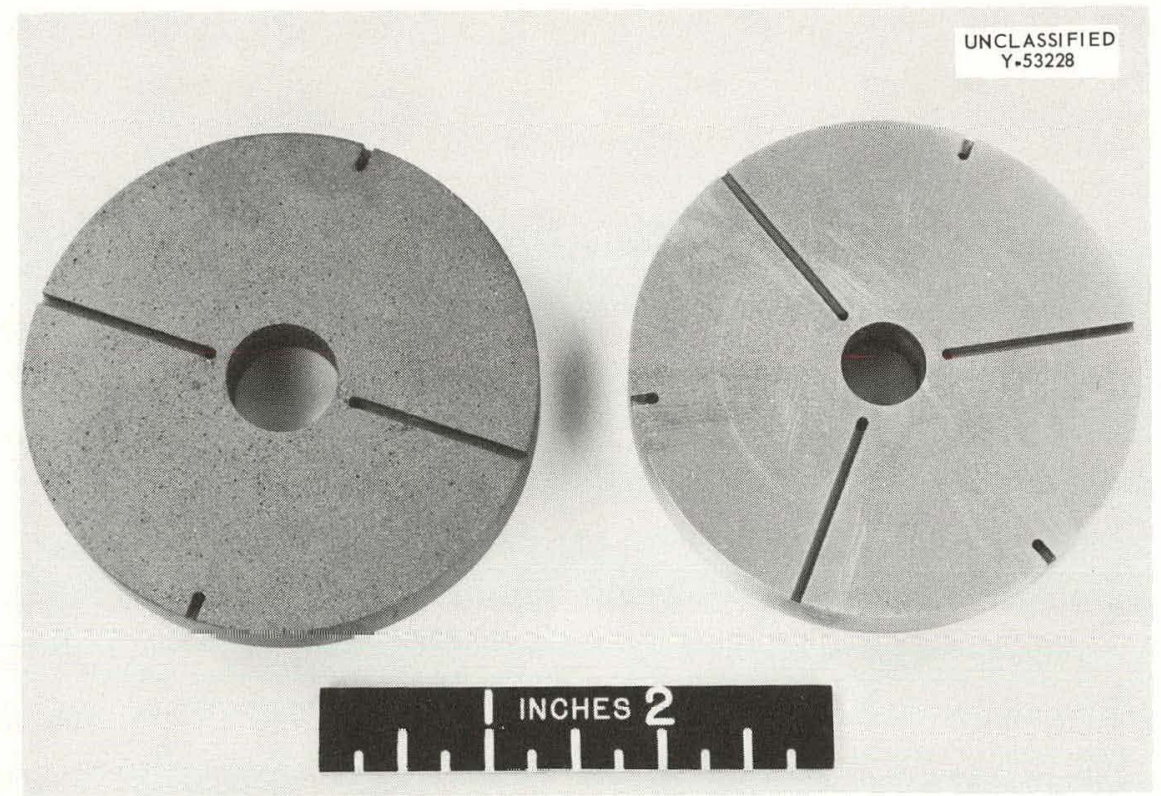

Fig. 3. Armco Iron and $\mathrm{UO}_{2}$ Measuring Plane Disks, Showing the Thermocouple Groove and Hole Arrangements fur llie Rudiul Heä Flow Apparatus.

disks, each containing six $\frac{3}{4}$-in.-deep thermocouple wells - three on an inside radius of 0.500 in. and three on an outside radius of $1.313 \mathrm{in}$. These disks were also placed in the center $3 \mathrm{in}$. of the stack and were separated from each other by a noninstrumented, 1-in.-thick disk, as shown in Fig. 2(a).

Precise temperature measurement is the most critical aspect of the experimcnt. The thermocouples used were made from Sigmund Cohn reference-grade annealed $\mathrm{Pt}$ and $\mathrm{Pt}-10 \% \mathrm{Kh}$ wire except for some low-temperature experiments on $\mathrm{UO}_{2}$ where copper/Constantan thermocouples were used because of their greater sensitivity and the fact that tabulated emf's exist. The hot junctions of the thermocouples were positioned near the bottom of the holes in the measuring disks. The wires from these junctions were insulated electrically by two one-hole 0.031 -in.OD $\times 0.015$-in.-ID Degussit A123 alumina tubes. The hot junction was insulated electrically

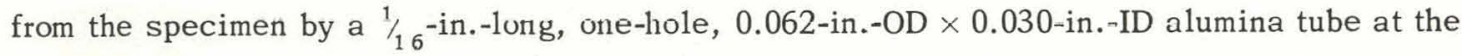
bottom of the hole which also served to position the junction along the axis of the hole.

The thermocouples were made from 0.010-in.-diam wire which was tweezer-welded to 0.020 in.-diam wire just outside the stack. The smaller wire was used to minimize conduction losses from the hot junction, and the larger wire was used to decrease the probability of developing compositional or structural inhomogeneities in the region where the wire passes through severe temperature gradients. The 0.020-in.-diam wires were insulated in two-hole Morganite $\Delta R R$ 
alumina tubing which was placed in the annulus between the muffle and the specimen and extended below the $\mathrm{Al}_{2} \mathrm{O}_{3}$ insulating pieces. From below these pieces the thermocouple wires extended through woven quartz tubing to fired lavite (hydrous aluminum silicate) tie-down blocks on the water-cooled brass baseplate as shown in Figs. 2(a) and 2(b). At these blocks the wires were mechanically connected to $\mathrm{Pt}$ and $\mathrm{Pt}-10 \% \mathrm{Rh}$ wires which extended to the cold junction terminal board. This mechanical connection was made by pressing one wire on top of the other under lavite pieces screwed to the tie-down blocks such that the wires were in contact with no second metal. Several thermocouples were later added to the system and employed a different type of tie-down block as may be seen at the rear of the baseplate in Figs. 2(a) and 2(b). This tie-down block was made from Micarta, * and the thermocouple wires were clamped under nylon-coated steel screws. When the apparatus was reinstrumented or a new specimen installed, it was necessary only to replace the thermocouple wires from the specimen to these tie-down blocks. The thermocouple wires passed through the baseplate in seals which are described in detail in Appendix A. Mechanical connections of these wires to the $\mathrm{Pt}$ and $\mathrm{Pt}-10 \% \mathrm{Rh}$ wires of the cold well were made at a shielded Micarta terminal board under nylon-coated steel screws. The cold junction was made by twisting the thermocouple wires to 0.020-in.-diam vinyl-insulated copper wires. The cold junctions were insulated from each other by vinyl tubing and were placed two each in 7-mm glass tubes partially filled with mineral oil for thermal cuntact. The glass tubes were fitted in a drilled copper block which was immersed in an ice bath. This copper block served to ensure that all of the cold junctions were at the same temperature such that the greatest accuracy could be attained for the differential emf measurements. It also served as a thermal inertia block in maintaining the cold junction temperature constant during the time the ice bath was being changed. The copper wires from the cold junction extended to vermiculite-filled switch boxes housing eight L\&N thermalfree two-pole twelve-position switches which allowed absolute and differential thermal emf measurements to be made. Connections at the switches were made using L\&N thermal-free sọlder.

The copper wires were 24-gage solid conductors from Western Electric Corporation telephone cable which contaned 25 pairs of color-rnded wires. This cable was very convenient to use because of the large number of thermocouples involved. Tests showed that the copper wilres in this cable were homogeneous and exhibited thermal emf's of $<0.02 \mu \mathrm{v}$ when coupled with L8.N thermalfree solder, switch lugs, and potentiumeter terminals.

A Rubicon six-dial potentiometer with a certified accuracy of $10.01 \%+0.01 \mu \mathrm{v}$ was used in conjunction with an L\&N upright galvanometer and a 20-ft optical lever to obtain a $0.01-\mu v$ null balance on all thermocouple emf's.

To minimize the effects of stray emf's and clectrostatic fields, all lead wires were sheathed with braided coppcr shielding, and all switch boxes and related components were tied to one earth

* Micarta is a trade name for phenol-formaldehyde compound laminated fabric base, thermosetting plastic, manufactured by Micarta Division of Westinghouse Electric and Manufacturing Company. 
ground with large conductors. The potentiometer was used to assure that parasitic or residual emf's due to placement of the wires were minimized and were less than $0.01 \mu \mathrm{v}$.

\section{Power and Temperature Control Systems}

The power to the core heater was supplied by a magnetic and transistor regulated dc power supply (Electronics Research Associated model 36-12M) which has $\pm 0.05 \%$ load and line regulation and $\pm 0.005 \%$ rms ripple. In-line tests showed that the unit is very acceptable for this application. In the early stages of the development of the apparatus, a bank of $12-v$ storage batteries, tapped such that multiples of $2 \mathrm{v}$ could be obtained, were used to supply power to the core heater. However, the voltage drift of these batteries was found to be excessive for this steady-state method.

The dc power to the central 3-in. section of the core heater was determined by measuring the voltage drop between the voltage taps and the voltage drop acruss a 0.U1-ohm L\&N standard resistor, model 4222 , through which the core heater current passed. These voltages were read using a $\mathrm{L} \& \mathrm{~N}$ type $\mathrm{K}-3$ potentiometer.

The overall temperature of the specimen was automatically controlled by the independent adjustment of the power to the three sections of the muffle furnace (in early runs on $\mathrm{UO}_{2}$ the muffle consisted of only one 10 -in. section). A Pt vs $\mathrm{Pt}-10 \% \mathrm{Rh}$ thermocouple was attached to each muffle heater section and was connected in series opposition with a Zener diode voltage source.* The output of the diode source was adjusted sn that tho differentlal emt was zero when the deslred temperature was reached. This differential emf was amplified by a L\&N Microvolt Amplifier and fed to a $-5-0+5$ mv span L\&N Speedomax H-DAT controller. Each DAT pulsed power from a suitable Variac power supply to achieve temperature control. In order to gain finte control and to reduce the effects of pickup by the thermocouples, only a small fraction of the total power to the heaters was pulsed. This was accomplished by the use of adjustable shunt resistors in parallel with the control relays of the power supplies. By this method the temperature control was $\pm 0.01^{\circ} \mathrm{C}( \pm 0.1 \mu \mathrm{v})$ at the heater thermocouples; this resulted in $\pm 0.002^{\circ} \mathrm{C}$ $( \pm 0.02 \mu \mathrm{v})$ control within the specimen stack which could be maintained constant for several hours. At high temperatures, to reduce pickup by the thermocouples, it was sometimes necessary to substitute a dc power supply to drive the muffles. This power supply was a full-wave silicon diode bridge rectifier capable of supplying $35 \mathrm{dc}$ amps at $140 \mathrm{v}$ and was installed at the output of the Variac power supplies.

Axial heat flow in the specimen was restricted by the end guard heaters, and two different thermocouple arrangements were used to achieve control of these heaters. In the first method 0.010-in.-diam $\mathrm{Pt}$ vs $\mathrm{Pt}-10 \% \mathrm{Rh}$ differential thermocouples were placed in comparable positions in the top and center disks and the bottom and center disks in the specimen stack. Each

*ORNL I\&C Division Stable Millivolt Reference Supply, model Q-2156-2. 
differential thermocouple was connected to a $L \& N$ Microvolt Amplifier which fed a $-5-0+5 \mathrm{mv}$ span L\&N Speedomax H-DAT controller which pulsed power from a Variac power supply to the guard heaters to maintain a zero differential emf. This method of control required minimum attention and performed well at temperatures below about $600^{\circ} \mathrm{C}$, but at higher temperatures it became unsatisfactory due to electrical leakage through the alumina insulators which tended to short the differential junctions. In order to circumvent these difficulties, 0.020-in.-diam thermocouples with grounded junctions were inserted in holes drilled in the end guard heaters and were used for absolute temperature control above $600^{\circ} \mathrm{C}$. These thermocouples were used in the Zener diode-type control systems as were described for the muffle heaters.

\section{METHOD OF OPERATION AND DATA ANALYSIS}

The thermal conductivity was calculated by using the following equation for steady-state radial heat flow in a continuous isotropic medium which is devoid of heat sources or sinks.

$$
k=\frac{Q}{2 \pi L^{*}} \frac{\ln r_{2} / r_{1}}{\Delta T}
$$

where $Q / L^{*}$ is the radial heat flow per unit time per unit length in the specimen, and $\Delta T$ is the temperature difference between the two radial positions, $r_{1}$ and $r_{2}$. This equation was derived from Fourier's equation for radial flow in a right circular cylinder, which is

$$
\frac{Q}{L^{*}}=-k 2 \pi r \frac{d T}{d r}=\text { constant }
$$

In calculating $k, Q$ is assumed to be equal to the joule heat dissipated per unit time in the length $L^{*}$ of the core heater between the voltage taps. The values of $r_{1}$ and $r_{2}$ were taken as the position of the renters of the inside and outside thermocouple holes with respect to the axis of the spccimen. Since $r_{1}$ and $r_{3}$ appear only as a ratio, the measurements are independent of the thermal expansion of the specimen, which constitutes an advantage over luingitudinal methods. However, the thermal expansion of the core heater will change $L^{*}$. This correction amounts to $<1 \%$ at $1000^{\circ} \mathrm{C}$ and was included in the calculation of $k$, by making $L^{*}$ of Eq. (2) temperature dependent using data supplied by the manufacturer for the thermal expansion of Coors AD-99 alumina. The $\Delta T$ in Eq. (1) was obtained by averaging the readings of the inner thermocouples, subtracting the average of the outside readings, and dividing the resulting difference by the thermnrouple sensitivity or Seebeck coefficient. The thermocouple sensitivity was obtained in two ways. In the first method the sensitivity was obtained by graphically smoothing the first differences taken from the NBS Bulletin No. 561, Table 1 (ref 11). In the second method the sensitivity was obtained by taking 1955).

${ }^{11}$ H. Shenker et al., "Reference Tables for Thermocouples," Nat1. Bur. Std. (U.S.), Circ. 561 (Apr. 27, 
the first derivative of an equation by Flynn ${ }^{12}$ which fits NBS Bulletin No. 561 (Table 1) between 0 and $1450^{\circ} \mathrm{C}$ to within about $\pm 10 \mu \mathrm{v}$. The two sensitivities obtained agreed for all temperatures to $1150^{\circ} \mathrm{C}$ to within $1 \%$.

The value of $k$ calculated by Eq. (1) corresponds to a temperature which is the arithmetic average of the temperatures at $r_{1}$ and $r_{2}$, if $k$ is no higher order than a linear function of temperature over the range $\Delta T$. Thus, in the experiment the $\Delta T$ was kept very small so that the temperature dependence of $k$ could be very accurately determined and at the same time minimize thermal stresses in the specimen. For Armco iron, the $\Delta T$ 's were $3 / 4$ to $4^{\circ} \mathrm{C}$ and for $\mathrm{UO}_{2}, 2$ to $6^{\circ} \mathrm{C}$ below $800^{\circ} \mathrm{C}$ and 6 to $20^{\circ} \mathrm{C}$ above $800^{\circ} \mathrm{C}$. For such small $\Delta T$ 's, calibration differences between the thermocouples were extremely important. For this reason the thermocouples were intercompared at so-called isothermal conditions before each data point was taken. Thus at a given temperature an isothermal test was performed by comparing the theilucuuuple readings with no power to the core heater. Then power was supplied to the core heater, and the average stack temperature was readjusted to the same value as for the isothormal test. The $\Lambda T$ used in Eq. (1) was then obtained by the relation,

$$
\Delta T=\Delta T_{\mathrm{data}}-\Delta T_{\mathrm{is}} \text {, }
$$

where $\Delta T_{\text {data }}$ is the difference of the averages of the inside and outside thermocouple readings, with the core heater on, divided by the sensitivity, and $\Delta T_{\text {is o }}$ is the corresponding difference with the core heater off. A set of sample calculations and data sheets are given in Appendix I.

The isothermal test also corrects for radial heat flow which might be present even when the core heater is turned off. For example, when tho cale lieder was olf, the specimen may not have been truly isothermal because of imperfect guarding and insulation; however, since Eq. (1) is linear in $Q$ and $1 / \Delta T$, the isothermal correstinn meroly subliacts the effect of these extra heat tiows. Furthermore, even though the "Isorhermal" hcat fluws are not entirely radial, the $\Delta T_{\text {is o }}$ will correct for their effect it the nonradial portion is not appreciably changed by turning on the core heater. Experimental evidence for this was obtained by purposely running the apparatus with varying guarding conditions. It was found that, if the isothermal test was made under the same guarding conditions used when the core heater was on, the l'esulting value of $k$ was largely independent of guarding. Thus for a fixed $Q$ applied to the core heater, $\Delta T$ was constant even though $\Delta T_{\text {iso }}$ and $\Delta T_{\text {data }}$ were severely changed by different guarding conditions. It should also be mentioned that at a given temperature the data fit Eq. (1) very well. That is, $\Delta T$ was directly proportional to $Q$, and the $k$ obtained was independent of the magnitude of $Q$. Obviously, the isothermal corrections were much more important at low values of $\Delta T$ and $Q$.

\section{ACCURACY AND REPRODUCIBILITY}

The accuracy of the method cannot be stated with absolute certainty. The maximum possible error in $k$ due to inaccuracies in the measurements of the quantities which are used in $\mathrm{Eq}$. (1) can

\footnotetext{
${ }^{12}$ D. R. Flynn, private communication, Apr. 10, 1963.
} 
be assessed, and this is done in Appendix B. This error is between \pm 3.8 to $4.9 \%$ with a most probable value of \pm 0.9 to $1.3 \%$, assuming that the errors are random. The real difficulty is in assessing how closely the experimental conditions fulfill the boundary condition used to derive Eq. (1). An indirect way to ascertain the overall accuracy of the method is to compare the results for some standard material with those of other laboratories. It will be pointed out below that the values obtained for $\mathrm{UO}_{2}$ and Armco iron in this work were acceptably close to those obtained by other authors. For Armco iron, which is considered by many to be a thermal conductivity standard, this agreement indicates that the above probable error estimate is also a reasonable absolute accuracy statement.

However, one would like to be able to check directly how closely the experiment comes to fulfilling the boundary conditions. This can be done by observing the effect on the results of systematic changes in the apparatus or its operation which cause the boundary conditions to be more nearly fulfilled. For example, a possible source of error in the experiment was deviation from radial heat flow caused by improper guarding. For this reason the length of the muffle heater was doubled, and the length of the core heater increased from 10 to $15 \mathrm{in}$. between runs 4 and 5 on $\mathrm{UO}_{2}$. The data given in Tables D.4 and D.5 Appendix D show that that this changed the results by $<0.6 \%$. Furthermore, it was shown that the results were largely insensitive to the longitudinal temperature profile in the stack so long as both the data and isothermal tests were taken under the same guarding conditions.

Auxiliary experiments described in Appendix $\mathrm{C}$ were performed to assess the possible error due to the $3 / 8$-in. thermocouple immersion depth in the $\mathrm{UO}_{2}$ specimen. It was found that the error was on the order of $0.1 \%$. In view of these test results the most probable accuracy of the technique appears to be that associated with the determinate errors, \pm 0.9 to $\pm 1.3 \%$.

If reproducibility or repeatability is defined as the percent change in the results for several sets of measurements without any intentional change in the system or operating conditinns, then the reproducibility of this system was better than $\pm 0.1 \%$. These repeat measurements were made under approximately steady-state conditions (i.e., drift rates $<0.1 \% / \mathrm{hr}$ ), and several hours were allowed to elapse between measurements. The $0.1 \%$ is of the same order as the estimaled uncertainties in determining the power and thermocouple emf's, as can be seen from rows 1, 6, and 7 of Table B.1, Appendix B. This excellent repeatability is one of the best features of this radial heat flow apparatus.

\section{EXPERIMENTAL RESULTS ON UO}

\section{Specimen Characterization}

The $\mathrm{UO}_{2}$ disks were made by culd pressing nuclear grade depleted $\mathrm{UO}_{2}$ powder and by sintering in hydrogen at $1850^{\circ} \mathrm{C}$ for $4 \mathrm{hr}$. This resulted in a solid with open and closed pores which 
was $93.4 \%$ of the theoretical density $\left(10.97 \mathrm{~g} / \mathrm{cm}^{3}\right)$. The powder was produced by the thermal decomposition and reduction of ammonium diuranate ( $\Lambda D U)$. Table 1 gives the analyzed impurity contents of the original specimen. The $\mathrm{O} / \mathrm{U}$ ratio was determined to be $2.01 \pm 0.01$. The \pm 0.01 indicates the range by which several different analyses of $O / U$ differed. However, the reproducibility of any given method was much better than this. Reliable measurements of the change in $\mathrm{O} / \mathrm{U}$ of the specimen which occurred during run 1 as discussed below were obtained by a thermogravimetric analysis technique before and after run 1 . Figure 4 shows a photomicrograph of this $\mathrm{UO}_{2}$ and indicates a mean grain diameter of 10 to $20 \mu$.

Table 1. Chemical Anolysis of $\mathrm{UO}_{2}$ Specimen

\begin{tabular}{|c|c|c|}
\hline Impurity & $(\mathrm{ppm})$ & $\begin{array}{c}\text { (Atoms per Molecule } \\
\text { of } \mathrm{UO}_{2} \text { ) }\end{array}$ \\
\hline & & $\times 1 \dot{0}=5$ \\
\hline Mo & 5.6 & 1.8 \\
\hline $\mathrm{Cr}$ & $2-14$ & 4.2 \\
\hline $\mathrm{Ni}$ & $2-11$ & 3.7 \\
\hline Al & h & 0.0 \\
\hline $\mathrm{Cu}$ & 300 & 203 \\
\hline $\mathrm{Na}$ & 1 & 1 \\
\hline $\mathrm{C}$ & 40 & 90 \\
\hline $\mathbf{N}$ & 30 & 58 \\
\hline$F$ & $<20$ & $<28$ \\
\hline Fe & 265 & 128 \\
\hline $\mathrm{Si}$ & $<10$ & $<13$ \\
\hline $\mathrm{Ag}$ & $<0.5$ & Negligible \\
\hline $\mathrm{B}$ & $<.0 .5$ & Negligible \\
\hline $\mathrm{Cd}$ & $<10$ & $<2.4$ \\
\hline $\mathrm{Nb}$ & 62 & 18 \\
\hline $\mathrm{Cu}$ & 0.2 & Negligible \\
\hline $\mathrm{Eu}$ & $<0.5$ & Neyligible \\
\hline Gd & $<0.3$ & Negligible \\
\hline $\mathrm{Pb}$ & $<5$ & $<0.7$ \\
\hline $\mathrm{sm}$ & $<4$ & $<0.7$ \\
\hline \multirow[t]{2}{*}{ Sn } & 37 & 8.4 \\
\hline & & 565.9 \\
\hline$O$ (excess) & 593 & 1000 \\
\hline
\end{tabular}




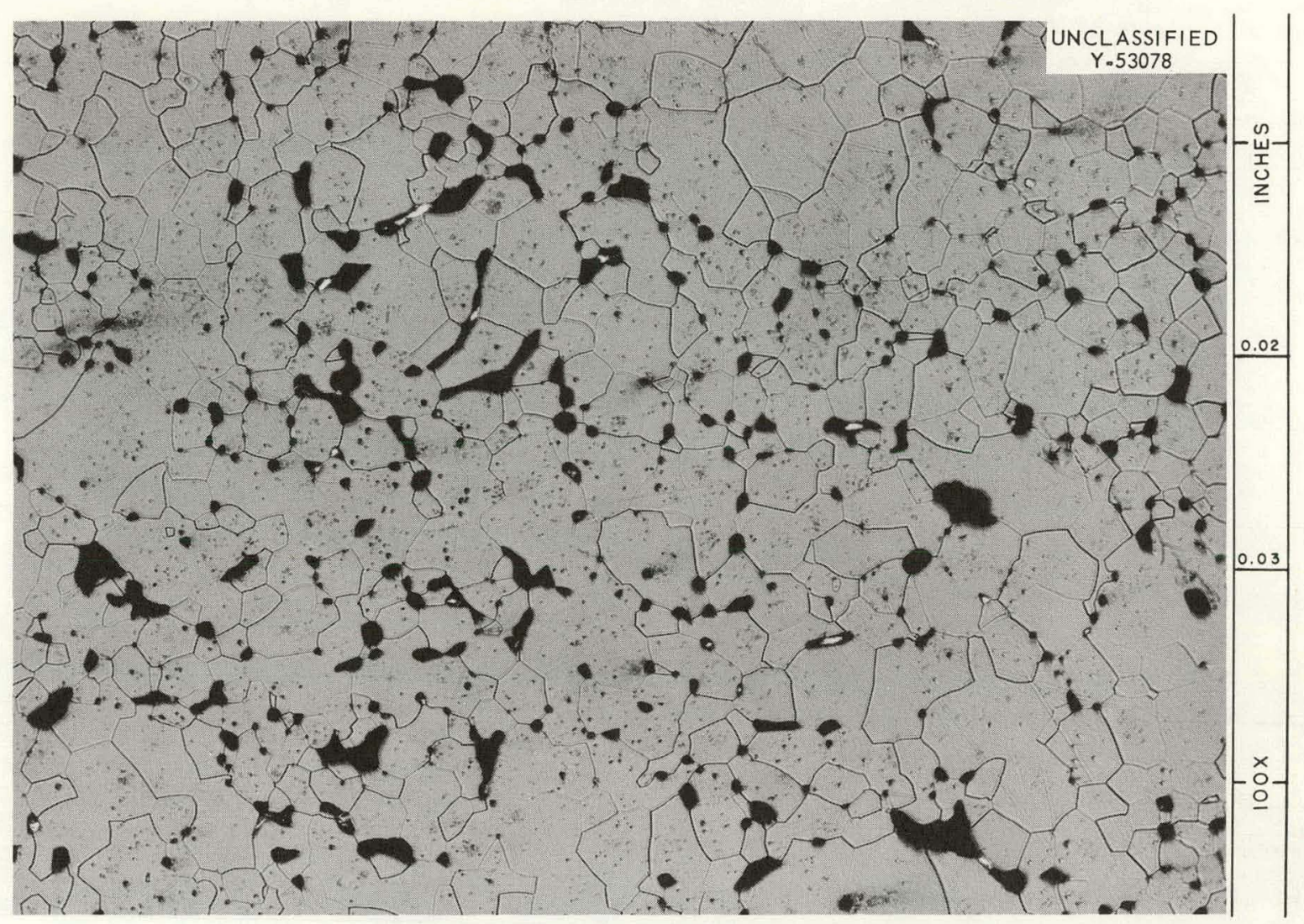

Fig. 4. Photomicrograph of the $\mathrm{UO}_{2}$ Specimen.

\section{Thermal Conductivity Data}

All of the data reported here was corrected to theoretical density by dividing the actual experimental values by 0.934 , the fraction of theoretical density. Ross ${ }^{13}$ has shown that this type of correction may be considerably in error, especially for specimens having average grain sizes less than $15 \mu$. However, his measurements were made at $60^{\circ} \mathrm{C}$, and the effects of grain size might be expected to decrease significantly at higher temperatures as the phonon mean free path becomes shorter.

It was found that between 200 and $1000^{\circ} \mathrm{C}$ a plot of thermal resistance, $1 / k$, vs absolute temperature $T$ for any given run gave a straight line to within $1 \%$ so that in this range

$$
\frac{1}{k}-R-A+B T
$$

Seven separate runs on the specimen were made, and the system usually underwent some slight modification between runs either by reinstrumenting with new thermocouples and/or by changes

\footnotetext{
${ }^{13}$ A. M. Ross, The Dependence of the Thermal Conductivity of Utanium Dioxide on Density, Microstructure, Stoichiomety dni Thernal Neutron Irradiation, CRFD-817 (AFCI,-1046) (September 1960).
} 
Table 2. Values of $A$ and $B$ of Eq. (4) for Various $U_{2}$ Runs Compared to Other Studies

\begin{tabular}{lccc}
\hline \multicolumn{1}{c}{ Author } & Run & $A\left(\frac{\mathrm{K} \mathrm{cm}}{\mathrm{w}}\right)$ & $B(\mathrm{~cm} / \mathrm{w})$ \\
\hline ORNL & $1^{a}$ & 5.46 & 0.0223 \\
ORNL. & 2 & 4.42 & 0.0225 \\
ORNL & 3 & 5.14 & 0.0225 \\
ORNL & 4 & 4.53 & 0.0237 \\
ORNL & 5 & 5.69 & 0.0221 \\
ORNL & 6 & 5.11 & 0.0221 \\
Howard and Gulvin ${ }^{14}$ & & $8.96-3.03$ & $0.0196-0.0213$ \\
Kingery & ${ }^{15}$ & 2.36 & 0.0222 \\
Hedge and Fieldhouse & & 7.98 & 0.0239 \\
Deem and Lucks ${ }^{17}$ & & 4.78 & 0.0246 \\
\hline
\end{tabular}

${ }^{a}$ Run 1 between 200 and $400^{\circ} \mathrm{C}$ upon first heating.

to other components of the apparatus. Run 7 was a low-temperature run using copper/Constantan thermocouples on one measuring plane. All other runs were above room temperature, and $\mathrm{Pt}$ vs $\mathrm{Pt}-10 \% \mathrm{Rh}$ thermocouples were used. The actual data for all the runs are given in Appendix D. For these six high-temperature runs, values of $A$ and $B$ in Eq. (4) are given in Table 2. The value of the intercept $A$ varies considerahly; whereas, with the excoptinn of run 4 , tho value of the slope $B$ was $0.0223 \pm 0.0002 \mathrm{~cm} / \mathrm{w}$. For run $4, B$ was 0.0237 and was based on only three measurements; however, considering the excellent agreement hetween the other runs, this valuc is discountcd.

Howard and Gulvin ${ }^{14}$ give values of $A$ and $B$ for their work and for other authors, and these are also shown in Table 2. Here again the agreement for values of $B$ is much better than agreement on values of $A$.

Run 1 gave a linear resistance plot between about 200 and $400^{\circ} \mathrm{C}$. with a slnpe of 0.0223 $\mathrm{cm} / \mathrm{w}$, in agreement with the other values; however, as the specimen was heated above $400^{\circ} \mathrm{C}$, the resistance showed a negative deviation from this line as shown in Fig. 5. Above $600^{\circ} \mathrm{C}$ the resistance was again linear with essentially the same slope as below $400^{\circ} \mathrm{C}$. Therefore the new line was shifted downward but remained parallel to the 200 to $400{ }^{\circ} \mathrm{C}$ line. Upon cooling and during reheating of the specimen in run 2, the data followed this second line. The shift

${ }^{14}$ V. C. Howard and T. F. Gulvin, Thermal Conductivity Determination on $\mathrm{UO}_{2}$ by a Radial Heat Flow Method, IG-51(RB/C) UKAEA Culcheth (Feb. 10, 1961).

${ }^{15}$ W. D. Kingery et a1., “Thermal Conductivity: X, Data for Several Pure Oxide Materials Corrected to Zero Porosity," J. Am. Ceram. Soc. 37, 107 (1954).

${ }^{16} \mathrm{~J}$. Hedge and I. Fieldhouse, Measurement of Thermal Conductivity of Uranium Dioxide, AECU-3381 (Sept. 20, 1956).

${ }^{17}$ H. W. Deem and C. F. Lucks, Thermal Conductivity of Uranium and UO, BMI-1324 (Mar. 1, 1959). 


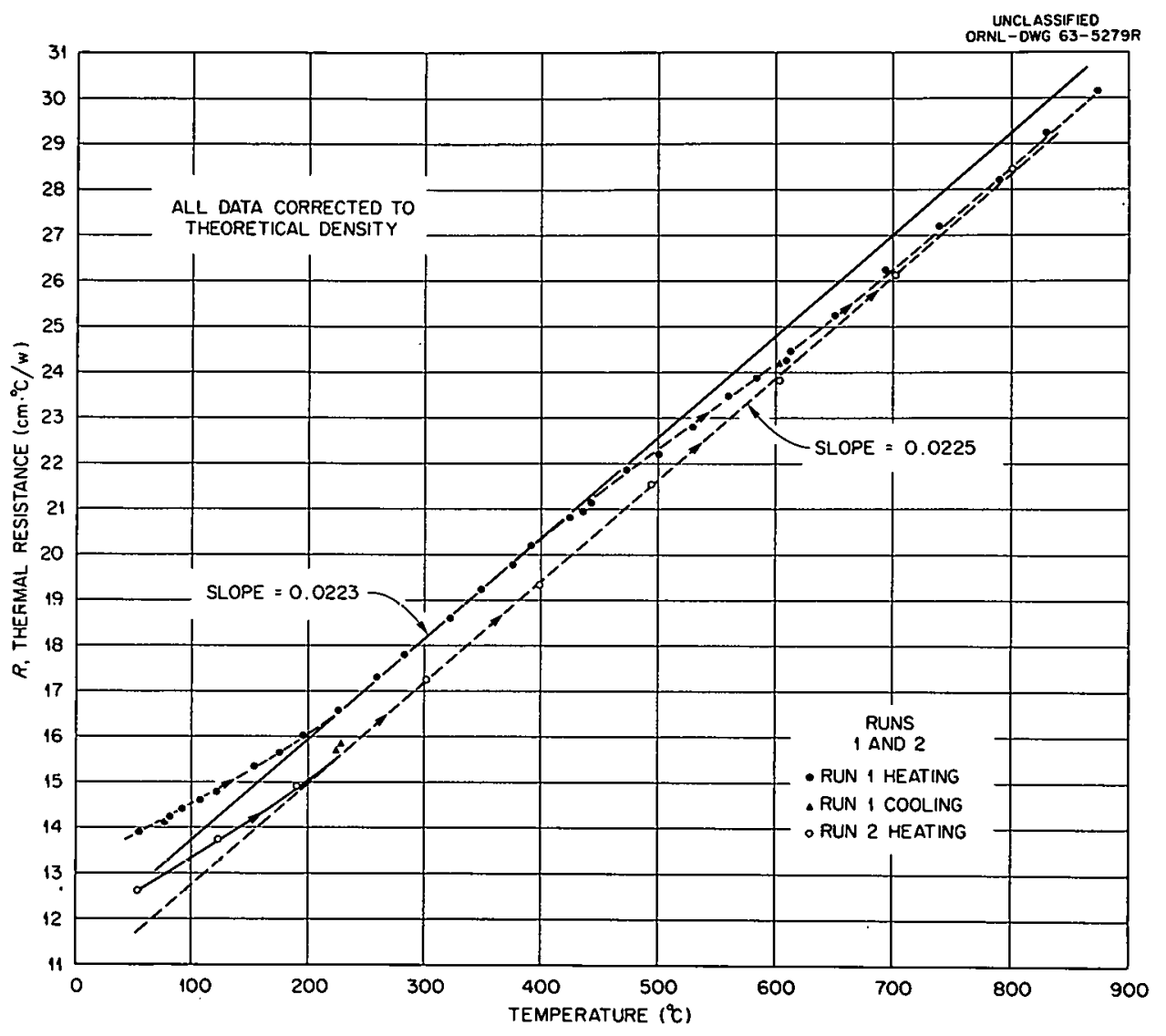

Fig. 5. Thermal Resistance of $\mathrm{UO}_{2}$ as a Function of Temperature for Runs 1 and 2 in the Radial Heat Flow Apparatus.

is believed to have been due to a decrease in the excess oxygen content of the specimen produced during heating in run 1 because of the scavenging effect of a tantalum liner between the specimen and the muffle heater. Upon cooling to room temperature after run 1, the tantalum liner was found to have been severely oxidized. A small portion of one of the specimen disks was analyzed for the $\mathrm{O} / \mathrm{U}$ ratio, and this was found to be 2.006 compared to 2.012 for the specimen prior to run 1 . The initial $\mathrm{UO}_{2}$ specimen (before first heat) yielded $\mathrm{O} / \mathrm{U}$ ratios of $2.012 \pm 0.002$ (wt gain on ignition in air) and $2.002 \pm 0.002$ (chemical analysis). After the first heat the $\mathrm{O} / \mathrm{U}$ ratios were $2.006 \pm 0.002$ (wt gain on ignition in air) and $<2.001 \pm 0.002$ (chemical analysis). The values determined by the ignition-in-air method are believed to indicate the change in the $\mathrm{O} / \mathrm{U}$ ratio more precisely than the chemical analysis method. The uncertainty stated above in the original composition, \pm 0.01 , was the average spread of the two analytical methods.

Figure 5 shows that the data for runs 1 and 2 below $200^{\circ} \mathrm{C}$ deviate in a regular way from the straight line. Béthoux, Thomas, and Weil ${ }^{8}$ recently found a maximum in the thermal conductivity curve of $\mathrm{UO}_{2}$ at about room temperature. Such a maximum would plot as a minimum in the thermal resistance plot, and this is indicated by the 55 to $200^{\circ} \mathrm{C}$ data of runs 1 and 2 . To check this point, 
in run 7 one plane was reinstrumented with copper/Constantan thermocouples, and the annular space between the muffle and the brass chamber wall was filled with dry ice. This permitted data to be obtained to $-57^{\circ} \mathrm{C}$; the results of runs 6 and 7 are shown in Fig. 6. These data show a minimum near $320^{\circ} \mathrm{K}$ although more scatter was observed at these temperatures.

In runs 3 to 5 , the apparatus was heated to temperatures above $1000^{\circ} \mathrm{C}$. In run 5 , a temperature greater than $1400^{\circ} \mathrm{C}$ was probably reached; however, during this run, rapid thermocouple drift was observed at the higher temperatures. The apparatus was cycled between 900 and $1350^{\circ} \mathrm{C}$ several times in an attempt to stabilize the thermocouples with the results shown in Fig. 7. The net effect of the thermocouple drift was to cause a hysteresis-type behavior, with each heating cycle yieiding lower $1 / k$ values than the preceding one. Upon final cooling, the results followed a line parallel to, but about $6 \%$ lower than, that obtained on the first heating of run 5 . To check the extent of the thermocouple drift which had occurred at high temperatures, the top two measuring planes were reinstrumented after run 5 , and the bottom plane was left intact. New thermocouples were attached to the outside surface of the bottom measuring disk and to the outside surface of the top measuring plane. During run 6 the readings of these thermocouples were compared to those of the old thermocouples on the bottom plane under isothermal conditions. The outside thermocouples on the top disk read the same as those within the disk to within $\pm 1 \mu \mathrm{v}$, whereas for the bottom plane a difference was observed which measured the error of the old thermocouples. This error increased with temperature and, on the average, amounted to $370 \mu \mathrm{v}$ (or $37^{\circ} \mathrm{C}$ ) at $600^{\circ} \mathrm{C}$. Figure 8 shows a plot of the error of the old thermocouples compared to NBS

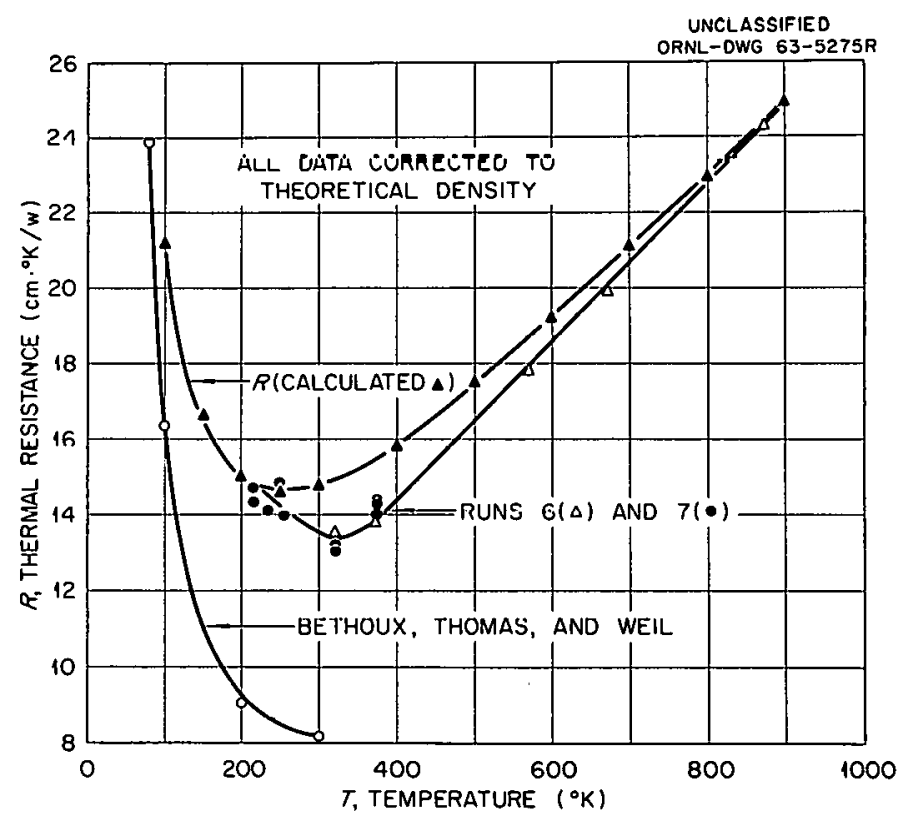

Fig. 6. Thermal Resistance of $\mathrm{UO}_{2}$ as a Function of Temperature for Runs 6 and 7 in the Radial Heat Flow Apparatus and Calculated Thermal Resistance. 
Bulletin No. 561, Table 1, values. This error enters the $k$ data in two ways. First, the wrong sensitivity was used to compute $\Delta T$ in Eq. (1); and second, the absolute temperature at which $k$ was measured was actually higher than it appeared. Because of these errors, the data taken in runs 3 to 5 above about $1100{ }^{\circ} \mathrm{C}$ and in run 5 upon cooling from high temperature are not valid.

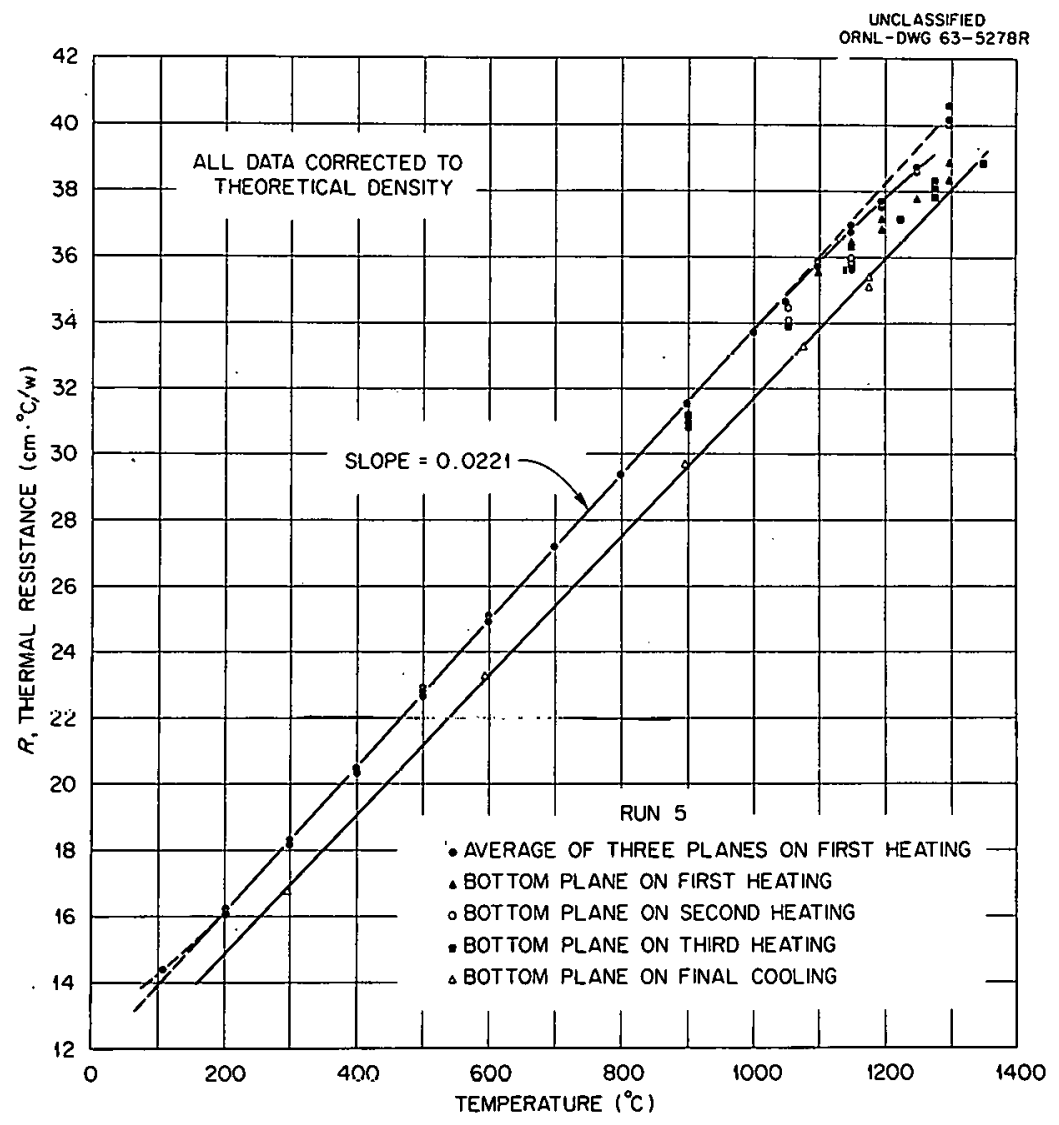

Fig. 7. Thermal Resistance of $\mathrm{UO}_{2}$ as a Function of Temperature for Run 5 In the Radial Heat Flow Apparatus.

Fig. 8. Thermal EMF Error in the Run 5 Thermocouples Caused by a High-Temperature Exposure, as Determined During Run 6 in the Radial Heul Flow Apparatus.

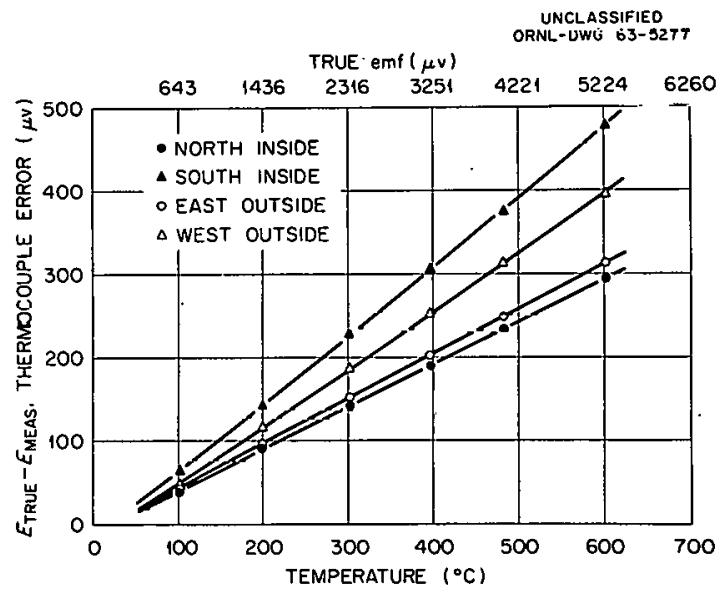


Because the thermocouple emf's did not drift below $1100^{\circ} \mathrm{C}$, the data taken in runs 3 to 5 below $1100^{\circ} \mathrm{C}$ are considered valid. The data between 1000 and $1100^{\circ} \mathrm{C}$ were 1 to $3 \%$ below the extrapolation of the 200 to $1000^{\circ} \mathrm{C}$ straight-line portion. Figure 9 is a $k$ vs temperature plot which shows the relative position of the $k$ values obtained in this work (shaded band) compared to other investigations. All values are corrected to theoretical density as discussed above.

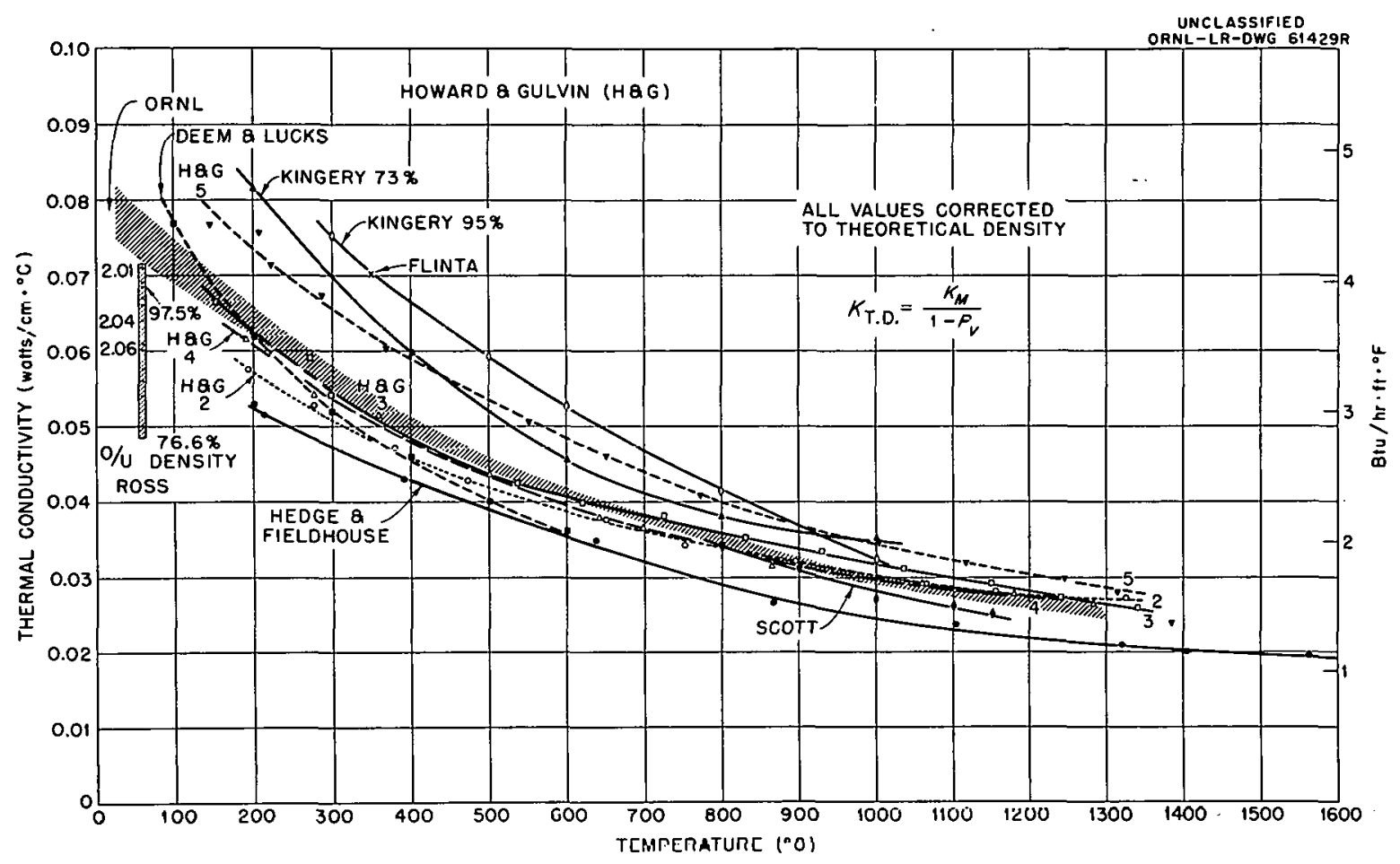

Fig. 9. Thermal Conductivity of $\mathrm{UO}_{2}$ as a Function of Temperature as Reported by Various Authors. Note the effects of $O / U$ ratio and density of $60^{\circ} \mathrm{C}$. The dota of Flinta was obtained from Thermal Conductivity of $\mathrm{UO}_{2}$, TID-7546 (Book 2) (November 1957), PP 516-25; and that of Scott from The Thermal Conductivity of $U \mathrm{O}_{2}$, AEREM/R 2526 (March 1958). The dato of Ross; Howard and Gulvin; Kingery; Hedge, and Fieldhouse; and Deem and Lucks were obtained from references 13-17, respectively.

To obtain higher temperature data, the present thermocouple error must be reduced, and this may be possible through the use of more stable thermocouples such as $\mathrm{Pt}-30 \% \mathrm{Rh}$ vs $\mathrm{Pt}-6 \% \mathrm{Rh}$. It is also possible to incorporate into the system a temperature standard against which the thermocouples can be calibrated during isothermal conditions. Such a standard is the electrical resistance of the Pt-10\% Rh core-heater wire. It was found that this is a sensitive, reproducible resistance thermometer. By use of this thermometer, it is possible to check the thermocouples in situ during a run and, if need be, recalibrate them when the system is isothermal. Therefore, if the thermocouple drift is not too rapid, data can be taken by preceding each data point with such an isothermal calibration. 
The resistivity of the $\mathrm{Pt}-10 \% \mathrm{Rh}$ wire was obtained from measurements of the core-heater resistance at isothermal conditions, and the data were fit by a least-mean-squares criterion to a second-order polynomial in temperature. This expression is

$$
\rho=18.50+3.100 \times 10^{-2} t-3.520 \times 10^{-6} t^{2} .
$$

The fit was made using experimental data in the temperature range 111 to $800^{\circ} \mathrm{C}$. Later, higher temperature values were measured, and these agreed with the extrapolation of the lower temperature equation to within $\pm 0.2 \%$ to $1000^{\circ} \mathrm{C}$. These data agree to within $\pm 0.4 \%$ of that reported by Roeser and Wensel. ${ }^{18}$ The experimental values are given in Appendix $\mathrm{H}$.

\section{DISCUSSION OF THE RESULTS ON $\mathrm{UO}_{2}$}

The data obtained in seven runs gave a consistent picture of the thermal conductivity of $\mathrm{UO}_{2}$ from -57 to $1000^{\circ} \mathrm{C}$. The results can be interpreted from the point of view that the only heat transport is by phonons.

It should be mentioned that none of the following calculations are rigorous, but they do show that the experimental results are in qualitative agreement with a simplified theory of thermal conductivity of electrically insulating solids.

\section{For the Temperature Range 200 to $1000^{\circ} \mathrm{C}$}

\section{Derivation of an Expression for Thermal Resistance}

If two scattering mechanisms (i.e., interaction between the phonons themselves, umklapp processes, and interaction between phonons and impurities) are assumed, the average phonon mean free path $\bar{l}$, in terms of the average mean free paths for the two scattering processes $\bar{l}_{u}$ and $\bar{l}_{I}$, can be expressed by

$$
\frac{1}{\bar{l}}=\frac{1}{\bar{l}_{t}}+\frac{1}{\bar{l}_{I}}
$$

if the additional assumption that the two processes are independent is made. Using an elementary but physically realistic model based on the thermal conductivity of a gas, the thermal conductivity of the solid can be expressed as

$$
k=\frac{1}{3} c_{v} \bar{v} \bar{l},
$$

where $c_{V}$ is the specific heat at constant volume per unit volume and $\bar{v}$ is the average velocity of phonons. Equation (7) also requires the assumption that the phonon scattering reaction at a

${ }^{18}$ W. F. Roeser and H. T. Wensel, "Table 15. Electrical Resistivity as a Function of Temperature," p 1312 in Temperature - Its Measurement and Control in Science and Industry, Reinhold, New York, 1941. 
point in the solid restores local thermodynamic equilibrium to the phonon distribution corresponding to the conditions at that point. ${ }^{19}$ If the further assumption is made that the scattering by impurities is independent of the phonon frequency (i.e., that the scattering cross section is independent of the phonon frequency), then $\bar{l}_{I}$ is independent of temperature provided that the impurity concentration does not change with temperature. Combining Eqs. (6) and (7), the thermal resistance becomes

$$
R=\frac{3}{c_{V} \bar{v}}\left(\frac{1}{\bar{l}_{u}}+\frac{1}{\bar{l}_{I}}\right)=R_{u}+R_{I}
$$

where $R_{t}$ is the umklapp contribution, and $R_{I}$ is the impurity contribution which is independent of temperature. For an electrically insulating solid well above its Debye temperature, the following expression for three phonon umklapp processes has been derived by Leibfried and Schlömann: ${ }^{20}$

$$
\frac{1}{k_{v}}=R_{11}=\frac{\gamma^{2} T}{\frac{24}{10}(4)^{1 / 3}\left(\frac{k}{h}\right)^{3} M \delta \theta_{D}^{3}}
$$

where

$y$ is the Gruneisen constant,

it is Doltemann's constant,

$h$ is Planck's constant,

$M$ is the mass per atom,

$\delta^{3}$ is the volume per atom,

$\theta_{D}$ is the Debye temperature.

For compounds, to a first approximation, $M$ is the average mass per atom, and $\delta^{3}$ is the average volume per atom. At high temperatures $c_{V}$ and $\bar{v}$ are approximately constant so the thermal resistance can be expressed by

$$
R=A+B T,
$$

where $A$ corresponds to the impurity resistance $R_{I}$, and $B T$ corresponds to the lattice resistance $R_{u}$. This is exactly the form of $R$ measured experimentally in runs 2 to 6 on $\mathrm{UO}_{2}$ between 200 and $1000^{\circ} \mathrm{C}$.

\footnotetext{
${ }^{19}$ J. R. Drable and H. J. Goldsmid, Thermal Conduction in Semiconductors, p 138, Pergamon Press, Oxford, 1961.

${ }^{20}$ G. Leibfried and E. Schlömann, "Wärmeleitung in elektrisch isolierenden Kristallen," (Heat Conduction in Electrically Insulating Crystals), Akad. Wiss. Gottingen, Math.-Physik. Kl. IIA, 71 (1954). (Translated for ORNL by the Technical Library Research Service under Purchase Order No. 34B-60150, Letter Release No. S-70.)
} 


\section{Calculation of Debye Characteristic Temperature}

A Debye temperature of $216^{\circ} \mathrm{K}$ was calculated using Eq. (9). This value compares to $160^{\circ} \mathrm{K}$ from specific heat measurements ${ }^{21}$ and to $188^{\circ} \mathrm{K}$ from $x$-ray results. ${ }^{22}$ This calculation used the measured value of $B, 14.94 \times 10^{-23} \mathrm{~g} /$ atom for $M, 1.37 \times 10^{-23} \mathrm{~cm}^{3} /$ atom for $\delta^{3}$, and 1.64 for $\gamma$. The value for $\gamma$ was calculated using the equation,

$$
y=\frac{a_{v}}{k c_{V}}
$$

where $a_{v}$ is the volume thermal expansion coefficient, and $k$ is the isothermal compressibility. A value for $\alpha_{v}$ of three times the linear expansion coefficient $\alpha_{L}$ was used, and $\alpha_{L}$ was taken to be $10.5 \times 10^{-6} /{ }^{\circ} \mathrm{C}$, the average value for the range 25 to $1000^{\circ} \mathrm{C} .{ }^{23}$ The compressibility was taken as $0.62 \times 10^{-5} \mathrm{~cm}^{3} /$ wsec (ref 24 ) and a value of $3.29 \mathrm{wsec}^{-3}\left(\mathrm{~cm}^{\circ} \mathrm{C}\right.$ ) ${ }^{-1}$ was used for $c_{V}$. This value of $c_{V}$ was obtained by dividing $C_{V}$, the molar heat capacity at constant volume at $700^{\circ} \mathrm{C}$, by $V$, the molar volume. Values of $C_{V}$ were calculated from $C_{P}$ data ${ }^{21.25}$ using the relation

$$
C_{V}=C_{P}-\frac{V a_{v}^{2}}{k} T
$$

where $V$ was taken as the molar volume at room temperature, $24.8 \mathrm{~cm} / /$ mole, and are plotted in Fig. 10.

\section{Impurity Scattering Cross-Section Estimation}

The average mean free path for $n$ different types of scattering impurities may be written as

$$
\frac{1}{\bar{l}_{I}}=\sum_{i}^{n} \frac{1}{\bar{l}_{i}}=\sum_{i}^{n} \bar{\sigma}_{i} N_{i},
$$

where $\bar{\sigma}_{i}$ is the average scattering cross section, and $N_{i}$ is the impurity concentration for impurity Lype " $i$." To get an order of magnitude estimate for the $\bar{\sigma}$ 's, they are all assumed to be the same. The concentration of impurities in the $\mathrm{UO}_{2}$ specimen was estimated from analysis to be about 15

\footnotetext{
${ }^{21}$ W. M. Jones, J. Gordon, and E. A. Long, "The Heat Capacities of Uranium, Uranium Trioxide, and Uranium Dioxide from $15^{\circ} \mathrm{K}$ to $300^{\circ} \mathrm{K}$," J. Chem. Phys. 20(4), 695 (1952).

${ }^{22}$ C. J. Sparks and B. S. Borie, "An X-Ray Determination of the Debye-Waller Factors for $\mathrm{Cu}_{2} \mathrm{O}$ and $\mathrm{UO}_{2}$ and the Atomic Scattering Factor for $\mathrm{Cu}$ in $\mathrm{Cu}_{2} \mathrm{O}$," pp 177-84 in Advances in $X$-Ray Analysis (ed. by William M. Mueller and Marie Fay), vol 6, Plenum Press, New York, 1963.

${ }^{23}$ J. Belle (ed.), Uranium Dioxide Properties and Nuclear Applications, p 176, GPO, Washington, D.C., July 1961.

${ }^{24} \mathrm{~J}$. Belle, ibid., p 208.

${ }^{25}$ G. E. Moote and K. K. Kelley, "High-Temperature Heat Contents of Uranium, Uranium Dioxide and Uranium Trioxide," J. Am. Chem. Soc. 69, 2105 (1947).
} 


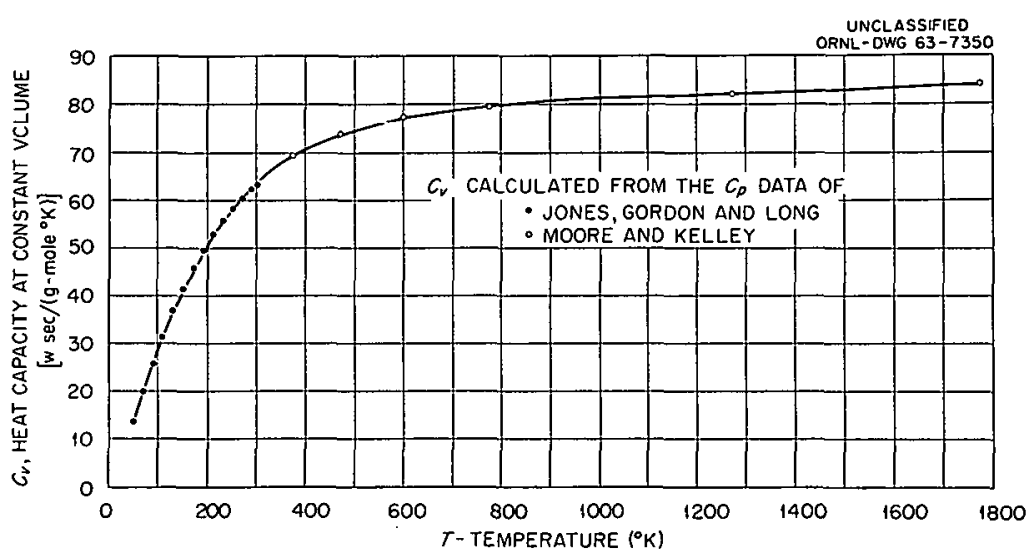

Fig. 10. Heat Capacity at Constant Volume per Gram-Mole of $\mathrm{UO}_{2}$ as a Function of Temperature.

impurity atoms (including excess oxygen) per $1000 \mathrm{UO}_{2}$ molecules, which corresponds to $3.64 \times$ $10^{20}$ impurities $/ \mathrm{cm}^{3}$. Using $81.6 \mathrm{wsec} \mathrm{mole}^{-1}\left({ }^{\circ} \mathrm{K}\right)^{-1}$ for $C_{V}, 4 \times 10^{5} \mathrm{~cm} / \mathrm{sec}$ for $\bar{v}$, and $5 \mathrm{~cm}$ ( $\left.{ }^{\mathrm{K}}\right) \mathrm{w}^{-1}$ for $R_{I}$ in Eq. (8), $1 / \bar{\ell}_{I}$ was found to be $2.19 \times 10^{6} \mathrm{~cm}^{-1}$. The value used for $R_{I}$ is the average experimental value of the intercept $A$ in our runs. The value of $\bar{v}$ was calculated as

$$
\bar{v}=\left(\frac{E}{\rho^{*}}\right)^{1 / 2}
$$

where $E$ is the modulus of elasticity which was taken to be $25 \times 10^{6}$ psi (ref 26 ), and $\rho^{*}$ is the $\mathrm{UO}_{2}$ density. From Eq. (13) $\bar{\sigma}_{i}$ was calculated as

$$
\left.\bar{\sigma}_{i}=\frac{2.19 \times 10^{6}}{3.64 \times 10^{20}}=6.0^{\prime}\right) \times 10^{-13} \mathrm{~cm}^{2} / \text { impurity. }
$$

This value seems reasonable since it is of the order of the square of the unit cell dimension for $\mathrm{UO}_{2}$.

\section{Effect of O/U Ratio on $k$}

Since the experimental values of the intercept $A$ varied from 5.67 to $4.42 \mathrm{~cm}^{\circ} \mathrm{K} \mathrm{w}^{-1}$ for all runs, the following analysis was made to determine if changes in $\mathrm{O} / \mathrm{U}$ ratio could cause these changes in $A$. Between runs 1 and 2 the $O / U$ ratio changed from 2.012 to 2.006 , corresponding to a $\Delta N$ of 6 excess oxygen atoms per $1000 \mathrm{UO}_{2}$ molecules. The change in resistance due to this $\Delta N$ is then calculated from Eq. (8) to be

$$
\Delta R_{I}=\frac{3}{c_{V} \bar{v}} \Delta\left(\frac{1}{\bar{\ell}_{1}}\right)=\frac{3}{c_{V} \bar{v}} \bar{\sigma}_{i} \Delta N .
$$

\footnotetext{
${ }^{26} \mathrm{~J}$. Belle, op. cit., p 206.
} 
But we can express the average value of $R_{I}$ as

$$
\bar{R}_{I}=\bar{A}=\frac{3}{\mathrm{c}_{V} \bar{v}} \bar{\sigma}_{i} N,
$$

so

$$
\frac{3}{c_{V} \bar{v}} \bar{\sigma}_{i}=\frac{\bar{R}_{I}}{N}=\frac{\bar{A}}{N} .
$$

Thus

$$
\Delta R_{I}=\bar{A} \frac{\Delta N}{N}=5 \times\left(\frac{-6}{15}\right)=-2 \mathrm{~cm} \mathrm{~K} \mathrm{w}^{-1}
$$

The observed change was $-1 \mathrm{~cm} \% / \mathrm{w}$, so this very rough calculation adequately describes both the direction and the order of magnitude of the change.

Several authors have observed a decrease in the thermal conductivity of $\mathrm{UO}_{2}$ with increasing $\mathrm{O} / \mathrm{U}$ ratio. ${ }^{13,14,27,28}$ In particular the results of $\operatorname{Ross}^{13}$ at $60^{\circ} \mathrm{C}$ show that a change in $\mathrm{O} / \mathrm{U}$ ratio from 2.00 to 2.02 changed the thermal conductivity by about $6 \%$, whereas Howard and Gulvin ${ }^{14}$ indicate a $16 \%$ decrease. The observed shift between runs 1 and 2 at this temperature was about $10 \%$ for an $\mathrm{O} / \mathrm{U}$ ratio change from 2.012 to 2.006 .

Low-temperature measurements by Bethoux, Thomas, and $\mathrm{Weil}^{8}$ on $\mathrm{UO}_{2}$ have shown that, beside ordinary lattice and impurity scattering, there is also a scattering of phonons by the magnetic moment of the $\mathrm{U}^{4+}$ ions. Further, these authors suggest that the mean free path associated with this mechanism may be independent of temperature, as has been assumed here for impurity scattering. In this case, the intercept $A$ should really be $R_{I}+R_{m}$, where $R_{m}$ is the magnetic moment contribution. This means that the above calculations for $1 / \bar{l}_{I}$ and $\Delta R$ are somewhat too large, which again agrees with experiment.

In the above calculation if the specimen is assumed to be pure and free of imperfections, the value of $A$ is zero. However, many insulating solids yield negative $A$ values and, furthermore, the linear dependence of $R$ extends to temperatures considerably below the Debye temperature [e.g., Si (ref 29) and BeO (ref 30)]. For temperatures below the Debye temperature an equation of the form ${ }^{31}$ is expected,

$$
k_{u}=a\left(\frac{T}{\theta_{D}}\right)^{n} \exp \left(\frac{\theta_{D}}{b T}\right),
$$

\footnotetext{
${ }^{27} \mathrm{~J}$. Belle, "Properties of Uranium Dioxide," Proc. Intern. Conf. Peaceful Uses At. Energy, 2nd Gieneva, 1958 6, 509 (1958).

${ }^{28}$ R. W. Nichols, “Ceramic Fuels - Properties and Technology," Nucl. Eng. (London) 3(8), 327-33 (1958).

${ }^{29}$ A. D. Stuckes, “The Thermal Conductivity of Germanium, Silicon and Indium Arsenide from 40 to $425^{\circ} \mathrm{C}, "$ Phil. Mag. 5, 84 (1960).

${ }^{30}$ R. E. Taylor, "Thermal Conduclivity and Expension of Beryllia at High Temperatures," J. Am. Ceram. Soc. 45(2), 74 (1962).

31 J. M. Ziman, Electrons and Phnnnns, The Theory of Transport Phenomena in Solids, p 291, Oxford at the Clarendon Press, 1960.
} 
where $a, n$, and $b$ are empirical constants not clearly defined by theory. Above the Debye temperature the Leibfried and Schlömann formula 9 should hold; this may be expressed as

$$
k_{u}=k_{0} \frac{\theta_{D}}{T}
$$

where $k_{0}$ is the thermal conductivity at the Debye temperature. Expressing the resistance as the reciprocal of $k_{u}$, the two equations will merge only if we make $n=-1$ and $a=k_{0}$. This can be seen by expanding the exponential in Eq. (16) using these values of the constants $n$ and $a$.

$$
\begin{aligned}
R_{u} & =\frac{1}{k_{u}}=\frac{1}{k_{0}} \frac{T}{\theta_{D}}\left[1-\frac{\theta_{D}}{b T}+\frac{1}{2}\left(\frac{\theta_{D}}{b T}\right)^{2}-\ldots\right] \\
& \cong \frac{1}{k_{0}} \frac{T}{\theta_{D}}-\frac{1}{k_{0} b}
\end{aligned}
$$

for reasonably high values of $T$ and $b$. If $b$ is fairly large, $R_{u}$ will be approximately linear well below the Debye temperature, and the intercept will be negative. At suffiriently high tempera* tures the constant term is negligible compared to the first tern, which is the reciprocal of $\mathrm{Eq}$. (17). A maximum value of $b$ is 2 (ref 31 ) and yields a negative intercept of $-0.0223 / 2 \times 216=$ $-2.4 \mathrm{~cm} \mathrm{~K} \mathrm{w} \mathrm{w}^{-1}$, where 216 is $\theta_{D}$ and $\theta_{D} B$ is equal to $1 / k_{0}$ by equating the slope of Eq. (18) with $B$. Therefore the impurity portion of the thermal resistance should be $A$, recorded in Table 2 , plus the absolute value of this negative intercept. This would change the calculated values of $1 / \bar{l}_{I}$ to $3.25 \times 10^{6}$ and $\sigma_{i}$ to $8.92 \times 10^{-15} \mathrm{~cm}^{2} /$ impurity. The value of $\Delta R_{I}$ would increase to $2.8 \mathrm{~cm} \mathrm{~K} \mathrm{w}^{-1}$.

\section{For the Temperature Range -57 to $200^{\circ} \mathrm{C}$}

The observed thermal resistance of $\mathrm{UO}_{2}$ below $200^{\circ} \mathrm{C}$ may be adequately ascribed to the fact that $\mathrm{C}_{V}$ of $\mathrm{UO}_{2}$ begins to drop rapidly below this temperature, as can be seen in Fig. 10 . Using the value of $1 / \bar{l}_{l}$ of $2.19 \times 10^{6} \mathrm{~cm}^{-1}$ derived initially and the values of $1 / \bar{l}_{u}$ given by the relation,

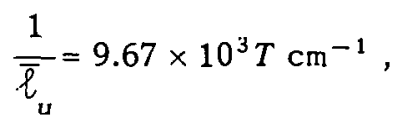

the thermal resistance at low temperatures can be calculated using experimental values of $C_{V}$ from Fig. 10. Equation (19) was derived by setting $R_{u}$ of Eq. (8) equal to $B T$, where $B$ was the high-temperature slope of the resistance plot, and using $3.29 \mathrm{wsec} \mathrm{cm}{ }^{-3}{ }^{\mathrm{K}^{-1}}$ for $\mathrm{c}_{v}$ and $4 \times 10^{5}$ $\mathrm{cm} / \mathrm{sec}$ for $\bar{v}$. The thermal resistance calculated in this way indeed shows an upswing at temperatures below about $300^{\circ} \mathrm{K}$ and of the same order of magnitude as was observed experimentally. Both theoretical and measured curves are shown in Fig. 7 together with the curve of Bethoux, Thomas, and Weil. ${ }^{8}$ 


\section{For the Temperature Range 1000 to $1100^{\circ} \mathrm{C}$}

The thermal resistance at $1100^{\circ} \mathrm{C}$ for runs 3 to 5 all lie 1 to $3 \%$ below the extrapolation of the linear portion of the thermal resistance plot. It is thought that the thermocouples were still giving reliable results in these runs at $1100^{\circ} \mathrm{C}$; therefore the deviation is real and probably due to an irreversible change in the specimen at these high temperatures. This supposition is based on the fact that run 6 made immediately after run 5 gave a resistance plot which was parallel to that of run 5 but which was lower by $0.6 \mathrm{~cm}^{\circ} \mathrm{K} \mathrm{w}^{-1}$. Evidently the high-temperature heat treatment of the specimen in run 5 produced this change, and on the basis of the above discussion this was a change in the impurity concentration.

The deviation of $R$ from a straight line between 1000 and $1100^{4} \mathrm{C}$ could also be due to an electronic contribution to the thermal conductivity. The electronic contribution for a nondegenerate semiconductor may be written as ${ }^{32}$

$$
k_{e}=\frac{2 k^{2}}{e^{2}} \sigma T+\frac{k^{2}}{e^{2}} \frac{\sigma_{h} \sigma_{e}}{\sigma}\left(4+\frac{E_{G}}{k T}\right)^{2} T,
$$

where $\sigma$ is the electrical conductivity, and

$$
\sigma=\sigma_{e}+\sigma_{h}
$$

where $\sigma_{e}$ and $\sigma_{h}$ are the portions of the electrical conductivity due to electrons and holes respectively. The term $E_{G}$ is the forbidden band gap which for $\mathrm{UO}_{2}$ is $\sim 1.9 \mathrm{ev}$ (ref 33). In Eq. (20), $k_{e}$ will be a maximum if $\sigma_{e}=\sigma_{h}$. At $1000^{\circ} \mathrm{C}$, assuming. $\sigma_{h}=\sigma_{e}$ and a fairly high value of 1 (ohm$\mathrm{cm})^{-1}$ for $\sigma$ (ref 33), one obtains $0.0011 \mathrm{w} \mathrm{cm}^{-1} \mathrm{~K}^{-1}$ for $k_{e}$, which is about. 3.8\% of the observed value. The following tabulation shows values of $k_{e}$ calculated using Eq. (20) and the assumption that $\sigma$ has an activation energy of $0.95 \mathrm{ev}$.

$$
\begin{array}{r}
+\left({ }^{\circ} \mathrm{C}\right) \\
.900 \\
1000 \\
1100
\end{array}
$$$$
k_{0}\left(w \mathrm{~cm}^{-1} o_{\mathrm{K}}^{-1}\right)
$$$$
\begin{aligned}
& 0.55 \times 10^{-3} \\
& 1.1 \times 10^{-3} \\
& 2.0 \times 10^{-3}
\end{aligned}
$$

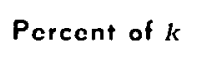

7.2

Hence the 1 to $3 \%$ negative deviation of $R$ from a straight line between 1000 and $1100^{\circ} \mathrm{C}$ could be explained as the influence of an electronic contribution.

\footnotetext{
${ }^{32}$ J. R. Drable and H. J. Goldsmid, op. cit., p 118.

${ }^{33}$ R. A. Wolfe, The Electrical Conductivity and Themoelectric Power of Uranium Dioxide, WAPD-270 (A.pril 1963).
} 
Finally, of direct interest to the above are two thermal conductivity studies on single-crystal $\mathrm{UO}_{2} \cdot{ }^{34,35}$ Both show the thermal conductivity of the single crystal to be much higher than the polycrystalline material, even at moderately low temperature ${ }_{x}$ and both show an increase at high temperatures. This very interesting difference needs to be explained quantitatively on the basis of the controlling heat transfer mechanism.

\section{EXPERIMENTAL RESULTS ON IRON}

Thermal conductivity measurements were made on Armco iron between 100 and $1000^{\circ} \mathrm{C}$ in the radial heat flow apparatus, and the results were analyzed in terms of two mechanisms contributing to the total thermal conductivity. To aid in this analysis, electrical conductivity measurements were made in the same temperature region on a sample fabricated from the same iron stock. The effects of the well-known solid-state changes which occur in iron on the mechanisms of thermal conduction made it a particularly interesting material for study.

\section{Specimen Characterization}

The Armco iron specimen had the composition listed in Table 3. With the exception of $O$, $\mathrm{N}, \mathrm{H}, \mathrm{C}, \mathrm{P}$, and $\mathrm{S}$, these numbers were the result of semiquantitative analyses and may vary from one-half to two times the values listed.

\footnotetext{
$1.962)$.

${ }^{34}$ J. L. Daniel, J. Matolich, Jr., and H. W. Deem, Thermal Conductivity of UO, HW-69945 (September

${ }^{35} \mathrm{~J}$. A. Christensen, Thermal Conductivity of $\mathrm{UO}_{2}, \mathrm{HW}-76301$ (August 1963), pp 2.30-2.33.
}

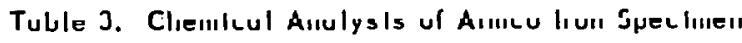

\begin{tabular}{cc}
\hline Element & $\begin{array}{c}\text { Concentration } \\
\text { (wt \%) }\end{array}$ \\
\hline Emission Spectroscopy & \\
Semiquantitative & $<0.05$ \\
$\mathrm{~A} 1$ & $<0.05$ \\
$\mathrm{Cr}$ & 0.1 \\
$\mathrm{Cu}$ & 0.05 \\
$\mathrm{Mn}$ & $<0.05$ \\
$\mathrm{Mo}$ & 0.1 \\
$\mathrm{Ni}$ & $<0.02$ \\
$\mathrm{Si}$ & $<0.01$ \\
$\mathrm{Ti}$ & $<0.02$ \\
$\mathrm{~V}$ & \\
Quantitative Analysis & 0.013 \\
$\mathrm{C}$ & 0.006 \\
$\mathrm{P}$ & 0.023 \\
$\mathrm{~S}$ & $<0.0001$ \\
$\mathrm{H}$ & 0.086 \\
$\mathrm{O}_{2}$ & 0.0050 \\
$\mathrm{~N}_{2}$ & \\
& \\
&
\end{tabular}




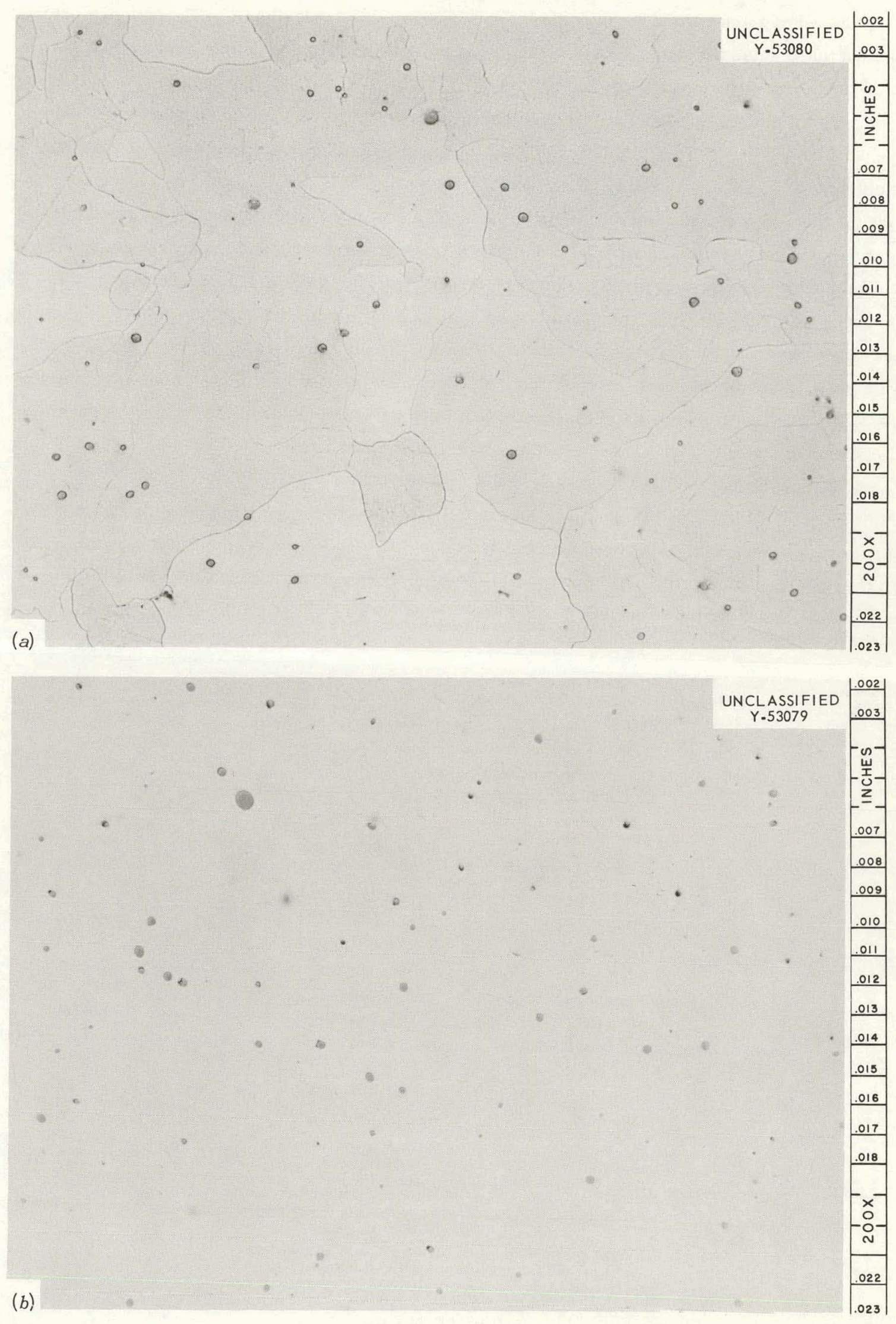

Fig. 11. Photomicrographs of Armco Iron. (a) Etched. (b) Unetched. 
Photomicrographs of the iron specimen, as viewed at 200X, are shown in Fig. 11. The etched and unetched microstructures show that a second phase is present. A point-count method was used to determine the volume percent of this phase to be $0.90 \pm 0.05$. This phase was not uniformly distributed in the specimen, as evidenced by local variations in the volume percent which ranged from 0.86 to 0.97 . Calculations based on the chemical analysis for oxygen of $0.086 \%$, yield volume percentages of $0.62,0.43$, and 0.47 assuming $\mathrm{FeO}, \mathrm{Fe}_{2} \mathrm{O}_{3}$, and $\mathrm{Fe}_{3} \mathrm{O}_{4}$ respectively. Since these volume percentages are less than observed, it is presumed that other compounds such as sulfides, phosphides, and other oxides are present. The photomicrograph of the etched specimen shows the grain diameter to be between 20 and $40 \mu$. The diamond pyramid hardness was 77. Previous investigators have attempted to correlate measurement results with the sum of total impurities present in their specimen. Interestingly, none of these analyses presented the oxygen content of the specimen, which is certainly not negligible in our specimen and possibly not in theirs. For comparison, Table 4 lists the summed carbon equivalent compnsitinn presented by Powel1 ${ }^{10}$ for various studies. This table indicates that the Armco iron used in this study was not as pure as that used in previous studies.

Early in 1959 the Battelle Memorial Institute (BMI) initiated a round robin on the thermal conductivity of Armco Iron. Specimen material from one 7-ft length of annealed stock was supplied to cooperating laboratories. A point-counting technique was performed on a specimen of this stock and revealed the presence of $1.3 \mathrm{vol} \%$ of second phase. This evidence supports the above

\begin{tabular}{lc}
$\begin{array}{r}\text { Table 4. } \begin{array}{c}\text { Carbon Equivalent Composition of Armco } \\
\text { Iron Used in Various Thermal Conductivity } \\
\text { Studies as Given by Powell }\end{array} \\
\text { Author }\end{array}$ \\
$\begin{array}{l}\text { Equivalent Carbon } \\
\text { Concentration }{ }^{2}\end{array}$ \\
\hline Powell & 0.041 \\
She1ton & 0.044 \\
Mauner & 0.042 \\
Huttori & 0.040 \\
Armstrong and Dauphinee & 0.070 \\
Silverman & 0.054 \\
Lucks and Deem & 0.036 \\
Zegler and Nevitt & 0.056 \\
Laubitz & 0.054 \\
ORNL & 0.06311 (min) \\
& 0.08276 (max) \\
& 0.1472 (max, \\
& including oxygen)
\end{tabular}

\footnotetext{
${ }^{a}$ Twelve times the sum of the ratio of the weight percent of each constituent to the atomic weight of the element.
} 
proposition that the oxygen content is not negligible in other thermal conductivity samples of Armco iron.

The electrical conductivity measurements were obtained using a rod which was swaged from a 1 in. diameter to a diameter of $0.11 \mathrm{in}$. and then ground to $0.1000 \pm 0.0001 \mathrm{in}$. This rod was annealed for $24 \mathrm{hr}$ at $600^{\circ} \mathrm{C}$ in a vacuum of $5 \times 10^{-7}$ torr prior to the measurements.

\section{Thermal Conductivity Data}

Two runs were made on iron in the range 100 to $1000^{\circ} \mathrm{C}$. Run 1 was terminated at $819^{\circ} \mathrm{C}$ by an open circuit in the core-heater system. This was repaired, and run 2 was initiated to investigate four overlapping temperature ranges: $2 \mathrm{~A}\left(100\right.$ to $\left.925^{\circ} \mathrm{C}\right) ; 2 \mathrm{~B}\left(700\right.$ to $\left.930^{\circ} \mathrm{C}\right) ; 2 \mathrm{C}(925$ to $\left.1000^{\circ} \mathrm{C}\right)$; and $2 \mathrm{D}\left(752\right.$ to $\left.925^{\circ} \mathrm{C}\right)$. Thermocouple instabilities were encountered between 840 and $950^{\circ} \mathrm{C}$ in run $2 \mathrm{~A}$, and the system was cooled to $700^{\circ} \mathrm{C}$ to determine the effect of these instabilities on the measured thermal conductivity. Isothermal cross checks between the electrical resistance of the $\mathrm{Pt}-10 \% \mathrm{Rh}$ core heater with the specimen thermocouples indicated that a change of less than $2^{\circ} \mathrm{C}$ had occurred in the thermocouples. An increase in $k$ of about $1 \%$ was observed between runs $2 \mathrm{~A}$ and $2 \mathrm{~B}$. During run $2 \mathrm{~B}$, the thermocouples were more consistent internally than during run 2.A in the same temperature region. The cause for this is not understood, but the general effect of enhanced thermocouple behavior at low temperatures after a high-temperature treatment (in this case $950^{\circ} \mathrm{C}$ ) was observed during several of the $\mathrm{UO}_{2}$ runs. Run $2 \mathrm{~B}$ ended at $933^{\circ} \mathrm{C}$, and the specimen was given an 8 -hr anneal at $1050^{\circ} \mathrm{C}$ to achieve thermocouple stability in the region 925 to $1000^{\circ} \mathrm{C}$. Thermal conductivity values at $933^{\circ} \mathrm{C}$ for runs $2 \mathrm{~B}$ and $2 \mathrm{C}$ checked to within $1 \%$, and the thermocouple performance during run $2 \mathrm{C}$ did not reveal any of the instabilities noted in run $2 \mathrm{~A}$; this justifies the $1050^{\circ} \mathrm{C}$ treatment. The final high-temperature run (run 2D) covered the range 750 to $925^{\circ} \mathrm{C}$ and was within $1 \%$ of runs $2 \mathrm{~B}$ and $2 \mathrm{C}$.

The data obtained in these runs are presented in Table E.1 of Appendix E and are plotted in Fig. 12. From 100 to $786^{\circ} \mathrm{C}$ the thermal conductivity of iron decreased with increasing temperature, and the data can be described to $\pm 1.5 \%$ by two linear equations:

$$
\begin{array}{ll}
k=0.7273-6.260 \times 10^{-4} t & \left(100 \leqq t \leqq 436^{\circ} \mathrm{C}\right), \\
k=0.6554-4.609 \times 10^{-4} t & \left(436 \leqq t \leqq 786^{\circ} \mathrm{C}\right) .
\end{array}
$$

Thus the slope of the temperature dependence of the thermal conductivity of iron changes by $30 \%$ at about $436^{\circ} \mathrm{C}$. The temperature dependence of $k$ undergoes a drastic change at $786^{\circ} \mathrm{C}$; in fact, $k$ goes through a minimum in the range 780 to $790^{\circ} \mathrm{C}$, and from 786 to $910^{\circ} \mathrm{C}$ the thermal conductivily increasca linearly with increasing lemperature. The data in this region may be represented by

$$
k=0.2703+2.854 \times 10^{-5} t \quad\left(786 \leqq t \leqq 910^{\circ} \mathrm{C}\right)
$$

The thermal conductivity decreases 3 to $4 \%$ at the $a-y$ phase transformation $\left(910^{\circ} \mathrm{C}\right.$ ). Above $910^{\circ} \mathrm{C}$ the thermal cunductivity of $\gamma$-iron increases with increasing temperature to at least $1000^{\circ} \mathrm{C}$, the 
upper limit of the present experiment, and may be represented by the linear equation,

$$
k=0.1736+1.211 \times 10^{-4} t \quad\left(910 \leqq t \leqq 1000^{\circ} \mathrm{C}\right) .
$$

Figure 13 is an expanded plot of the thermal conductivity data between 700 and $1000^{\circ} \mathrm{C}$ and shows that most of the data points lie in a $\pm 1.5 \%$ band around the equations.

A limited comparison of the results obtained on iron to $1000^{\circ} \mathrm{C}$ is made in Fig. 14. 'The four equations which fit the ORNL data to better than $\pm 1.5 \%$ were used in their appropriate temperature ranges to obtain a difference plot with increasing temperature. Thus in Fig. 14 the zero

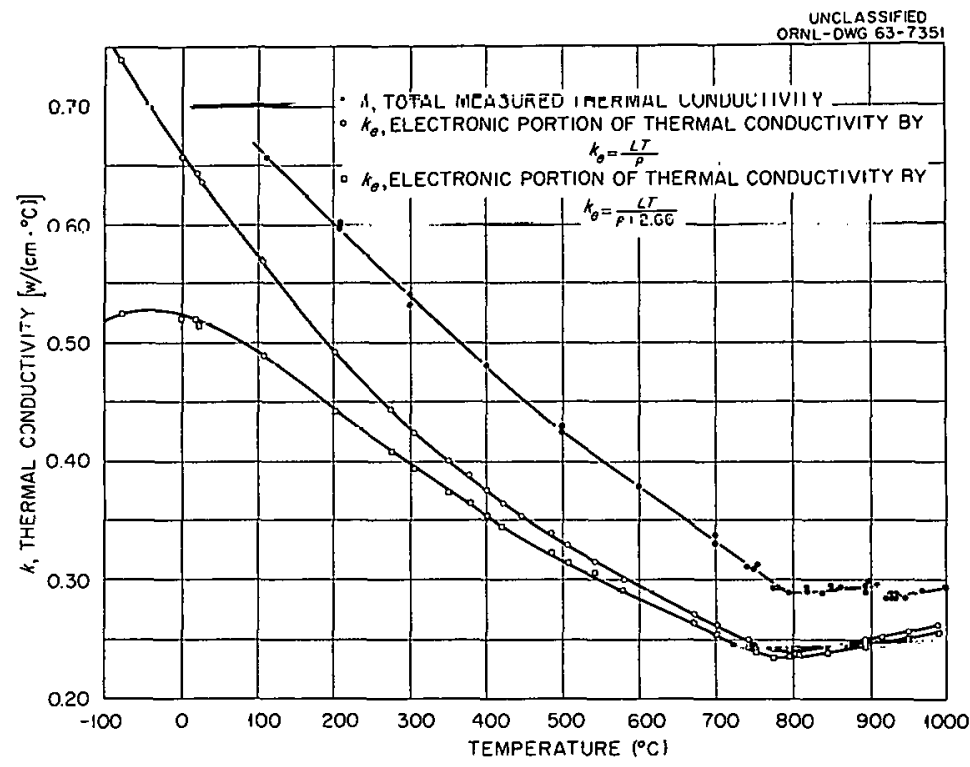

Fig. 12. Thormal Conductivliy Resulis on Armen Iron from 100 to $1000^{\circ} \mathrm{C}$ and llie Electronle Coñtribution Calculated by Tíno Methods.

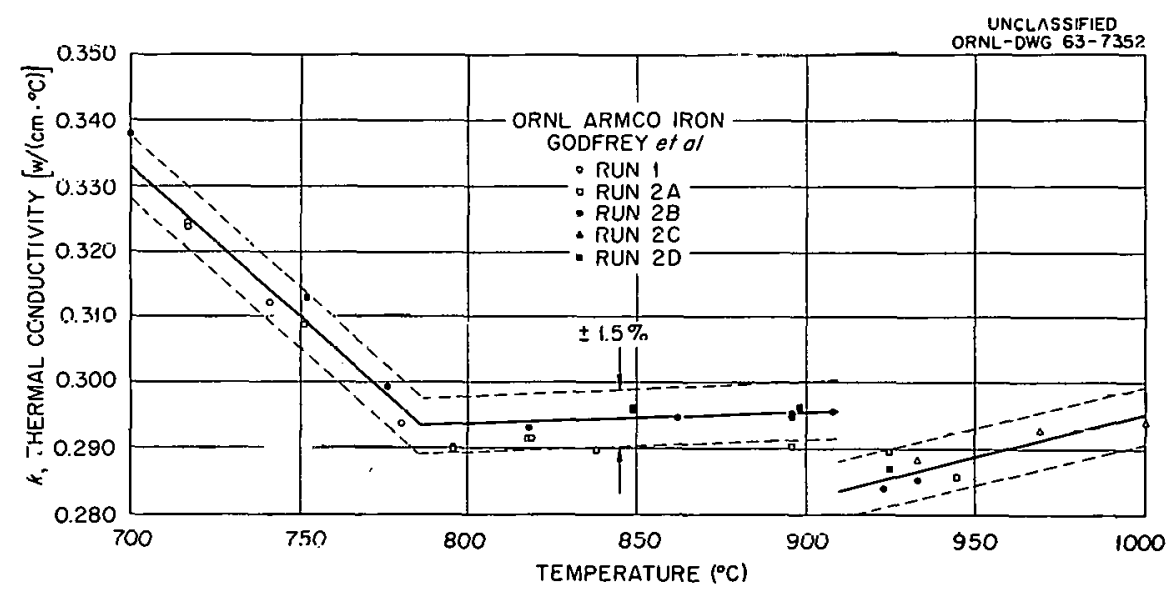

Fig. 13. ORNL Thermol Conductivity Results on Armco Iron from 700 to $1000^{\circ} \mathrm{C}$. 


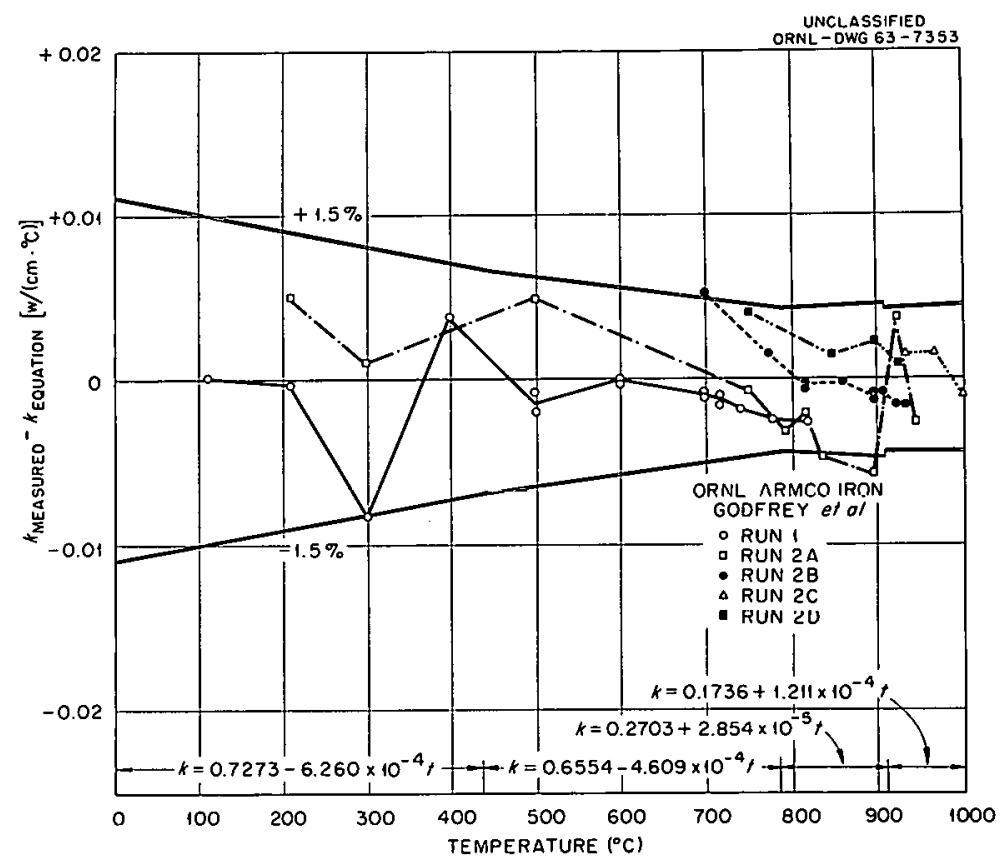

Fig. 14. Comparison of the ORNL Thermal Conductivity Results on Armco Iron to the Four Equations Which Span the Region 100 to $1000^{\circ} \mathrm{C}$.

axis represents $k$ vs $t$ as determined by the equation indicated in the figure. A positive deviation represents a measured $k$ greater than predicted by the equation, and a negative deviation represents a measured $k$ less than predicted by the equation.

The deviation of the ORNL results from these equations shows the previously mentioned changes which occurred between the runs. Run 1 generated results to $820^{\circ} \mathrm{C}$ which, with one exception (the $300^{\circ} \mathrm{C}$ data), were well within $1 \%$ of the stated equations. The results of run $2 \mathrm{~A}$ were nominally $1 \%$ above run 1 values and scattered above $820^{\circ} \mathrm{C}$. The run $2 \mathrm{~A}$ data above $820^{\circ} \mathrm{C}$ were not used in calculating Eqs. (24) and (25). Run $2 \mathrm{~B}$ results were 1 to $2 \%$ above the results of run 1 and show a minimum scatter, reflecting the thermocouple stability induced by the $950^{\circ} \mathrm{C}$ anneal. Run $2 \mathrm{C}$ which was entirely in the $\gamma$-iron region and was preceded by the $1050^{\circ} \mathrm{C}$ anneal, yielded very consistent results. The results of run $2 \mathrm{C}$ were about $1 \%$ above the results of run $2 \mathrm{~B}$ in the $y$-iron region. The run 2D results were within $1 \%$ of all of the results of run $2 \mathrm{~B}$. and are remarkably close to the run $2 \mathrm{C}$ results in the gamma region. Thus the measured results increased in value with increasing time above $700^{\circ} \mathrm{C}$ and reached stable values in runs $2 \mathrm{C}$ and $2 \mathrm{D}$. The possibility of normalizing the results of run 2 to run 1 was considered but rejected at this stage of data presentation and interpretation. Naturally, all of the results are near the zero deviation line because these data were used to generate the rnmparison equations, 
A similar comparison of the ORNL data and four sets of recent literature values on Armco iron are made in Fig. 15. Two of the four sets of data under comparison, those of the National Physical Laboratory (NPL) ${ }^{36}$ and the National Research Council (NRC), ${ }^{37}$ were obtained using specimens fabricated from the Armco iron circulated by BMI. The third data set was that presented by Powell ${ }^{10}$ and termed by him to be the most probable value. The fourth set of data was obtained by Cody, Abeles, and Beers ${ }^{38}$ of Radio Corporation of America Laboratories (RCA) on an Armco iron specimen by a thermal diffusivity technique. As will be discussed later, the RCA thermal conductivity values quoted here were obtained using a more recent set of specific heat data ${ }^{39}$ than they originally used. The data plotted in Fig. 15 are presented in Table E.2. The NPL ${ }^{36}$ and $\mathrm{NRC}^{37}$ data were not corrected for thermal expansion, whereas the ORNL and RCA data were corrected.

${ }^{36}$ R. W. Powell et al., "Armco Iron as a Thermal Conductivity Standard. Part II, Ncw Determinations at the National Physical Laboratory," $\mathrm{p} 454$ in Progress in Intemational Research on Thermodynamic and Transport Properties (ed. by J. F. Masi and D. H. Tsai), The American Society of Mechanical Engineers and Academic Press, New York, 1962.

${ }^{37}$ M. J. Laubitz, "Thermal and Electrical Properties of Armco Iron at High Temperatures," Can. J. Phys. 38(7), 887 (1960).

${ }^{38}$ G. D. Cody, B. Abeles, and D. S. Beers, "Thermal Diffusivity of Armco Iron," Trans. Met. Soc. AIME 221(2), 25 (1961).

${ }^{39}$ D. L. McElroy, "The Application of Dynamic Adiabatic Calorimetry to the Iron-Iron Carbide System," Ph.D. dissertation, University of Tennessee (August 1957).

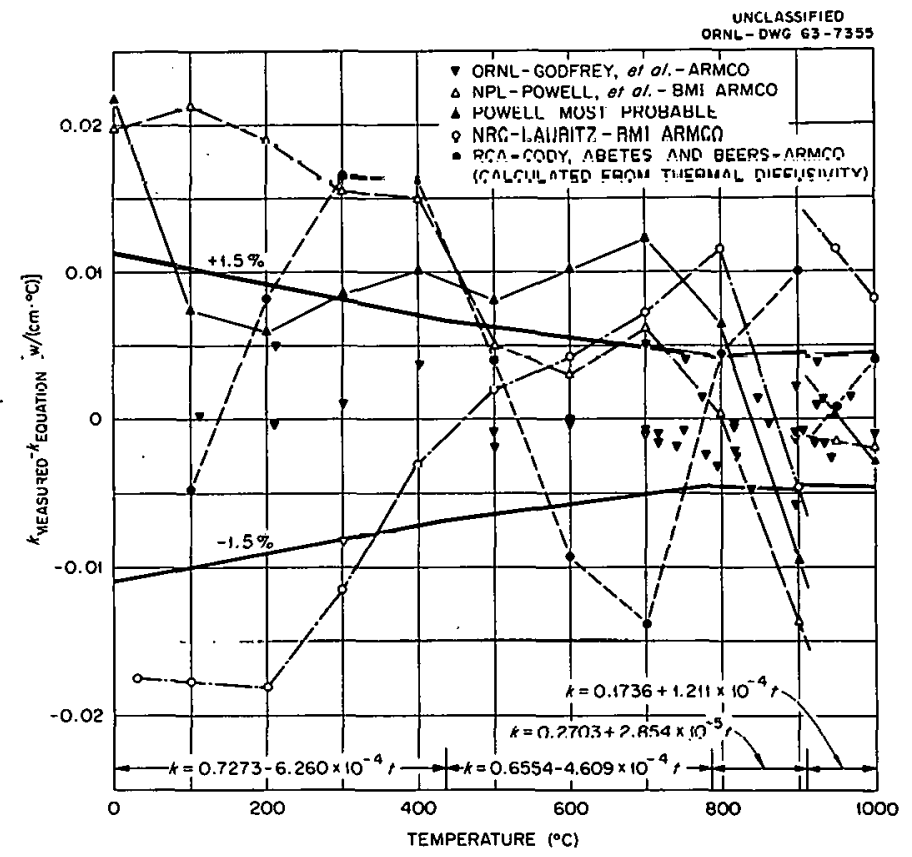

Fig. 15(a). Comparison of the Thermal Conductivity of Armco Iron of Vorious Studies to the Four Equations That Represent the ORNL Results from 0 to $1000^{\circ} \mathrm{C}$. 


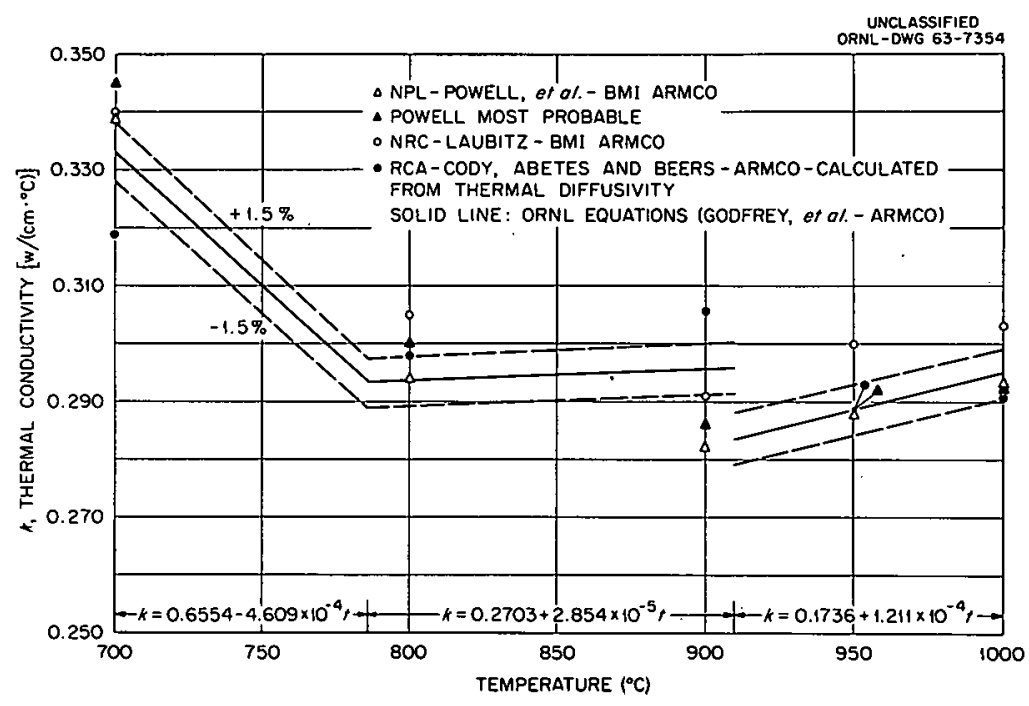

Fig. 15(b). Comporison of the Thermal Conductivity of Armco Iron of Various Studies to the Three Equations That Represent the ORNL Results from 700 to $1000^{\circ} \mathrm{C}$.

On the BMI samples the NPL results are $3 \%$ higher than the equations to $400^{\circ} \mathrm{C}$. On the other hand, the NRC values* are $3 \%$ below the ORNL equations to $200^{\circ} \mathrm{C}$, approach the equations from 200 to $500^{\circ} \mathrm{C}$, and deviate from the equations from 500 to $900^{\circ} \mathrm{C}$. Powell's most probable values ${ }^{10}$ are 1 to $2 \%$ above the equations from 100 to $800^{\circ} \mathrm{C}$ but deviate at 0 and $900{ }^{\circ} \mathrm{C}$ by as much as $3 \%$. From 900 to $1000^{\circ} \mathrm{C}$ the NPL results and Powell's most probable values are within $1.5 \%$ of the equation, whereas the NRC results are about $3 \%$ high. The RCA data scatter in a $\pm 3 \%$ band around the equations from 100 to $900^{\circ} \mathrm{C}$ but are in good agreement from 900 to $1000^{\circ} \mathrm{C}$ with the equations. Only the RCA and ORNL data show a decrease in thermal conductivity at the $a-y$ transformation; however, the RCA data indicate a 6 to $7 \%$ change, while the ORNL values indicate a $4 \%$ change. Not included in Fig. 15, but of significance is the data of Claussen, ${ }^{40}$ who also observed a decrease of $k$ on passing through the $a-\gamma$ transition; this decrease amounted to a 15 to $20 \%$ change at pressures of 9000 atm. Perhaps the most striking observation of this comparison is that four different laboratories using four different methods of measurement obtained results within $\pm 3 \%$ over the 100 to $1000^{\circ} \mathrm{C}$ range.

\section{Electrical Resistivity Data}

Electrical resistivity measurements were made on a rod specimen 12 in. long and 0.1 in. in diameter. For temperatures above room temperature the specimen was directly heated by a direct current in a vacuum of $5 \times 10^{-7}$ torr. The center 6 in. of the rod was instrumented with

*Dr. Laubitz has informed us that the low-temperature NRC data are plotted about $1 \%$ lower than they should be. This is due to the fact that a small correction was overlooked when the data was reported in ref 37.

${ }^{40}$ W. F. Claussen, "Detection of the $\alpha-y$ Iron Phase Transformation by Differential Thermal Conductivity Analysis, Rev. Sci. Instr. 31(8), 878 (1960). 
seven 0.005-in.-diam Pt vs Pt-10\% Rh thermocouples spaced at 1 -in. intervals. The thermocouples were tweezer-welded to the rod so that the junction was made through the iron specimen. The 0.005-in.-diam $\mathrm{Pt}-10 \% \mathrm{Rh}$ and $\mathrm{Pt}$ wires were welded to 0.020-in.-diam wires a few inches away from the specimen, and these larger wires extended out of the vacuum chamber through epoxy resin seals to an ice-bath cold well similar to the one described for the radial heat flow apparatus. The thermocouple emf's were read using an L\&N type K-3 potentiometer. The current through the specimen was produced by a PRL 50 -amp-dc power supply model CM03-5L-CC and was measured by reading the potential drop across a series-connected 0.01 -ohm L\&N standard resistor, model No. 4361 , with the L\&N type K-3 potentiometer. For temperatures below room temperature the specimen was immersed in three baths: ice and water $\left(0^{\circ} \mathrm{C}\right)$; dry ice and alcohol $\left(-78.9^{\circ} \mathrm{C}\right)$; and liquid nitrogen $\left(-196^{\circ} \mathrm{C}\right)$.

The resistivity was obtained by measuring the current and the corresponding potential drop between the $\mathrm{Pt}-10 \% \mathrm{Rh}$ legs of a set of adjacent thermocouples at a given temperature. The set of thermocouples chosen were near the center of the rod so that both thermocouples were at essentially the same temperature. Readings were made at each temperature with the current in one direction and then the other so that pickup errors in the thermocouples could be eliminated. The resistivity was calculated using the formula

$$
\rho=\frac{\Delta \bar{V}}{\bar{I}} \frac{A^{*}}{L^{*}}\left[1+\alpha_{L}(t-23)\right],
$$

where

$\Delta \bar{V}$ is the average potential drop between the $\mathrm{Pt}-10 \% \mathrm{Rh}$ legs for the current in the forward and reverse directions,

$\bar{I}$ is the average of the forward and reversed currents,

$L^{*}$ is the distance between the $\mathrm{Pt}-10 \% \mathrm{Rh}$ wires,

$A^{*}$ is the cross-sectional area of the rod,

$t$ is the temperature in ${ }^{\circ} \mathrm{C}$,

$\alpha_{L}$ is the expansion coefficient, $13.5 \times 10^{-6}$ per ${ }^{\circ} \mathrm{C}$ (ref 37 ).

The maximum determinate error in $\rho$ due to measurement uncertainties in the quantities of Eq.

(26) was estimated (as shown in Appendix F) to be $\pm 1.3 \%$, with a most probable value of $\pm 1.0 \%$ if the errors behave randomly.

Using this technique the resistivity vs temperature curve was found to be concuve upward to about $750^{\circ} \mathrm{C}$, where an inflection occurs and the resistivity increases approximately linearly above $900^{\circ} \mathrm{C}$. This is the usual shape of the electrical resistivity curve for ferromagnetic materials near the Curie temperature. The data were fit by least-mean-squares criteria to within $2 \%$ in the range 194 to $780^{\circ} \mathrm{K}$ by a cubic equation

$$
\begin{aligned}
\rho & =C_{1}+C_{2} T+C_{3} T^{3}, \\
& =-1.43+3.85 \times 10^{-2} T+6.30 \times 10^{-8} T^{3},
\end{aligned}
$$

where $\rho$ is in $\mu \mathrm{ohm}-\mathrm{cm}$, and $T$ is absolute Kelvin temperature. Above $800^{\circ} \mathrm{C}$ the resistivity could 
be expressed by the linear relation

$$
\rho=74.9+3.38 \times 10^{-2} T .
$$

Following the electrical resistivity measurements, the distances between thermocouples and the diameter of the rod were remeasured and were found to be the same as originally even though the specimen had been cycled through the $a-y$ transformation several times. It was impossible to so examine the thermal conductivity specimen because the disks of the stack became welded together during the experiment.

Values of $\rho$ obtained between $-196^{\circ} \mathrm{C}$ and $1000^{\circ} \mathrm{C}$ are given in Table G.1 of Appendix G. Smoothed values are presented in Table 5 at $50^{\circ} \mathrm{C}$ increments together with values of Powell et al. ${ }^{36}$ and Laubitz. ${ }^{37}$ The data of the other laboratories as well as the ORNL data have been corrected for ther'mal expansiun using $13.5 \times 10^{-6} /{ }^{\circ} \mathrm{C}$ as the thermal expansion coefficient throughout the entire temperature range even though iron undergoes a linear contraction

Table 5. Smoothed Electrical Resistivity Values for Armeo Iron

\begin{tabular}{|c|c|c|c|c|c|}
\hline \multicolumn{2}{|c|}{ ORNL } & \multicolumn{2}{|c|}{ NPL } & \multicolumn{2}{|c|}{ NRC } \\
\hline $\begin{array}{c}\text { Temperature } \\
\left({ }^{\circ} \mathrm{C}\right)\end{array}$ & $\begin{array}{c}\rho \\
(\mu \mathrm{ohm}-\mathrm{cm})\end{array}$ & $\begin{array}{c}\rho \\
(\mu \mathrm{ohm}-\mathrm{cm})\end{array}$ & $\begin{array}{c}\text { Deviation } \\
(\%)\end{array}$ & $\begin{array}{c}\rho \\
(\mu \mathrm{ohm}-\mathrm{cm})\end{array}$ & $\begin{array}{c}\text { Deviation } \\
(\%)\end{array}$ \\
\hline-150 & .3 .2 & 3.3 & +3.0 & & \\
\hline-100 & 5.3 & 5.3 & 0.0 & & \\
\hline-50 & 7.6 & 7.5 & -1.3 & & \\
\hline 0 & 10.2 & 10.0 & & 10.4 & \\
\hline 50 & 12.6 & 12.5 & -0.8 & & \\
\hline 100 & 15.9 & 15.6 & -1.9 & 15.6 & -1.9 \\
\hline 150 & 19.4 & 19.1 & -1.6 & & \\
\hline 2.00 & 23.3 & 23.1 & -0.9 & 23.0 & -1.3 \\
\hline 250 & 27.8 & 27.1 & -2.6 & & \\
\hline 300 & 32.7 & 31.3 & -4.4 & 32.1 & -1.9 \\
\hline 350 & 38.2 & 36.5 & -4.6 & & \\
\hline 400 & 44.0 & 42.0 & -4.7 & 43.1 & -2.1 \\
\hline 450 & 50.3 & 47.7 & -5.3 & & \\
\hline 500 & 56.7 & 54.4 & -4.2 & 56.1 & -1.1 \\
\hline 550 & 64.1 & 61.4 & -4.3 & & \\
\hline 600 & 72.0 & 69.4 & -3.7 & 70.9 & -1.5 \\
\hline 650 & 80.7 & 77.8 & -3.7 & & \\
\hline 700 & 90.2 & 87.0 & -3.6 & 88.8 & $-\% .5$ \\
\hline 750 & 101.2 & 97.8 & -3.4 & & \\
\hline 800 & 108.7 & 106.4 & -2.1 & 107.1 & -1.5 \\
\hline 850 & 112.4 & 111.1 & -1.2 & & \\
\hline 900 & 114.5 & 11.3 .8 & -0.7 & 113.4 & -1.0 \\
\hline 950 & 116.2 & 115.6 & -0.5 & & \\
\hline 1000 & 117.7 & 117.4 & -0.3 & 116.8 & -0.8 \\
\hline
\end{tabular}


of about $0.3 \%$ (ref 37) at the $\alpha-\gamma$ transition at $910^{\circ} \mathrm{C}$. The percent deviation of the data is also shown in this table. It is seen that, except for the value at $700^{\circ} \mathrm{C}$, the ORNL data agree with that of $\mathrm{NRC}^{37}$ to within $2 \%$, which is within the sum of the estimated accuracies of the measurements. The disagreement with NPL ${ }^{36}$ was less than $2 \%$ from -150 to $200{ }^{\circ} \mathrm{C}$ and again from 800 to $1000^{\circ} \mathrm{C}$, but the deviation in the range from 200 to $800^{\circ} \mathrm{C}$ was as much as $5 \%$, which is well outside the estimated accuracies of the methods used in the two laboratories. The reason for the discrepancies may be due to specimen differences or to some unassessed inaccuracies in the measurement techniques. It is interesting to note that the discrepancies are greatest in the temperature range where the resistivity changes most rapidly, indicating that temperature measurement errors may be present. Powell et al. ${ }^{36}$ report a sudden drop in the electrical resistivity at the $a-y$ transition of about $1.6 \mu \mathrm{ohm}-\mathrm{cm}$. Such a change, if it occurred, was $<1$ $\mu \mathrm{ohm}-\mathrm{cm}$ for the ORNL specimen but insufficient data were taken around the transformation temperature to establish the effect accurately.

\section{DISCUSSION OF THE RESULTS ON IRON}

$$
\text { Discussion of } k_{e} \text { and } k_{L} \text {. }
$$

For the purpose of discussion it will be assumed that the thermal condictivity of 1run may be expressed as

$$
k=k_{e}+k_{L}
$$

where $k_{e}$ is the contribution due to transport of heat by electrons, and $k_{L}$ is the contribution due to transport by heat by phonons. Actually the two mechanisms are coupled, although it is generally assumed that the coupling is weak. The electronic portion, $k_{e}$, can be calculated from the electrical resistivity data using the theoretical Wiedemann-Franz-Lorenz constant $L$ by the equation

$$
\frac{k_{\mathrm{e}} \rho}{T}=L=2.45 \times 10^{-8} \cdot \mathrm{w}-\mathrm{ohm} /\left(\mathrm{O}^{\mathrm{K}}\right)^{2} .
$$

The validity of this relation depends on the relaxation time for electrons under the disturbance of an electric field being the same as that for the disturbance caused by a thermal gradient. It is also necessary that the relaxation time and the rate of change of the energy of the electron states with change of the wave vector be slowly changing functions of the electron energy near the Fermi surface. These conditions should be fulfilled for a one-band metal at high temperatures. There is some doubt, however, whether the relation is valid for transition metals where the $s$ and $d$ bands may overlap. 
Recently, Backlund ${ }^{4}$ suggested that a modified Wiedemann-Franz-Lorenz type relation, originally proposed by Linde, ${ }^{42}$ should be applied to iron. This relation is

$$
k_{e}=\frac{L T}{\rho+\rho_{0}} .
$$

The constant $\rho_{0}$ was obtained by Backlund for "pure" iron by fitting his data together with those of Pallister ${ }^{43}$ in the temperature range 195 to $373^{\circ} \mathrm{K}$ to a cubic equation of the same form as Eq. (27), where $\rho_{0}$ is the absolute value of the constant term $C_{1}$ in this equation. In his paper Backlund indicates three different values of $\rho_{0}(+2.4,2.6$, and $2.66 \mu \mathrm{ohm}-\mathrm{Cm})$, but evidently 2.66 is the value which he considers to correspond to pure iron. 'Since impurities contribute to $C_{1}$, the apparent value of $\rho_{0}$ will be changed by impurities. This evidently accounted for the various values cited. 'This impurity effect is shown in Table 6 . The values of the three constants in the cubic equation for $\rho$ are given as obtained by least-mean-squares fitting of the ORNL data and those of Powell et al. ${ }^{36}$ The values of $C_{1}$ for Armco iron (an impure iron) are considerably larger than Backlund's value of $-\rho_{0}$. The table also shows that the value of the coefficients vary, depending on the temperature range over which the fit was made.

Backlund contends that the cubic term $C_{3} T^{3}$ represents a spin scattering contribution which should become constant above the Curie temperature. Therefore the slope of Eq. (28) should be the same as the constant $C_{2}$ of Eq. (27). Examination of Table 6 shows that the values of $C_{2}$ agree well with the value of the slope, $3.38 \times 10^{-2} \mu \mathrm{ohm}-\mathrm{cm} /{ }^{\circ} \mathrm{K}$ in Eq. (28), which supports Backlund's contention.

${ }^{41}$ N. G. Backlund, "An Experimental Investigation of the Electrical and Thermal Conductivity of Iron and Some Dilute Iron Alloys at Temperatures Above 100\%," J. Phys. Chem. Solids 20 (1/2), 1-16 (1961).

42 J. O. Linde, "An Investigation of the Validity of the Wiedemann-Franz-Lorenz I.aw," Arkiv. Fysik $4(38), 541(1951)$.

${ }^{43}$ P. K. Pallister, "The Specific Heat and Resistivity of High Purity Iron Up to $1250^{\circ} \mathrm{C}$," J. Iron Steel Inst. 161,87 (1949).

Table 6. Constants for a Cubic Fit of the Electrical Resistivity Data for Armco Iron Where $\rho=C_{1}+C_{2} T+C_{3} T^{3}$

\begin{tabular}{|c|c|c|c|c|}
\hline Author & $\begin{array}{c}\text { Temperature } \\
\text { Range } \\
\left({ }^{\circ}\right)\end{array}$ & $\begin{array}{c}C_{1} \\
(\mu \mathrm{ohm}-\mathrm{cm})\end{array}$ & $\begin{array}{c}c_{2} \times 10^{2} \\
\left(\mu \mathrm{ohm}-\mathrm{cm} /{ }^{\mathrm{K}}\right)\end{array}$ & $\begin{array}{c}c_{3} \times 10^{8} \\
\left(\mu \mathrm{ohm}+\mathrm{cm} / \mathrm{K}^{3}\right)\end{array}$ \\
\hline \multirow[t]{2}{*}{ ORNL } & $195-380$ & -1.69 & 3.88 & 6.03 \\
\hline & $195-780$ & -1.4 .3 & 3.85 & 6.30 \\
\hline \multirow[t]{2}{*}{ Powe11 ${ }^{36}$} & $173-373$ & -1.34 & 3.65 & 6.33 \\
\hline & $173-723$ & -1.03 & 3.98 & 5.58 \\
\hline Backlund ${ }^{41}$ and Pallister ${ }^{43}$ & $195-373$ & -2.4 & 3.65 & $6.4^{a}$ \\
\hline
\end{tabular}

${ }^{a}$ This value appeared as $64 \times 10^{-8}$ in ref 41 , evidently by misprint. 


$$
\text { Calculation of } k_{\mathrm{e}} \text { and } k_{L}
$$

Despite the uncertainty in $\rho_{0}, k_{e}$ was calculated using Eq. (31). A value of $\rho_{0}$ of $2.7 \mu \mathrm{ohm}-\mathrm{cm}$ was used. The values of $k$ are plotted in Fig. 12 along with $k_{e}$ calculated by Eqs. (30) and (31). Figure 16 shows $k_{L}$ obtained as the difference $k-k_{e}$ using both values of $k_{e}$. With the conventional Wiedemann-Franz-Lorenz relation, $k_{\mathrm{e}}$ accounts for $80 \%$ or more of the total thermal conductivity and therefore largely controls the temperature dependence of the thermal conductivity. This is also true at high temperatures for $k_{e}$ calculated by Eq. (31) but at $100^{\circ} \mathrm{C}$ is only $73 \%$ of $k$ and displays a maximum near $250^{\circ} \mathrm{K}$. Using the usual Wiedemann-FranzLorenz approach, $k_{L}$ peaks at about $300^{\circ} \mathrm{C}$, which is considerably above the Debye temperature of $147^{\circ} \mathrm{C}$ (ref 44 ). Generally, the lattice conductivity peaks at temperatures considerably

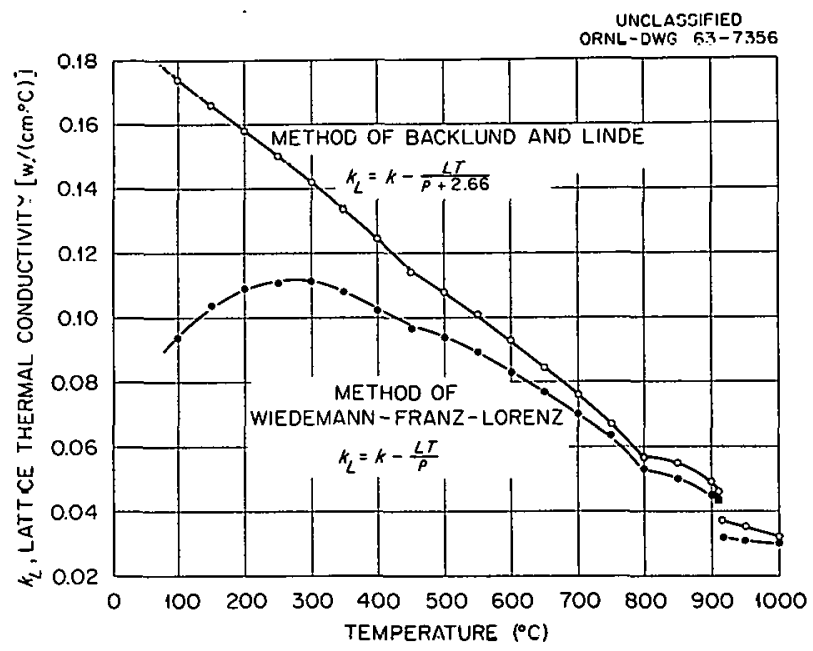

Fig. 16. Lattice Thermal Conductivity of Armco Iron as a Function of Temperuture, Calculated by Two Methods.

below the Debye temperature. However, we have already seen that this rule does not apply to $\mathrm{UO}_{2}$ because of a low-temperature antiferromagnetic-paramagnetic transformation. Some similar phenomenon of magnetic origin may explain the behavior of iron. Using the Backlund modified Wiedemann-Franz-Lorenz äpproach, unt tlininlales the high-tcmpcraturo poals in $\underline{t}_{\bar{L}}$ However, as can be seen from Fig. 12, the Backlund $k_{e}$ has a peak at about $250 \%$, which seems just as unreasonable as the peak in $k_{L}$ obtained using the Wiedemann-Franz-Lorenz relation. At the present state of the theory of thermal conductivity, it is not at all obvious which of the approaches for calculating $k_{\mathrm{e}}$ and $k_{L}$ approaches closest to reality.

${ }^{44}$ F. Seitz, The Modern Theory of Solids, p 110, McGraw-Hill, New York, 1940. 


\section{Decrease in $k$ at $910^{\circ} \mathrm{C}$}

The $4 \%$ decrease at the $a-\gamma$ transition is not predicted by the $k_{e}$ 's. In fact, the electrical resistivity decrease at the transition temperature reported by Powell et al. ${ }^{36}$ should be reflected by an increase in $k$ rather than the decrease observed. The change in $k$ at $910^{\circ} \mathrm{C}$ must be due to a decrease in the lattice portion of the conductivity as shown in Fig. 15 and is tied to the fact that a change from body-centered cubic to face-centered cubic structure causes an appreciable modification of the phonon distribution. Cody, Abeles, and Beers ${ }^{38}$ have pointed out that if Eq. (9) applies to $k_{L}$ of iron at high temperatures, then the decrease in the Debye temperalure upon going from $a$ to $\gamma$ phases (which is consistent with existing heat capacity data for the phases) can explain the drop in $k_{L}$. At $910^{\circ} \mathrm{C} k_{L}$ amounted to $\sim 15 \%$ of the total thermal conductivity, and the ubserved 3 to $4 \%$ decrease in $k$ can be explained by a $10 \%$ decrease in the Debye temperalure. However, it should be pointed out that if $k_{L}$ obeys Eq. (9), it should have a $1 / T$ temperature dependence, which it does not have regardless of the method one uses to calculate $k_{\mathrm{e}}$. The temperature dependence of $k_{L}$ is closer to a $1 / T$ relation using the BacklundLinde method.

\section{Slope Change of $k$ at $780^{\circ} \mathrm{C}$}

The minimum in $k$ just above the Curie temperature is reflected by both $k_{e}$ 's and is apparently due to the effect of the changed magnetic properties on the electronic portion of the thermal conductivity since $k_{e}$ also changes slope, as shown in Fig. 12. It should be pointed out that no

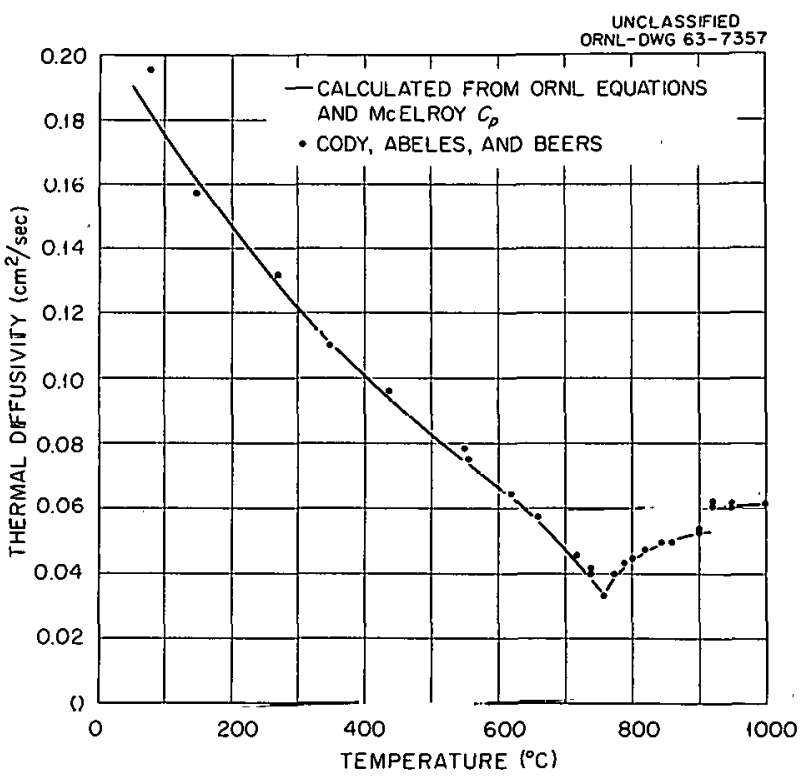

Fig. 17. Thermal Diffusivity of Armeo Iron Calculated from ORNL Thermal Conductivity Data and Heat Ca. pacity Data of McElroy 39 and Compared with the Thermal Diffusivity Data of Cody, Aheles, and Boors. 38 
break or discontinuity in the data of the type reported by Cody, Abeles, and Beers ${ }^{38}$ at the magnetic transformation temperature $768^{\circ} \mathrm{C}$ was observed. Data were taken in this temperature region, as shown in Fig. 13, and the average $\Delta t$ between inside and outside thermocouples was only 3 to $4^{\circ} \mathrm{C}$; therefore any discontinuity or drastic change in slope should have been detected. This points out the difficulty of obtaining accurate thermal conductivity values from thermal diffusivity measurements in a temperature range where the heat capacity of the specimen is changing rapidly with temperature.

The thermal diffusivity data of Cody, Abeles, and Beers ${ }^{38}$ is plotted in Fig. 17, and these data are compared with thermal diffusivities calculated using the ORNL thermal conductivity values and McElroy's values ${ }^{39}$ for the specific heat of iron. It is seen that the agreement is excellent over the whole temperature range, including the region near the Curie point. This clearly shows the need for very good heat capaclty values when the thormul counduclivity is calculated from thermal diffusivity measurements.

\section{Slope Change of $k$ at $436^{\circ} \mathrm{C}$}

The break in $k$ at $436^{\circ} \mathrm{C}$ may be an impurity or magnetic effect since iron itself does not have a solid-state phase change in this region. It is. interesting to note that Laubit ${ }^{37}$ has reported a minimum in the thermoelectric power of Armco iron at about this temperature.

\section{Cinrrelation of $k$ at $100^{\circ} \mathrm{C}$ with Impurity Content}

Powel1 $1^{10}$ gives a linear correlation between measured $k$ values at $100{ }^{\circ} \mathrm{C}$ and the equivalent carbon content of all reported impurities; this correlation predicts a thermal conductivity of 0.694 $\mathrm{w} \mathrm{cm}^{-1}{ }^{\circ} \mathrm{C}^{-1}$ for pure iron. The ORNL dala fit this correlation if oxygen is excluded; however, inclusion of oxygen would lead to a prediction of $0.726 \mathrm{w} \mathrm{cm}^{-1}{ }^{\circ} \mathrm{C}^{-1}$ for pure iron using a parallel straight line. As was previously stated, our calculatiuns indicated that sulfides, phosphides, and oxides were also prosent as a second phase. Theory dictates that only the impurities in solution should be included in a correlation such as Powell's. However, he has included sulfur and phosphorus in his correlation. If it is assumed that the second phase has a thermal conductivity smaller than that of the iron, its effect on $k$ should be a reduction which is no greater than the volume percent of the phase (in this case, <1\%). The effect of dissolved impurities should be much larger than, but in the same direction as that of the second phase. The point to be stressed is that one must know not only the composition of the specimen but also the physical state in which the impurities are found in order to assess the effects of these impurities on thermal and electrical conductivity. 


\section{CONCLUSIONS}

The radial heat flow apparatus was shown to give absolute thermal conductivity results with a probable accuracy of $\pm 1.5 \%$ and a repeatability of $0.1 \%$ from 100 to $1100^{\circ} \mathrm{C}$ on both a lowconductivity semiconductor, $\mathrm{UO}_{2}$, and a high-conductivity metal, Armco iron. The upper temperature limit was imposed by $\mathrm{Pt}$ vs $\mathrm{Pt}-10 \% \mathrm{Rh}$ thermocouple instability although the apparatus was structurally sound and operable to at least $1400^{\circ} \mathrm{C}$. The lower temperature limit was imposed by present design, but tests have shown that with only slight modification much lower temperatures can be obtained.

The ORNL results on polycrystalline $\mathrm{UO}_{2}$ showed:

1. The thermal resistance, $1 / k$, is linear between 200 and $1000^{\circ} \mathrm{C}$ with a characteristic slope of $0.0223 \mathrm{~cm} / \mathrm{w}$ from which a Debye temperature of $216^{\circ} \mathrm{C}$ was derived. Below $1000^{4} \mathrm{C}$, heat is transported by phonons.

2. The intercept of the linear portion of the thermal resistance is sensitive to impurity changes (i.e., stoichiometry changes).

3. The thermal conductivity displays a maximum near room temperature which can be associated with the behavior of the specific heat.

4. Between 1000 and $1100^{\circ} \mathrm{C}$ the negative deviation of the thermal resistance of 1 to $3 \%$ from the extrapolation of the linear portion was probably due to a compositional change in the material; however, the possibility of an electronic or radiation contribution to the thermal conductivity is not ruled out.

The ORNL results on Armco iron showed:

1. The thermal conductivity of polycrystalline Armco iron could be represented to within $\pm 1.5 \%$ from 100 to $1000^{\circ} \mathrm{C}$ by the four linear relations:

$$
\begin{aligned}
& k=0.7273-6.260 \times 10^{-4} t \quad\left(100 \leqq t \leqq 436^{\circ} \mathrm{C}\right), \\
& k=0.6554-4.609 \times 10^{-4} t \quad\left(436 \leqq t \leqq 786^{\circ} \mathrm{C}\right), \\
& k=0.2703+2.854 \times 10^{-5} t \quad\left(786 \leqq t \leqq 910^{\circ} \mathrm{C}\right), \\
& k=0.1736+1.211 \times 10^{-4} t \quad\left(910 \leqq t \leqq 1000^{\circ} \mathrm{C}\right) \text {. }
\end{aligned}
$$

The values given by these equations are within $\pm 3 \%$ of the best numbers available from the literature.

2. The cause for the change in slope at $436^{\circ} \mathrm{C}$ is not known, but it may be related to the fact that Armco iron has a minimum in the Seebeck coefficient at about this temperature.

3. 'The minimum in the thermal conductivity at $780^{\circ} \mathrm{C}$, just above the Curie temperature, reflects the change in magnetic properties of the material.

4. Electrical resistivity measurements showed that about $80 \%$ of the thermal conductivity can be attributed to electronic conduction; therefore this contribution largely controls the temperature dependence of the thermal conductivity.

5. The $4 \%$ drop in the thermal conductivity observed at the $a-y$ transformation is attributed to a $30 \%$ drop in the lattice portion of the thermal condurtivity.

In this work we have made an intensive effort to obtain the best possible thermal conductivity measurements. We believe that the results show some interesting and important behaviors which could not have been detected without careful measurements, for example, the $4 \%$ drop in $k$ at the 
$a-y$ transformation in iron. It goes without saying that, having once invested the price of development of careful techniques, we are now in a position to make good measurements in the future routinely with as little effort as would be required for far less precise methods.

\section{RECOMMENDATIONS}

A report such as the foregoing is most worthwhile if it accomplishes the goals of the research, reveals new and useful information, points out gaps in current knowledge of science and technology, and indicates profitable routes for future work to pursue. It is in this light that we believe this research was worthwhile. As the Conclusions point out, a useful, arcurate, and absolute device was develöped. New und cunlinmalury inlüntation was ob tained on two most different and interesting materials which had previously been extensively investigated. The information obtained is not in itself complete, but it should assist future research of these and other materials.

Based on the reported results, we recommend the following as profitable avenues for future research.

1. Development work on the radial heat flow apparatus should continue with the simultaneous goals of (a) expanding the existing temperature range of operation; (b) reducing the specimen size requirements; (c) maintaining and improving the accuracy and reproducibility of the data; (d) reducing the time of measurement; and (e) simplifying the operation of the equipment.

2. Accurate thermal conductivity measurements on both polycrystalline $\mathrm{UO}_{2}$ and Armco iron to higher temperatures should be continued, as well as simultaneous measurement of other thermnphysical properties such as electrical resistivity, Seebeck coefficient, specitic heat, and infrared absorption coefficients. Specimen variables worthy of consideration include purity, grain size, porosity, and thermal and mechanical treatments.

3. The accuracy achieved in this apparatus warrants extension of it to measurements on other solids, including those materials classified as scientifically interesting, to sludy phenomological effects (such as the various heat transport mechanisms); those materials which can be classified as new and as possessing unknown thermal properties; those classified as thermal conductivity reference standards to allow more meaningful measurements by investigators using comparative methods; and those classified as engineering materials whose thermal properties are critical to obtain efficient devices. Generally the specimen size requirements for this apparatus are a trivial problem in the latter two cases, and technological advances in material processes are making this less of a problem in the former two cases.

4. The sophistication of any quantitative data treatment or theoretical analysis is limited by the accuracy of the measurements of numerous physical properties, and this is the main product a careful and critical experimentalist can supply to a theoretician. The experimentalist is often requested for an answer regardless of accuracy. Undoubtedly, such requests must be 
honored; but when they are so honored, the result is that the experimentalist is reduced to a weil-paid technician, the information useful to a theoretician is drastically reduced, and the entire measurement must normally be repeated within a few years using careful procedures. This is not a recommendation for the experimentalist to reduce the quantity level of his work but to define and increase the quality of his work to allow meaningful progress to be obtained in the physical properties field. One particular aspect which would be of invaluable aid is the tabulation of raw data to avoid meaningless cross comparisons which are based on interpolations of smooth curves drawn on postage-stamp-size graphs! 


\section{THIS PAGE}

\section{WAS INTENTIONALLY LEFT BLANK}




\section{Appendix A}

\section{THERMOCOUPLE LEAD-THROUGHS}

In order to make the apparatus more versatile, a demountable thermocouple lead-through was devised which would accommodate many thermocouple wires using minimum space. Design criteria were (1) ease of assembly, (2) continuity of thermocouple wire without the use of a second metal in the circuit, (3) vacuum tightness, and (4) mechanical strength. The basic design of the lead-through is shown in Fig. A.1. The pieces were machined from brass stock and tubing. The

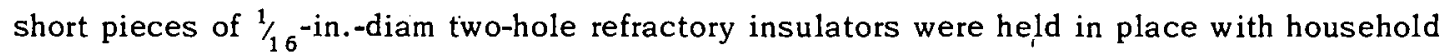
cement. The thermocouple wires were threaded through the insulators, and the cavity was filled with a low-vapor-pressure epoxy resin. The vacuum seal to the baseplate was effected with an O-ring. Sealing pressure was supplied by a flat steel washer and four machine screws threaded into blind holes in the baseplate. The lead-through proved tu be entirely satisfactory in all respects.

The use of a taper seal on the O-ring was dictated by the fact that the lead-through holes in the baseplate of the apparatus had been machined previously with the recessed shoulder for another type of seal. Had it been possible to use the more desirable flat O-ring seal, the brass body of the lead-through would have been made larger to accommodate the O-ring gronve and the holes for the clamping screws, thus eliminating the steel washer.

Fig. A.1. Thermocouple Lend-Througli Design.
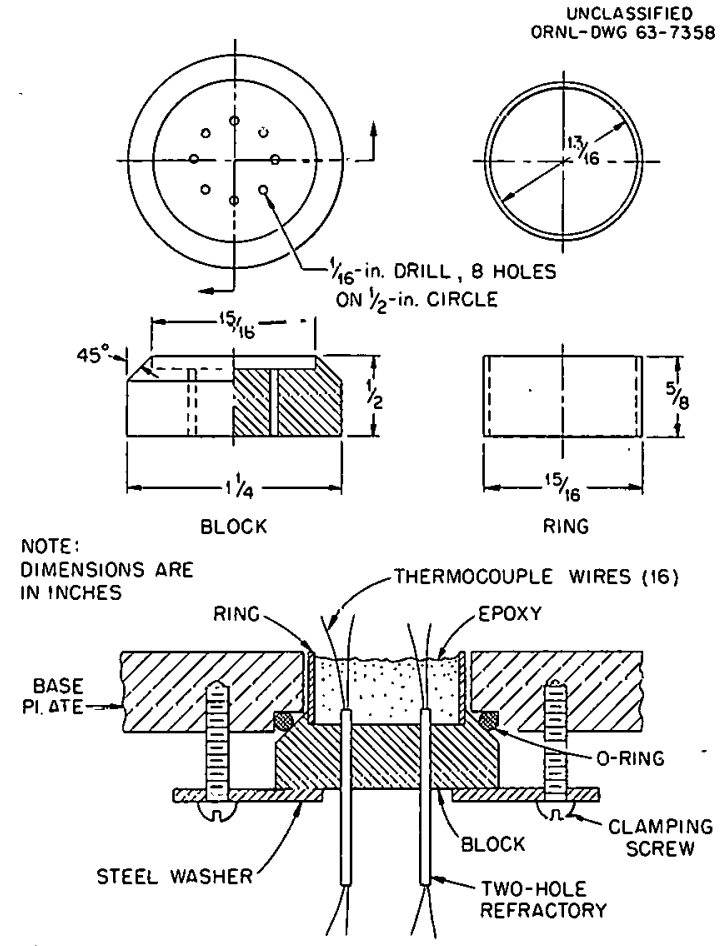
A second type of thermocouple lead-through was used to accommodate several thermocouples which were added to the system at a later date. This lead-through employed the body of a $1 / 4$-in. male-pipe-to-tube brass fitting. The thermocouple wires passed through two-hole refractory tubes which extended part way through the fitting. After the openings on one end were sealed with putty, the center cavity was filled with epoxy resin. The brass fitting was then screwed into a tapped hole in the baseplate with Teflon tape as the thread sealant. This lead-through also satisfied the criteria enumerated previously. 


\section{Appendix B}

\section{DETERMINABLE ERRORS FOR THE RADIAL HEAT FLOW APPARATUS}

Equations (1) and (3) may be rewritten as

$$
k=\frac{S Q\left(\ln r_{2}-\ln r_{1}\right)}{2 \pi L^{*}\left[\left(\bar{V}_{1}-\bar{V}_{2}\right)_{\mathrm{data}}-\left(\bar{V}_{1}-\bar{V}_{2}\right)_{\text {is o }}\right]},
$$

where $\bar{V}_{2}$ is the average reading of the thermocouples at radius $r_{2}, \bar{V}_{1}$ is the average at $r_{1}$, and $S$ is the thermocouple sensitivity. The uncertainty in $k(\Delta k)$, due to uncertainties in the quantities on the right side of Eq. (B.1), may be determined by partial differentiation, which yields

$$
\begin{aligned}
|\Delta k|=\left|\frac{\partial k}{\partial Q} \Delta Q\right|+\left|\frac{\partial k}{\partial S} \Delta S\right|+\left|\frac{\partial k}{\partial L^{*}} \Delta L^{*}\right|+\left|\frac{\partial k}{\partial r_{2}} \Delta r_{2}\right|+\left|\frac{\partial k}{\partial t_{1}} \Delta t_{1}\right| \\
+\left|\frac{\partial k}{\partial\left(\bar{V}_{1}-\bar{V}_{2}\right)_{\text {data }}} \Delta\left(\bar{V}_{1}-\bar{V}_{2}\right)_{\text {da ta }}\right|+\left|\frac{\partial k}{\partial\left(\bar{V}_{1}-\bar{V}_{2}\right)_{\text {iso }}} \Delta\left(\bar{V}_{1}-\bar{V}_{2}\right)_{\text {iso }}\right| .
\end{aligned}
$$

Taking the indicated partials and dividing the result by Eq. (B.1) yields

$$
\begin{aligned}
\epsilon_{k}=\frac{|\Delta k|}{k}=\frac{|\Delta Q|}{Q} & +\frac{|\Delta S|}{S}+\frac{|\Delta L *|}{L^{*}}+\frac{\left|\Delta r_{2}\right|}{r_{2} \ln \left(r_{2} / r_{1}\right)}+\frac{\left|\Delta r_{1}\right|}{r_{1} \ln \left(r_{2} / r_{1}\right)} \\
& +\frac{\left|\Delta\left(\bar{V}_{1}-\bar{V}_{2}\right)_{\mathrm{data}}\right|}{\left(\bar{V}_{1}-\bar{V}_{2}\right)_{\mathrm{data}}-\left(\bar{V}_{1}-\bar{V}_{2}\right)_{\text {iso }}}+\frac{\left|\Delta\left(\bar{V}_{1}-\bar{V}_{2}\right)_{\text {iso }}\right|}{\left(\bar{V}_{1}-\bar{V}_{2}\right)_{\mathrm{data}}-\left(\bar{V}_{1}-\bar{V}_{2}\right)_{\text {iso }}}=\Sigma \epsilon_{i} .
\end{aligned}
$$

where $\epsilon_{k}$ is the fractional uncertainty in $k$, and $\epsilon_{i}$ is the fractional uncertainties in the quantities on the right-hand side of Eq. (B.1). Substitution of the proper values yields the maximum value of the fractional uncertainty in $k$. These values are given in Table B.1 for the iron and $\mathrm{UO}_{2}$ specimens.

If the measurement errors are assumed to be random, the "most probable" value of the error due to these measurements may be assessed as

$$
\epsilon_{\substack{\text { most } \\ \text { probable }}}=\left(\Sigma \epsilon_{i}^{2}\right)^{1 / 2}
$$

It must also be considered that for a given measuring planc, there are several thermocouples, $n$, at both $r_{1}$ and $r_{2}$, so that the probable errur in $r_{1}$ and $r_{2}$ is the value shown in Eq. (B.3) reduced by a factor $1 / \sqrt{n}$. Similarly there are $m$ measuring planes so that the most probable error for the average value of all the planes is the value of $\epsilon_{\text {most probable }}$ from Eq. (B.4) reduced by a factor $1 / \sqrt{m}$. From the values in Table B.1, after multiplying the values of $\left|\Delta r_{1}\right| /\left[r_{1} \ln \left(r_{2} / r_{1}\right)\right]$ and $\left.\left|\Delta r_{2}\right| / L r_{2} \ln \left(r_{2} / r_{1}\right)\right]$ by $1 / \sqrt{2}$ for $\mathrm{UO}_{2}$ and $1 / \sqrt{3}$ for iron, one obtains $\epsilon_{\mathrm{most} \text { probable }}$ for UO $\mathrm{UO}_{2}$ of 0.0164 and 0.0176 for iron. These values are then multiplied by $1 / \sqrt{3}$ and $1 / \sqrt{2}$, respectivcly, to allow for three measuring planes for $\mathrm{UO}_{2}$ and two measuring planes for iron to obtain $\epsilon_{\text {most probable }}$ values of 0.0095 for $\mathrm{UO}_{2}$ and 0.0125 for iron. 
Table B.1. Calculation of Determinable Errors

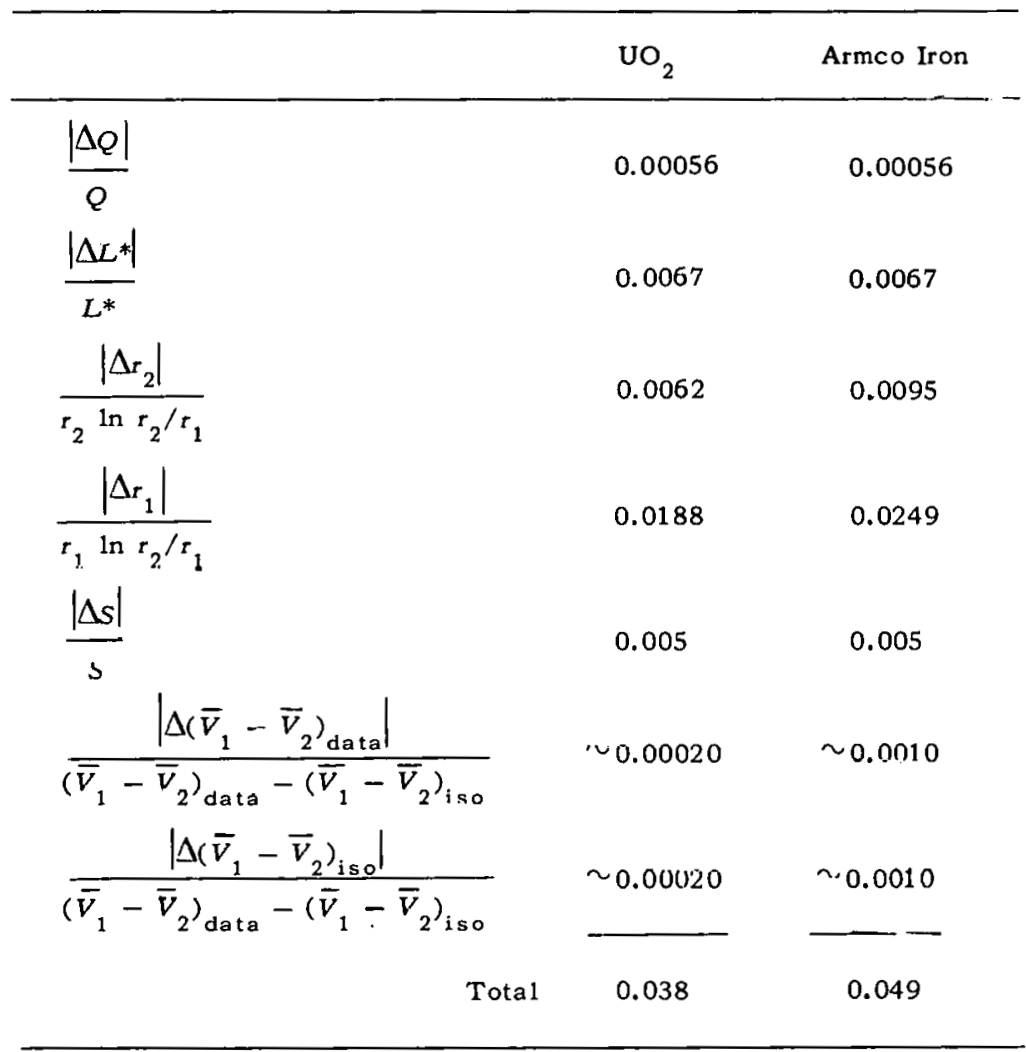




\section{Appendix C}

\section{THERMOCOUPLE-IMMERSION-DEPTH TEST}

An auxiliary experiment was performed to assess the possible error due to the fairly shallow $\left(\frac{3}{8}\right.$ in. $)$ thermocouple immersion in the $\mathrm{UO}_{2}$ specimen. The test consisted in probing, with several thermocouple configurations, the length of a 0.063 -in.-diam hole along the axis of a 4-in.diam 2-in.-long copper cylinder. The cylinder was heated on the face opposite the thermocouple entry hole by a laboratory hot plate to temperatures from 27 to $120^{\circ} \mathrm{C}$, while the other face freely radiated. The cylindrical surface was insulated to promote axial heat flow. Auxiliary thermocouple probes perpendicular to the cylinder axis established that the copper block maintained an axial gradient less than $0.1 \mu \mathrm{v} / \mathrm{in} .\left(0.02^{\circ} \mathrm{C} / \mathrm{in}.\right)$.

This test approximated the conditions that exist in the radial heat flow apparatus in that the copper block represents the isothermal zone of the thermocouple well in the specimen, and the copper-air interface temperature drop represents the gradient imposed on the thermocouple as it extends from the well radially to the surface of the specimen. However, the test was overly severe in that the copper-air interface gradient was much greater than actually exists in the apparatus and that the conducting gas (air) in the thermocouple well had a much lower conductivity than helium. Also, these low-temperature tests were stringent in that radiative heat transfer to the thermocouple was negligible.

All of the thermocouple configurations tested employed 0.010-in.-diam Pt vs Pt-10\% Rh wire insulated in (1) unbroken two-hole 0.0625-in.-diam $\mathrm{Al}_{2} \mathrm{O}_{3}$ tubing; (2) the same tubing broken into $\frac{1}{8}$-in.-long pieces; (3) two 0.030-in.-diam one-hole Degussa A123 tubes; (4) the same as (3) except broken into $1 / 8$-in.-long pieces; and (5) the broken Degussa pieces of

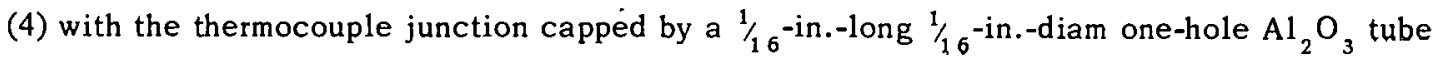
as is used in the radial heat flow apparatus.

Results typical of those obtained are shown in Fig. C.1. The thermocouple insulated with the broken Degussa pieces showed a 50\% smaller error than the one with unbroken tubes at an immersion of $3 / \frac{3}{\mathrm{in}}$., while the addition of the end cap reduccd the errur by an additional $50 \%$. Figure C. 2 shows a summary of all results expressed as the error for a $3 / 8-i n$. immersion dcpth. These results are entirely consistent with expectations and show that for the broken-Degussawith-end-cap configuration, the error is $0.04 \mu \mathrm{v} /\left({ }^{\circ} \mathrm{C} \Delta T\right)$ or about $0.007 \mu \mathrm{v} /(\mu \mathrm{v} \Delta E)$ at these temperatures. The error that would appear in a thermal conductivity measurement in the radial heat flow apparatus would be the difference between the errors for the two radial positions with their different radial gradients. In the copper block experiment, the gradient exists over a very short distance, certainly no more than 0.1 in. into the air. By analysis of the gradients over comparable distances at the two radial positions in the radial heat flow apparatus, it may be shown that the error introduced in $k$ is $<0.1 \%$ for a $\frac{3}{8}$-in. immersion depth and is independent of specimen thermal conductivity and radial temperature gradient. It should be noted that this analysis does not take into account the possible perturbations in the temperature gradient caused by the thermucuuple well itself, but only the erroi due to heat flow down the thermocouple assembly. 


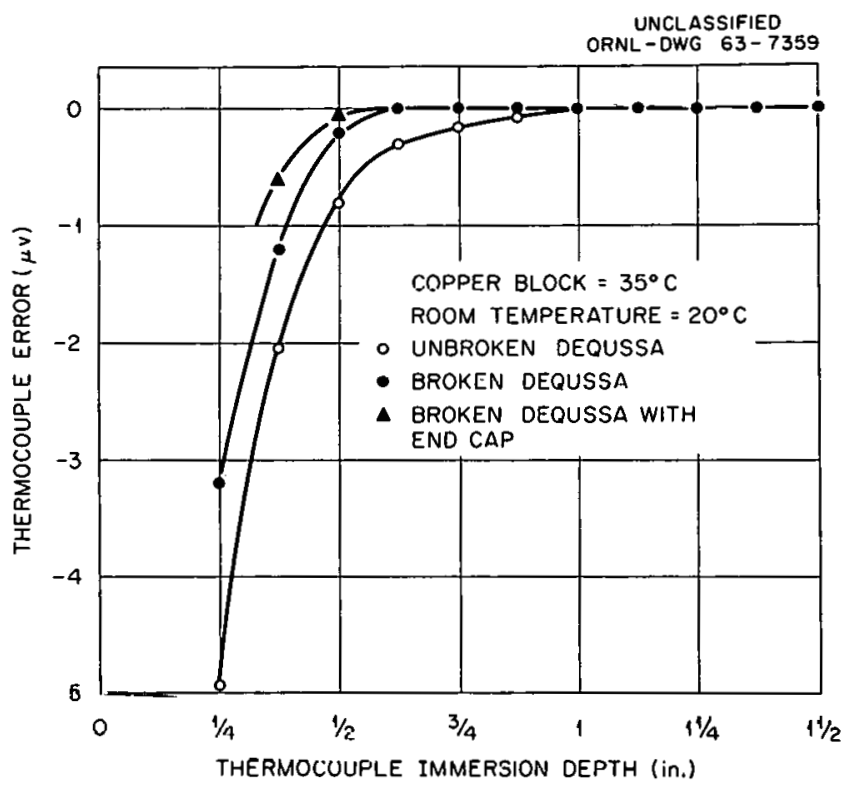

Fig. C.1. Thermocouple Error as a Function of Immersion Depth.

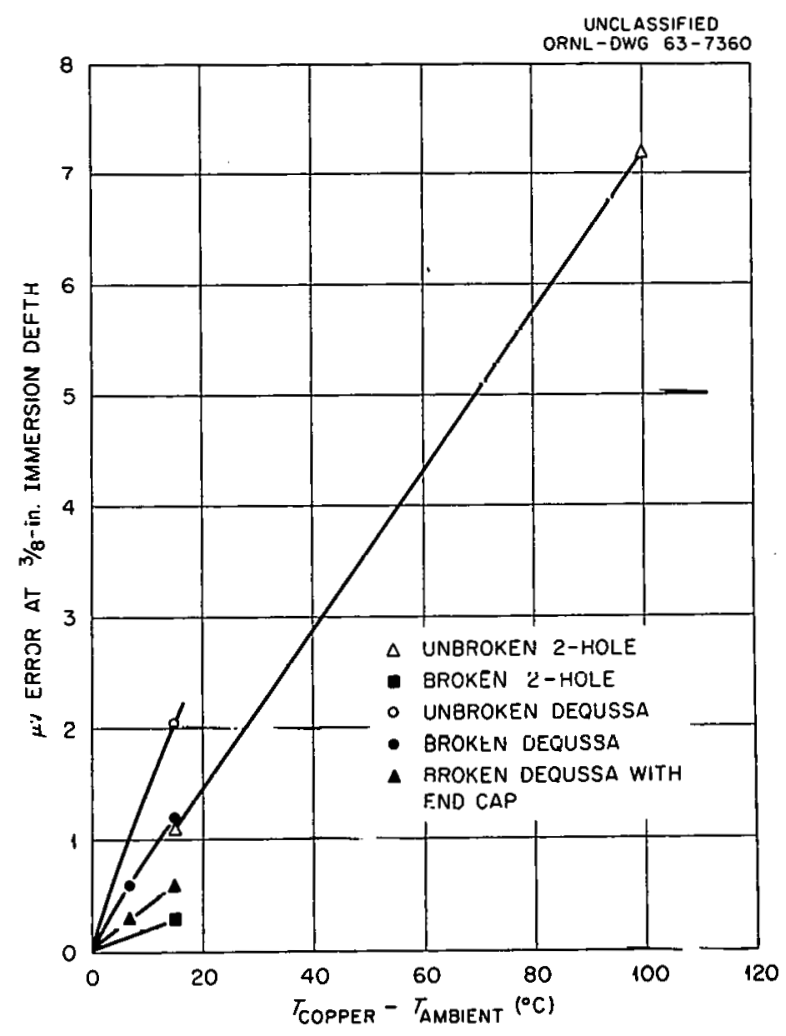

Fig. C.2. Thermocouple Error as a Function of the Temperature Gradient on the Thermocouple for a $3 / 8$-in. Immersion Depth. 


\section{Appendix D \\ $\mathrm{UO}_{2}$ THERMAL CONDUCTIVITY DATA}

Table D.1. Measured Thermal Conductivity Values from Run 1

(Corrected for core-heater expansion)

\begin{tabular}{|c|c|c|c|}
\hline$T\left({ }^{\circ} \mathrm{C}\right)$ & $\begin{array}{c}k, \text { meas } \\
\left(\mathrm{w} \mathrm{cm}-1{ }^{\circ} \mathrm{C}^{-1}\right)\end{array}$ & $\begin{array}{c}k_{t}, \text { corr } \\
\left(\mathrm{w} \mathrm{cm}-1{ }^{\circ} \mathrm{C}^{-1}\right)\end{array}$ & $(\mathrm{w} \mathrm{cm}-1 / k$, \\
\hline 55 & 0.06730 & 0.07205 & 13.88 \\
\hline 77 & 0.06605 & 0.07073 & 14.13 \\
\hline 81 & 0.06550 & 0.07012 & 14.25 \\
\hline 91.5 & 0.06475 & 0.06932 & 14.42 \\
\hline 107 & 0.06395 & 0.06844 & 14.60 \\
\hline 121.5 & 0.06327 & 0.06770 & 14.76 \\
\hline 154.5 & 0.06085 & 0.06513 & 15.35 \\
\hline 174.5 & 0.05960 & 0.06376 & 15.68 \\
\hline 195 & 0.05820 & 0.06226 & 16.06 \\
\hline 226 & 0.05632 & 0.06024 & 16.60 \\
\hline 259 & 0.05384 & 0.05757 & 17.36 \\
\hline 283 & 0.05234 & 0.05596 & 17.87 \\
\hline 321 & 0.05018 & 0.05362 & 18.66 \\
\hline 348 & 0.04838 & 0.05192 & 19.26 \\
\hline 375 & 0.04723 & 0.05046 & 19.81 \\
\hline 391 & 0.04622 & 0.04938 & 20.25 \\
\hline 424 & 0.04487 & 0.04793 & 20.88 \\
\hline 436 & 0.04456 & 0.04758 & 21.02 \\
\hline 443 & 0.04416 & 0.04715 & 21.20 \\
\hline 473 & 0.04270 & 0.04558 & 21.95 \\
\hline 500 & 0.04204 & 0.04487 & 22.30 \\
\hline 529 & 0.04097 & 0.04372 & 22.88 \\
\hline 559.5 & 0.03978 & 0.04246 & 23.57 \\
\hline 584.5 & 0.03910 & 0.04168 & 23.99 \\
\hline 609 & 0.038 .50 & 0.04100 & 24.37 \\
\hline 612.5 & 0.03827 & $0.04 n 81$ & 24.61 \\
\hline bsu & 0.03699 & 0.03943 & 25.37 \\
\hline 693 & 0.03558 & 0.03792 & 26.39 \\
\hline 739 & 0.03431 & 0.03654 & 27.38 \\
\hline 790.5 & 0.03289 & 0.03500 & 28.58 \\
\hline 830 & 0.03192 & 0.03496 & 29.43 \\
\hline 873 & 0.03100 & 0.03297 & 30.33 \\
\hline 601 & 0.03860 & 0.01116 & 24.31 \\
\hline 223 & 0.05935 & 0.06346 & 15.76 \\
\hline 227 & 0.05900 & 0.06310 & 15.86 \\
\hline
\end{tabular}


Table D.2. Measured Thermal Conductivity Values from Run 2

(Corrected)

\begin{tabular}{lccc}
\hline$T\left({ }^{\circ} \mathrm{C}\right)$ & $\begin{array}{c}k, \text { meas } \\
\left(\mathrm{w} \mathrm{cm}^{-1} \mathrm{C}^{-1}\right)\end{array}$ & $\begin{array}{c}k_{t^{\prime}} \text { corr } \\
\left(\mathrm{w} \mathrm{cm}^{-1}{ }^{\circ} \mathrm{C}^{-1}\right)\end{array}$ & $\begin{array}{c}1 / k \\
\left(\mathrm{w} \mathrm{cm}^{-1}{ }^{t} \mathrm{C}^{-1}\right)^{-1}\end{array}$ \\
\hline 54 & 0.07400 & 0.07923 & 12.62 \\
123 & 0.06798 & 0.07273 & 13.75 \\
189.5 & 0.06263 & 0.06699 & 1.4 .92 \\
301 & 0.05410 & 0.05786 & 17.29 \\
399.5 & 0.04762 & 0.05090 & 19.65 \\
494 & 0.04336 & 0.04627 & 21.62 \\
603.5 & 0.03918 & 0.04178 & 23.94 \\
702.5 & 0.03577 & 0.03811 & 26.25 \\
801 & 0.03283 & 0.03496 & 28.61 \\
\hline
\end{tabular}

Table D.3. Measured Thermal Conductivity Volues fram Run 3

(Corrected)

\begin{tabular}{|c|c|c|c|}
\hline$T\left({ }^{\circ} \mathrm{C}\right)$ & $\begin{array}{c}k, \text { meas } \\
\left(\mathrm{w} \mathrm{cm} \mathrm{cm}^{-1} \mathrm{O}^{-1}\right)\end{array}$ & $\begin{array}{c}k_{t^{\prime}} \text { corr } \\
\left(w \operatorname{tin}^{-1} U_{\mathrm{C}^{-1}}\right)\end{array}$ & $\left(w \operatorname{cm}^{-1}{ }^{1 / k}{ }^{t} \mathrm{C}^{-1}\right)^{-1}$ \\
\hline 100 & 0.06722 & 0.07195 & 13.89 \\
\hline 202 & 0.05905 & 0.06317 & 15.83 \\
\hline 402 & 0.04620 & 0.04936 & $20.26^{\circ}$ \\
\hline 597 & 0.03810 & 0.04062 & 24.63 \\
\hline 596 & 0.03848 & 0.0410 .3 & 24.38 \\
\hline 607.5 & 0.03503 & 0.03733 & 26.79 \\
\hline 798.5 & 0.03201 & U.0340 & 29.3 .5 \\
\hline 892 & 0.03007 & 0.03196 & 31.28 \\
\hline 900 & 0.02997 & 0.03185 & 31.39 \\
\hline 1006 & 0.02797 & 0.02970 & 33.67 \\
\hline 1009 & 0.03778 & 0.02950 & 33.89 \\
\hline 1099 & 0.02658 & $0: 02810$ & 35.45 \\
\hline 1192 & 0.02532 & 0.02683 & 37.25 \\
\hline
\end{tabular}

Table D.4. Measured Thermal Conductivity Values from Run 4

(Corrected)

\begin{tabular}{lccc}
$T\left({ }^{\circ} \mathrm{C}\right)$ & $\begin{array}{c}k, \text { meas } \\
\left(\mathrm{w} \mathrm{cm}^{-1} \mathrm{C}^{-1}\right)\end{array}$ & $\begin{array}{c}k_{t^{\prime}} \text { corr } \\
\left(\mathrm{w} \mathrm{cm}^{-1}{ }^{\circ} \mathrm{C}^{-1}\right)\end{array}$ & $\begin{array}{c}1 / k \\
\left(\mathrm{w}^{-1} \mathrm{~cm}^{t} \mathrm{C}^{-1}\right)^{-1}\end{array}$ \\
\hline 298.5 & 0.05196 & 0.05554 & 18.00 \\
597 & 0.03752 & 0.04001 & 25.00 \\
597 & 0.03705 & 0.03951 & 25.31 \\
598.5 & 0.03697 & 0.03941 & 25.38 \\
898 & 0.02909 & 0.03092 & 32.32 \\
902 & 0.02890 & 0.03073 & 32.52 \\
1104 & $0.0261 \%$ & 0.02775 & 36.02 \\
1201.5 & 0.02457 & 0.02601 & 38.40 \\
1202 & 0.02407 & 0.02549 & 39.18 \\
1298 & 0.02390 & 0.02528 & 39.56 \\
\hline
\end{tabular}


Table D.5. Meosured Thermal Conductivity Values from Run 5

(Corrected)

\begin{tabular}{|c|c|c|c|c|c|}
\hline \multirow[b]{2}{*}{$T\left({ }^{\circ} \mathrm{C}\right)$} & \multirow{2}{*}{$\begin{array}{c}k \text {, meas } \\
\left(w \mathrm{~cm}^{-1}{ }^{\circ} \mathrm{C}^{-1}\right)\end{array}$} & \multirow{2}{*}{$\begin{array}{c}k_{t^{\prime}} \text { corr } \\
\left(w \mathrm{~cm}^{-1}{ }^{\circ} \mathrm{C}^{-1}\right)\end{array}$} & \multirow{2}{*}{$\left(w \mathrm{~cm}^{-1 /{ }^{\circ} \mathrm{C}^{t}} \mathrm{C}^{-1}\right)^{-1}$} & \multicolumn{2}{|c|}{ Bottom Plane Only } \\
\hline & & & & $T\left({ }^{\circ} \mathrm{C}\right)$ & $\left(\mathrm{w} \mathrm{cm}^{-1} \stackrel{1 / k}{{ }^{\circ}} \mathrm{C}^{-1}\right)^{-1}$ \\
\hline 109 & 0.06497 & 0.06953 & 14.38 & 1052 & 34.70 \\
\hline 110 & 0.06508 & 0.06962 & 14.35 & 1052 & 34.31 \\
\hline 201 & 0.05813 & 0.06216 & 16.08 & 1149 & 36.15 \\
\hline 200 & 0.05763 & 0.06166 & 16.01 & 903 & 31.10 \\
\hline 296.5 & 0.05147 & 0.05503 & 18.09 & 903 & 31.27 \\
\hline 298.5 & 0.05120 & 0.05472 & 18.13 & 1052 & 34.23 \\
\hline 400 & 0.04600 & 0.04913 & 20.35 & 1052 & 34.41 \\
\hline 400 & 0.04568 & 0.04879 & 20.37 & 1145 & 36.04 \\
\hline 501 & 0.04090 & 0.04365 & 22.90 & 1224 & 37.54 \\
\hline 501 & 0.04110 & 0.04385 & 22.80 & 1224 & 37.82 \\
\hline 601.5 & 0.03726 & 0.03973 & 25.17 & 1272 & 38.28 \\
\hline 601.5 & 0.03750 & 0.03998 & 25.01 & 1272 & 38.49 \\
\hline 700 & 0.03432 & 0.03657 & 27.34 & 1351 & 38.49 \\
\hline 700 & 0.03434 & 0.03658 & 27.33 & 1351 & 39.25 \\
\hline 798 & 0.03188 & 0.03393 & 29.48 & 1178 & 35.44 \\
\hline 798 & 0.03183 & 0.03388 & 29.52 & 1076 & 33.56 \\
\hline 900 & 0.02970 & 0.03158 & 31.65 & 897 & 29.83 \\
\hline 998 & 0.02773 & 0,02945 & 33.95 & 897 & 29.84 \\
\hline 1050 & 0.02700 & 0.02871 & 34.90 & 595 & 23.35 \\
\hline 1099 & 0.02619 & 0.02776 & 36.00 & 296 & 16.79 \\
\hline 1099 & 0.02615 & 0.02773 & 36.02 & & . \\
\hline 1149 & 0.02543 & 0.02694 & 37.07 & & \\
\hline 1150 & 0.02530 & 0.02681 & 37.26 & & \\
\hline 1195 & 0.02481 & 0.02628 & 38.01 & & \\
\hline 1248 & 0.02417 & 0.02557 & 39.10 & & \\
\hline 1250 & 0.02433 & 0.02575 & 38.92 & & \\
\hline 1296 & 0.02339 & 0.02470 & 40.45 & & \\
\hline 1296 & 0.02334 & 0.02469 & 40.56 & & \\
\hline 1296 & 0.02317 & 0.02450 & 41.00 & & \\
\hline
\end{tabular}

Table D.6. Measured Thermal Couductlviry Values trom Run 6

(Corrected)

\begin{tabular}{cccc}
$T\left({ }^{\circ} \mathrm{C}\right)$ & $\begin{array}{c}k, \text { meas } \\
\left(\mathrm{w} \mathrm{cm}^{-1}{ }^{\circ} \mathrm{C}^{-1}\right)\end{array}$ & $\begin{array}{c}k_{\mathrm{t}^{\prime}} \text { corr } \\
\left(\mathrm{w} \mathrm{cm}^{-1}{ }^{\circ} \mathrm{C}^{-1}\right)\end{array}$ & $\begin{array}{c}1 / k \\
\left(\mathrm{w} \mathrm{cm}^{-1}{ }^{{ }^{t}} \mathrm{C}^{-1}\right)^{-1}\end{array}$ \\
\hline 103 & 0.06802 & 0.07281 & 13.73 \\
103 & 0.06740 & 0.07221 & 13.84 \\
303 & 0.05241 & 0.05602 & 17.8 .5 \\
303 & 0.05238 & 0.05590 & 17.86 \\
397.5 & 0.04702 & 0.05023 & 19.91 \\
397.5 & 0.04701 & 0.05022 & 19.91 \\
397.5 & 0.04707 & 0.05038 & 19.89 \\
601 & 0.03836 & 0.04091 & 24.45 \\
50 & 0.07137 & 0.07640 & 13.09 \\
\hline
\end{tabular}


Table D.7. Neasured Thermal Conductivity Values from Run 7

(Corrected)

\begin{tabular}{|c|c|c|c|c|c|c|}
\hline \multirow[b]{2}{*}{$T\left({ }^{\circ} \mathrm{C}\right)$} & \multicolumn{3}{|c|}{ Top Plane with Copper/Constantar. Thermocouples } & \multicolumn{3}{|c|}{ Center Plane with $\mathrm{Pt}$ vs $\mathrm{Pt}-10 \% \mathrm{Rh}$ Thermocoupies } \\
\hline & $\begin{array}{c}k, \text { meas } \\
\left(\mathrm{w} \mathrm{cm}^{-1}{ }^{\circ} \mathrm{C}^{-1}\right)\end{array}$ & $\begin{array}{c}k_{t}, \text { corr } \\
\left(w \mathrm{~cm}^{-1}{ }^{\circ} \mathrm{C}^{-1}\right)\end{array}$ & $\left(\mathrm{w} \mathrm{cm^{-t } o ^ { o } \mathrm { C } ^ { - 1 } ) ^ { - 1 }}\right.$ & $\begin{array}{c}k, \text { meas } \\
\left(w \mathrm{~cm}^{-1}{ }^{\circ} \mathrm{C}^{-i}\right)\end{array}$ & $\begin{array}{c}k_{t}, \operatorname{corr} \\
\left(w \mathrm{~cm}^{-1} \mathrm{o}^{\circ} \mathrm{C}^{-1}\right)\end{array}$ & $\left(w \mathrm{~cm}^{-1 / k}{ }^{\circ} \mathrm{C}^{-1}\right)^{-1}$ \\
\hline 51 & 0.07057 & 0.07555 & 13.23 & & & \\
\hline-18 & 0.06660 & 0.07130 & 14.02 & & & \\
\hline-57 & 0.06347 & 0.06795 & $=4.72$ & . & & \\
\hline-56 & 0.06524 & 0.06985 & 14.32 & & & \\
\hline-39 & 0.06634 & 0.07102 & 14.08 & & & \\
\hline-21 & 0.06285 & 0.06729 & .14 .86 & & & \\
\hline 52 & 0.07111 & 0.07613 & 13.13 & 0.06896 & 0.07383 & 13.54 \\
\hline 104 & 0.06651 & 0.07118 & 14.04 & 0.06491 & 0.06947 & 14.39 \\
\hline 104 & 0.06656 & 0.07124 & 14.03 & 0.06488 & 0.06944 & 14.40 \\
\hline 106 & 0.06692 & 0.07162 & 13.96 & 0.06527 & 0.06986 & 14.31 \\
\hline 105 & 0.06533 & 0.06991 & 14.30 & 0.06415 & 0.06866 & 14.56 \\
\hline 105 & 0.06528 & 0.06986 & 14.31 & 0.06420 & 0.06871 & 14.55 \\
\hline 107 & 0.06534 & 0.06993 & 14.29 & 0.06423 & 0.06874 & 14.54 \\
\hline 109 & 0.06687 & 0.07157 & 13.97 & 0.06532 & 0.06981 & 14.32 \\
\hline
\end{tabular}


Appendix E

ARMCO IRON THERMAL CONDUCTIVITY AND THERMAL DIFFUSIVITY DATA

Table E.1. Thermal Conductivity Data for Armco Iron

\begin{tabular}{|c|c|c|c|}
\hline$T\left({ }^{\circ} \mathrm{C}\right)$ & $\left(w \mathrm{~cm}^{-1} \circ_{\mathrm{O}^{-1}}\right)$ & $\left(\begin{array}{c}k_{\text {corr }}^{a} \\
\left(w \mathrm{~cm}^{-1}{ }^{\circ} \mathrm{C}^{-1}\right)\end{array}\right.$ & $\begin{array}{c}k_{\mathrm{corr}}{ }^{-k} \text { eq. } \\
\left(w \mathrm{~cm}^{-1}{ }^{\circ} \mathrm{C}^{-1}\right)\end{array}$ \\
\hline \multicolumn{4}{|c|}{ Run 1} \\
\hline 112 & 0.6577 & 0.6574 & +0.0002 \\
\hline 210 & 0.5963 & 0.5956 & -0.0003 \\
\hline 300 & 0.5324 & 0.5314 & -0.0083 \\
\hline 400 & 0.4818 & 0.4806 & +0.0038 \\
\hline 500 & 0.4256 & 0.4242 & -0.0008 \\
\hline 500 & 0.4245 & 0.4231 & -0.0019 \\
\hline 600 & 0.3803 & 0.3787 & -0.0002 \\
\hline 600 & 0.3806 & 0.3790 & 0 \\
\hline 698 & 0.3346 & 0.3329 & -0.0011 \\
\hline 698 & 0.3350 & 0.3333 & -0.0007 \\
\hline 717 & 0.3254 & 0.3237 & -0.0015 \\
\hline 717 & 0.3260 & 0.3243 & -0.0009 \\
\hline 741 & 0.3140 & 0.3122 & -0.0018 \\
\hline 741 & 0.3139 & 0.3121 & -0.0019 \\
\hline 780 & 0.2955 & 0.2937 & -0.0024 \\
\hline 780 & 0.2954 & 0.2936 & -0.0025 \\
\hline 819 & 0.2933 & 0.2914 & -0.0026 \\
\hline \multicolumn{4}{|c|}{ Run 2A } \\
\hline 211 & 0.6009 & 0.6002 & +0.0050 \\
\hline 299 & 0.5422 & 0.5412 & +0.0011 \\
\hline 501 & 0.4308 & 0.4294 & +0.0049 \\
\hline 501 & 0.4310 & 0.4296 & +0.0051 \\
\hline 751 & 0.3105 & 0.3087 & -0.0007 \\
\hline 796 & 0.2917 & 0.2899 & -0.0031 \\
\hline 818 & 0.2934 & 0.2915 & -0.0021 \\
\hline 838 & 0.2914 & 0.2895 & -0.0047 \\
\hline 1838 & 0.2915 & 0.2896 & -0.0046 \\
\hline 896 & 0.2923 & 0.2902 & -0.0057 \\
\hline 945 & 0.2877 & 0.2855 & -0.0025 \\
\hline 925 & 0.2916 & 0.2895 & +0.0 .038 \\
\hline \multicolumn{4}{|c|}{ Run 2B } \\
\hline 700 & 0.3398 & 0.3381 & +0.0052 \\
\hline 776 & 0.3011 & 0.2993 & +0.0015 \\
\hline 818 & 0.2950 & 0.2931 & -0.0005 \\
\hline 818 & ก. 2953 & 0.2934 & -0.0002 \\
\hline 862 & 0.2967 & 0.2947 & -0.0002 \\
\hline 896 & 0.2967 & 0.2946 & -0.0013 \\
\hline 896 & 0.2972 & 0.2951 & -0.0008 \\
\hline 908 & 0.2976 & 0.2955 & -0.0007 \\
\hline 923 & 0.2859 & 0.2838 & -0.0016 \\
\hline 9.33 & 0.2872 & 0.2851 & -0.0015 \\
\hline \multicolumn{4}{|c|}{ Run $2 \mathrm{C}$} \\
\hline 933 & 0.2902 & 0.2881 & 10.0015 \\
\hline 060 & 0.2948 & 0.2925 & +0.0016 \\
\hline 1000 & 0.2962 & 0.2938 & -0.0009 \\
\hline \multicolumn{4}{|c|}{ Run 20} \\
\hline 752 & 0.3147 & 0.3129 & +0.0041 \\
\hline 752 & 0.3146 & 0.3128 & +0.0040 \\
\hline $84 y$ & 0.2980 & 0.2960 & +0.0015 \\
\hline 898 & 0.3003 & 0.2982 & +0.0023 \\
\hline 925 & 0.2888 & 0.2867 & +0.0010 \\
\hline
\end{tabular}

${ }^{8}$ Corrected for core heater expansion. 
Table E.2. Cemparison of C.ther Measurements with ORNL Equations

\begin{tabular}{|c|c|c|c|c|c|c|c|c|c|}
\hline \multirow[b]{2}{*}{$\begin{array}{c}\text { Temperature } \\
\left({ }^{\circ} \mathrm{C}\right)\end{array}$} & \multicolumn{8}{|c|}{ Thermal Conductivity $\left(\mathrm{w} \mathrm{cm}^{-1}{ }^{\circ} \mathrm{C}^{-1}\right)$} & \multirow[b]{2}{*}{$E-A$} \\
\hline & $\begin{array}{c}\text { A } \\
\text { ORNL }\end{array}$ & $\begin{array}{c}\text { B } \\
\text { Powell } \\
\text { (BMI Iron) }\end{array}$ & $B-A$ & $\begin{array}{c}\text { C } \\
\text { Powell } \\
\text { (Most Probable) }\end{array}$ & $\mathrm{C}-\mathrm{A}$ & $\begin{array}{c}\text { D } \\
\text { Laubitz } \\
\text { (BMI Iron) }\end{array}$ & $D-A$ & $\begin{array}{c}E \\
\text { Cody, Abeles, } \\
\text { and Beers }\end{array}$ & \\
\hline 0 & 0.7273 & 0.747 & +0.0197 & 0.749 & +0.0277 & & & & \\
\hline 30 & 0.7085 & & & & & 0.691 & -0.0175 & & \\
\hline 100 & 0.6647 & 0.686 & +0.0213 & $0.6: 2$ & +0.0073 & 0.647 & -0.0177 & 0.6600 & -0.0047 \\
\hline 200 & 0.6021 & 0.621 & $+0.018 \subseteq$ & 0.608 & +0.0059 & 0.554 & -0.0181 & 0.6103 & +0.0882 \\
\hline 300 & 0.5395 & 0.555 & +0.0155 & 0.548 & +0.0085 & 0.528 & -0.0115 & 0.5561 & +0.0166 \\
\hline 400 & 0.4769 & 0.492 & +0.015 & 0.437 & +0.0101 & 0.474 & -0.0029 & 0.4932 & +0.0163 \\
\hline 500 & 0.4249 & 0.430 & $+0.005 I$ & 0.433 & +0.0081 & 0.427 & +0.0021 & 0.4290 & +0.0041 \\
\hline 600 & 0.3788 & 0.382 & +0.0032 & 0.339 & +0.0102 & 0.333 & +0.0042 & 0.3696 & -0.0092 \\
\hline 700 & 0.3328 & 0.339 & +0.0062 & 0.345 & +0.0122 & 0.340 & +0.0072 & 0.3190 & -0.0138 \\
\hline 800 & 0.2936 & 0.294 & +0.0064 & 0.500 & +0.0064 & 0.305 & +0.0114 & 0.2982 & +0.0046 \\
\hline 900 & 0.2956 & 0.282 & $-0.01 \leqslant 6$ & $0 .: 86$ & -0.0096 & 0.291 & -0.0046 & 0.3056 & +0.0100 \\
\hline $1000^{\circ}$ & 0.2948 & 0.293 & $-0.00: \varepsilon$ & 0.392 & -0.0023 & 0.303 & +0.0082 & 0.2907 & -0.0041 \\
\hline
\end{tabular}

${ }^{a}$ Calculated from diffusivity values read from curve and MCElro:'s specific heat data.

${ }^{b}$ Read from graphs by Powell and Laubitz. 
Table E.3. Thermal Diffusivity Data of Cody, Abeles, and Beers ${ }^{38}$ Compared to Values Calculated from ORNL Data and McElroy's ${ }^{39}$ Specific Heat Values

\begin{tabular}{|c|c|c|c|c|c|}
\hline $\begin{array}{c}\text { Temperature } \\
\left({ }^{\circ} \mathrm{C}\right)\end{array}$ & $\begin{array}{c}k_{\text {eq. }} \\
\left(\mathrm{w} \mathrm{cm}^{-1}{ }^{\circ} \mathrm{C}^{-1}\right)\end{array}$ & $\left(\right.$ wsec $\mathrm{g}^{\left.-1{ }^{\circ} \mathrm{C}^{-1}\right)}$ & $\begin{array}{l}\alpha=\frac{k}{c_{P}, \rho^{*^{\theta}}} \\
\left(\mathrm{cm}^{2} / \mathrm{sec}\right)\end{array}$ & $\begin{array}{c}\text { Temperature } \\
\left({ }^{\circ} \mathrm{C}\right)\end{array}$ & $\begin{array}{c}a, \\
\text { Cody, Abeles, } \\
\text { and Beers } \\
\left(\mathrm{cm}^{2} / \mathrm{sec}\right)\end{array}$ \\
\hline 100 & 0.6647 & 0.4813 & 0.1761 & 80 & 0.196 \\
\hline 200 & 0.6021 & 0.5245 & 0.1471 & 150 & 0.1 .57 \\
\hline 300 & 0.5395 & 0.5660 & 0.1227 & 270 & 0.132 \\
\hline 400 & 0.4769 & 0.6098 & 0.1012 & 350 & 0.110 \\
\hline 500 & 0.4249 & 0.6638 & 0.0832 & 440 & 0.096 \\
\hline 600 & 0.3788 & 0.7446 & 0.0664 & 550 & 0.078 \\
\hline 700 & 0.3328 & 0.9260 & 0.0471 & 555 & 0.075 \\
\hline 720 & 0.3238 & 0.9920 & 0.0428 & 620 & 0.064 \\
\hline 730 & 0.3191 & 1.029 & 0.0408 & 660 & 0.057 \\
\hline 750 & 0.3099 & 1.267 & 0.0362 & 720 & 0.045 \\
\hline 760 & 0.3054 & 1.229 & 0.0327 & 740 & 0.041 \\
\hline 780 & 0.2961 & 0.9852 & 0.0396 & 740 & 0.040 \\
\hline 800 & 0.2936 & 0.8860 & 0.0437 & 760 & 0.033 \\
\hline 820 & 0.2940 & 0.8386 & 0.0462 & 775 & 0.040 \\
\hline 850 & 0.2947 & 0.7934 & 0.0491 & 790 & 0.043 \\
\hline 900 & 0.2956 & 0.7516 & 0.0520 & 800 & 0.044 \\
\hline 925 & 0.2857 & 0.6222 & 0.0601 & 820 & 0.047 \\
\hline 950 & 0.2886 & 0.6264 & 0.0604 & 845 & 0.049 \\
\hline \multirow[t]{8}{*}{1000} & 0.2948 & 0.6347 & 0.0610 & 860 & 0.049 \\
\hline & & & & 900 & 0.054 \\
\hline & & & & 900 & 0.053 \\
\hline & & & & 920 & 0.062 \\
\hline & & & & 920 & ก. กאח \\
\hline & & & & 950 & 0.061 \\
\hline & & & & 950 & 0.060 \\
\hline & & & & 1000 & 0.061 \\
\hline
\end{tabular}

${ }^{a} \rho^{*}=\rho_{0}^{*}\left(1-3 \alpha_{L} t\right) ; \alpha_{L}$ obtained from Metals Handbook, vol 1, 8th Ed. p 1207.

$\rho_{0}^{*}=7.874 \mathrm{~g} / \mathrm{cm}^{3}$. 
Table E.4. Lattice Electronic Portion of Thermal Conductivity of Armco Iron Obtained by Two Methods and Resulting Lattice Thermal Conductivity

\begin{tabular}{|c|c|c|}
\hline \multirow{3}{*}{$\begin{array}{c}\text { Temperature } \\
\left({ }^{\circ} \mathrm{C}\right)\end{array}$} & \multicolumn{2}{|c|}{ Conductivity, $k_{L}\left(\mathrm{w} \mathrm{cm}-1{ }^{\circ} \mathrm{C}^{-1}\right)$} \\
\hline & From & From \\
\hline & Backlund and Linde ${ }^{a}$ & Wiedemann-Franz-Loren $z^{b}$ \\
\hline 100 & 0.174 & 0.094 \\
\hline 150 & 0.166 & 0.104 \\
\hline 200 & 0.158 & 0.109 \\
\hline 250 & 0.150 & 0.110 \\
\hline 300 & 0.142 & 0.110 \\
\hline 350 & 0.133 & 0.108 \\
\hline 400 & 0.124 & 0.102 \\
\hline 450 & 0.114 & 0.097 \\
\hline 500 & 0.108 & 0.094 \\
\hline bsu & 0.101 & 0.089 \\
\hline 600 & 0.093 & 0.083 \\
\hline 650 & 0.084 & 0.077 \\
\hline 700 & 0.076 & 0.070 \\
\hline 750 & 0.067 & 0.063 \\
\hline 800 & 0.056 & 0.053 \\
\hline 850 & 0.055 & 0.050 \\
\hline 900 & 0.049 & 0.045 \\
\hline 910 & 0.046 & 0.044 \\
\hline 920 & 0.037 & 0.032 \\
\hline 950 & 0.035 & 0.031 \\
\hline 1000 & 0.032 & $0.03 n$ \\
\hline
\end{tabular}

$\left(k_{L}-k+\frac{L T}{\rho+2.66}\right) ; k_{L}$ from Backlund and Linde, and $k$ from OKNL equativins.

$\left(k_{L}=k-\frac{L T}{\rho}\right) ; k_{L}$ from Wiedemann-Franz-Lorenz, and $k$ from ORNL equations. 


\section{Appendix F}

\section{DETERMINATE ERRORS IN ELECTRICAL RESISTIVITY MEASUREMENTS}

Equation (21), used to calculate the electrical resistivity of Armco iron, can be differentiated to give an expression for the fractional error in $\rho(\Delta \rho / \rho)$ due to errors in the terms of the equation, and this yields

$$
\left|\frac{\Delta \rho}{\rho}\right|_{\max }=\left|\frac{\Delta(\Delta \bar{V})}{\Delta \bar{V}}\right|+\left|\frac{\Delta A^{*}}{A^{*}}\right|+\left|\frac{\Delta L^{*}}{L^{*}}\right|+\left|\frac{\Delta \bar{I}}{I}\right|,
$$

if one ignores the uncertainty in the expansion coefficient, $a$. The error in the potentiometer reading, $\Delta \bar{V}$, depended on the range used in the measurement, but the maximum value was about $\pm 0.02 \%$. The same error is involved in the current measurement along with about a $0.05 \%$ uncertainty in the resistance of the standard resistor. The specimen was ground to a diameter of $0.1000 \pm 0.0001$ in. as measured by a micrometer so that the uncertainty in $A^{*}, \Delta A^{*}$, was $0.2 \%$ since the diameter is squared. The error in the length between $\mathrm{Pt}-10 \% \mathrm{Rh}$ legs was no greater than twice the diameter of the wire, or $2 \times 0.005 \mathrm{in}$. This length was measured by a traveling stage microscope. Thus the error in the length was about $1 \%$. Adding these contributions yields a $|\Delta \rho / \rho|_{\max }$ of about $1.3 \%$, which is reduced to $1.0 \%$ if the various contributions are random. 
Appendix G

ELECTRICAL RESISTIVITY DATA FOR ARMCO IRON

Table G.1: Measured Electrical Resistivity Values for Armco Iron and Calculated Electronic Portion of Thermal Conductivity

\begin{tabular}{|c|c|c|c|c|}
\hline \multicolumn{2}{|c|}{ Temperature } & \multirow{2}{*}{$\begin{array}{c}\rho \\
(\mu \circ \mathrm{hm}-\mathrm{cm})\end{array}$} & \multirow{2}{*}{$\begin{array}{c}k_{e}=\frac{L T}{\rho} \\
\left(\mathrm{w} \mathrm{cm}^{-1}{ }^{\circ} \mathrm{C}^{-1}\right)\end{array}$} & \multirow{2}{*}{$\begin{array}{c}k_{c}=\frac{L T}{\rho+2.66} \\
\left(\mathrm{w} \mathrm{cm}^{-1}{ }^{\circ} \mathrm{C}^{-1}\right)\end{array}$} \\
\hline$\left({ }^{\circ} \mathrm{C}\right)$ & $(\mathrm{K})$ & & & \\
\hline 99.8 & & $16.3^{a}$ & & \\
\hline 205.0 & & $24.3^{a}$ & & \\
\hline 311.8 & & $34.3^{a}$ & & \\
\hline $314 A$ & & $34.6^{a}$ & . & \\
\hline 618.2 & & $75.2^{n}$ & & \\
\hline-196.0 & 77.2 & $1.92^{b}$ & 0.982 & 0.413 \\
\hline-18.9 & 194.3 & $0.43^{b}$ & 0.741 & 0.523 \\
\hline 0 & 273.2 & $10.19^{b}$ & 0.658 & 0.519 \\
\hline 18.3 & 291.5 & 11.08 & 0.644 & 0.518 \\
\hline 23.0 & 296.2 & $11.40^{b}$ & 0.637 & 0.515 \\
\hline 103.7 & 376.9 & 10.2 & ก.570 & 0.488 \\
\hline 107.4 & 380.6 . & 16.4 & 0.568 & 0.488 \\
\hline 201.8 & 475.0 & 23.6 & 0.493 & 0.442 \\
\hline 227.8 & 501.0 & 25.7 & 0.478 & 0.431 \\
\hline 276.5 & 549.7 & 30.4 & 0.443 & 0.407 \\
\hline 307.7 & 580.9 & 33.5 & 0.425 & 0.393 \\
\hline 350.8 & 624.0 & 38.2 & 0.400 & 0.374 \\
\hline 378.2 & bb1.4 & 11.1 & 0.388 & 0.365 \\
\hline 401.1 & 674.3 & 44.0 & 0.375 & u. 354 \\
\hline 122.0 & 695.2 & 46.6 & 0.365 & 0.345 \\
\hline 446.5 & 719.7 & 49.8 & 0.354 & 0.336 \\
\hline 485.9 & 759.1 & 54.9 & 0.330 & 0.323 \\
\hline 507.8 & 781.0 & 58.1 & 0.329 & 0.325 \\
\hline 542.8 & 815.9 & 63.1 & 0.317 & 0.307 \\
\hline 581.6 & 854.8 & 69.1 & 0.303 & 0.292 \\
\hline 672.8 & 946.0 & 85.1 & 0.273 & 0.264 \\
\hline 703.8 & 977.0 & 91.1 & 0.263 & 0.255 \\
\hline 744.6 & 1017.8 & 99.3 & 0.231 & 0.244 \\
\hline 752.8 & 1026.0 & 102.2 & 0.246 & 0.240 \\
\hline 776.8 & 1050.0 & 106.3 & 0.242 & 0.236 \\
\hline 797.3 & 1070.5 & 108.4 & 0.242 & 0.237 \\
\hline $798 . ?$ & 1071.4 & 108.6 & 0.241 & 0.236 \\
\hline 807.7 & 1080.9 & 109.3 & 0.311 & 0.238 \\
\hline 847.0 & 1120.2 & 112.2 & 0.244 & 0.238 \\
\hline 896.9 & 1170.1 & 114.3 & 0.251 & 0.245 \\
\hline 918.8 & 1192.0 & 115.1 & 0.25 .3 & 0.247 \\
\hline 951.5 & 1224.7 & 116.2 & 0.258 & 0.252 \\
\hline 991.4 & 1264.6 & 117.5 & 0.264 & ก. 257 \\
\hline 996.4 & 1269.6 & 117.4 & 0.265 & 0.260 \\
\hline
\end{tabular}

${ }^{a}$ Results obtained prior to $620^{\circ} \mathrm{C}$ anneal.

${ }^{b}$ Results obtained in different apparatus on same specimen. 


\section{Appendix H}

\section{ELECTRICAL RESISTIVITY DATA OF Pł vs Pł-10\% Rh}

Table H.1. Measured Electrical Resistance and Calculated Electrical Resistivity

\begin{tabular}{ccc}
\hline $\begin{array}{c}\text { Temperature } \\
\left({ }^{\circ} \mathrm{C}\right)\end{array}$ & $\begin{array}{c}\text { Core-Heater } \\
\text { Resistance } \\
(\text { ohms })\end{array}$ & $\begin{array}{c}\text { Calculated Resistivity } \\
\text { of Pt-10\% Rh }\end{array}$ \\
\hline 23.5 & 0.3704 & $\begin{array}{c}\text { Core Heater }(\mu \mathrm{ohm}-\mathrm{cm}) \\
95\end{array}$ \\
210 & 0.4131 & 19.20 \\
299 & 0.4800 & 21.41 \\
400 & 0.5300 & 24.88 \\
500 & 0.5845 & 27.48 \\
600 & 0.6382 & 30.30 \\
698 & 0.6913 & 33.09 \\
741 & 0.7410 & 35.81 \\
780 & 0.7624 & 38.40 \\
211 & 0.7819 & 39.51 \\
500 & 0.4812 & 40.51 \\
751 & 0.6398 & 24.95 \\
795 & 0.7680 & 33.14 \\
818 & 0.7892 & 39.80 \\
838 & 0.8004 & 40.90 \\
896 & 0.8097 & 41.49 \\
945 & 0.8372 & 41.95 \\
925 & 0.8606 & 43.39 \\
700 & 0.8514 & 44.60 \\
\hline & 0.7433 & 44.11 \\
\hline & & 38.51 \\
\hline
\end{tabular}

${ }^{a} \rho=\Omega A^{*} / L^{*} ; L^{*}=30.75$ in.; $A^{*}=\pi d^{2} / 4 ; d=0.0508 \mathrm{~cm}$. 


\section{Appendix 1 \\ SAMPLE DATA SHEETS AND CALCULATIONS}

All data were recorded on sheets similar to those of Figs. I.1 and I.2. The letters $I$ and $O$ designate thermocouples located at the inside $\left(r_{1}\right)$ and outside $\left(r_{2}\right)$ radii, respectively, while the small hyphenated numbers refer to the thermocouple switching circuitry.

\begin{tabular}{|c|c|c|}
\hline Sheet No.: 36 & Sample: Armco & Date: $8-9-63$ \\
\hline TSOTHFRMAL & Operator: & 3:00 PM \\
\hline
\end{tabular}

\begin{tabular}{|c|c|c|c|c|c|}
\hline $1-1$ & $\begin{array}{c}\text { Top } \\
\text { Plane }\end{array}$ & $\begin{array}{c}\text { Bottonm } \\
\text { Flane }\end{array}$ & $\begin{array}{l}\text { Murfle } \\
\text { Contrng } \\
\end{array}$ & $\begin{array}{l}\text { Inside } \\
\text { Control } \\
\end{array}$ & $\begin{array}{r}\text { Guard } \\
\text { Cuntrol } \\
\end{array}$ \\
\hline$I_{1}$ & $\begin{array}{l}2-1 \\
5233.97\end{array}$ & $\begin{array}{l}2-7 \\
5231.97\end{array}$ & $\begin{array}{l}7-6 \\
\text { T } 4582.0\end{array}$ & $\stackrel{1-4}{T} 5234.48$ & $\begin{array}{c}7-5 \\
\text { T } 5173.34\end{array}$ \\
\hline$I_{2}$ & $\begin{array}{l}2-2 \\
5233.23\end{array}$ & $\begin{array}{l}2-8 \\
5234.43\end{array}$ & $\begin{array}{l}1-7 \\
\mathrm{C} \quad 5127.4\end{array}$ & $\begin{array}{l}1-5 \\
C \quad 5232.07\end{array}$ & $\begin{array}{c}7-2 \\
\text { B } 5195.57\end{array}$ \\
\hline $\mathrm{I}_{3}$ & $\begin{array}{l}2-3 \\
5232.36 \\
\end{array}$ & $\begin{array}{l}2-9 \\
5232.76 \\
\end{array}$ & $\begin{array}{l}7-1 \\
\text { B } 4606.0\end{array}$ & $\begin{array}{l}1-6 \\
\text { B } 5234.43\end{array}$ & \\
\hline $\mathrm{Av}$ & 5233.18 & 5233.05 & & 5232.98 & \\
\hline
\end{tabular}

\begin{tabular}{l|l|l||c|}
\hline$\dot{U}_{1}$ & $\begin{array}{l}2-4 \\
5232.61\end{array}$ & $\begin{array}{l}2-10 \\
5233.01\end{array}$ & $\begin{array}{c}\text { Center } \\
\text { I'Iank }\end{array}$ \\
\hline $0_{2}$ & $2-5$ & $2-11$ & $7-3$ \\
& 5233.12 & 5233.07 & $\mathrm{I}$ \\
\hline $0_{3}$ & $2-6$ & $2-12$ & $7-4$ \\
& 5232.13 & 5233.18 & 0 \\
\hline \hline $\mathrm{AV}$ & 5232.62 & 5233.09 & \\
\hline
\end{tabular}

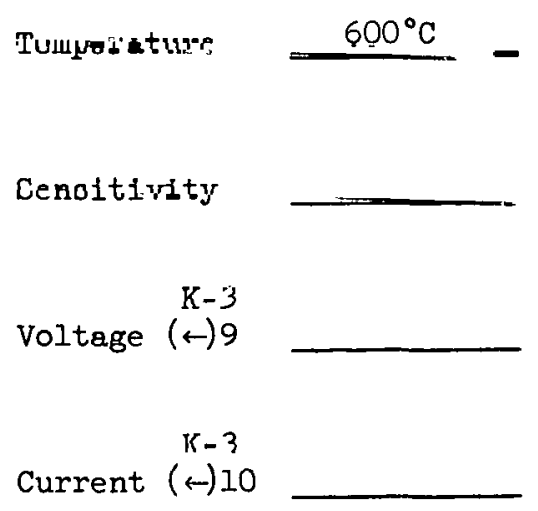

\begin{tabular}{|l|l|l|l|}
\hline$\Delta v$ \\
Diff. \\
$\begin{array}{l}\text { TC } \\
\text { Corr. }\end{array}$ & +0.56 & $-U .04$ & \\
\hline Corr. & & +0.04 & \\
Diff. & & & \\
\hline
\end{tabular}

Power

\begin{tabular}{c|l|l|l|}
\hline $\mathrm{X}$ & & & \\
\hline $\mathrm{XVIS}$ & & & \\
\hline
\end{tabular}

\section{Power}

VIS

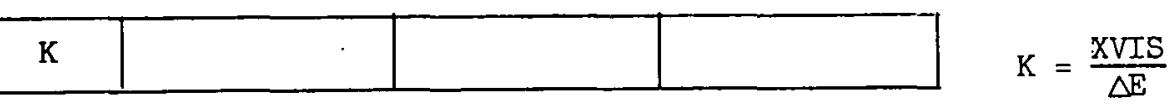

Fig. 1.1. Sample "Isothermal" Data Sheet for Armco Iron at $600^{\circ} \mathrm{C}$. 
Figure I.1 shows a set of Armco iron data taken under isothermal conditions at $600^{\circ} \mathrm{C}$. The twelve thermocouple emf's of the two measuring planes were read directly, the readings were properly averaged, and the average differences between the inside and outside positions were

Sheet No.: 38

DATA

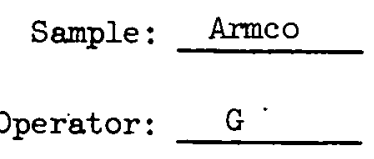

Date: $8-12-63$

Time: $4: 15$ PM

\begin{tabular}{|c|c|c|c|c|c|}
\hline $1-1$ & $\begin{array}{c}\text { Top } \\
\text { Plane }\end{array}$ & $\begin{array}{r}\begin{array}{r}\text { Bottom } \\
\text { Plane }\end{array} \\
\end{array}$ & $\begin{array}{l}\text { Muffle } \\
\text { Control }\end{array}$ & $\begin{array}{l}\text { Inside } \\
\text { Control } \\
\end{array}$ & $\begin{array}{c}\text { Guard } \\
\text { Control } \\
\end{array}$ \\
\hline$I_{1}$ & $\begin{array}{l}2-1 \\
5252.20 \\
\end{array}$ & $\begin{array}{l}2-7 \\
5247 \cdot 10\end{array}$ & $\begin{array}{cc}7-6 \\
T \quad 4395.0 \\
\end{array}$ & $\begin{array}{|cc|}1-4 & \\
T & 5227.46 \\
\end{array}$ & $\begin{array}{ll}7-5 & \\
T & 5277.3\end{array}$ \\
\hline$I_{2}$ & $\begin{array}{r}2-2 \\
51.73 \\
\end{array}$ & $\begin{array}{r}2-8 \\
52.61 \\
\end{array}$ & $\begin{array}{c}1-7 \\
\mathrm{C}\end{array}$ & $\begin{array}{c}1-5 \\
\mathrm{C}\end{array}$ & $\begin{array}{c}7-2 \\
B \quad 5355.2\end{array}$ \\
\hline$I_{3}$ & $\begin{array}{r}2-3 \\
50.60\end{array}$ & $\begin{array}{r}2-9 \\
50.38 \\
\end{array}$ & $\begin{array}{l}7-1 \\
\text { B } 4393.0\end{array}$ & 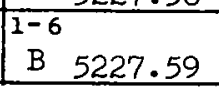 & \\
\hline $\mathrm{Av}$ & 5251.51 & 5250.03 & & & \\
\hline
\end{tabular}

\begin{tabular}{c|c|c||c|}
\hline$O_{1}$ & $\begin{array}{c}2-4 \\
5220.03\end{array}$ & $\begin{array}{c}2-10 \\
5218.28\end{array}$ & $\begin{array}{c}\text { Center } \\
\text { Plane }\end{array}$ \\
\hline $0_{2}$ & $2-5$ & $2-11$ & $7-3$ \\
& 21.34 & 20.68 & $\mathrm{I}$ \\
\hline$O_{3}$ & $2-6$ & $2-12$ & $7-4$ \\
19.67 & 19.04 & 0 \\
\hline \hline $\mathrm{Av}$ & 5220.35 & 5219.33 & \\
\hline
\end{tabular}

Temperature

Sensitivity $\quad 10.196$

$\mathrm{K}-3 \quad 6.3835$

Voltage $(\leftarrow) 9 \quad \underline{6.3837}$

$\mathrm{K}-3 \quad 8.8914$

Current $(\leftrightarrow) 10 \quad 8.8916$

Power

56.7598

\begin{tabular}{c|l|l|l|}
\hline $\mathrm{X}$ & 0.020155 & 0.020154 & \\
\hline $\mathrm{XVIS}$ & 1.1664156 & 1.1663577 & \\
\hline
\end{tabular}

VIS

57.87227

$$
\begin{aligned}
& \begin{array}{l|l|l|l|}
\hline \mathrm{K} & 0.38118 & 0.37943 & \\
\hline
\end{array} \\
& 0.38030=\bar{k}_{\text {meas }}=\bar{k}_{m} \\
& \mathrm{k}_{\text {true }}=\overline{\mathrm{k}}_{\mathrm{m}}(1-\alpha \mathrm{T}) \\
& =0.38030(0.9958) \\
& =0.37870
\end{aligned}
$$

Fig. 1.2. Sample Data Sheet for Armen Iran at $600^{\circ} \mathrm{C}$. 
recorded. These numbers are the so-called isothermal corrections. It should be noted that in the case of Armco iron the differential emf's were obtained only from absolute measurements rather than from both direct differential, emf and absolute emf measurements as in the case of UO, It was observed during the course of measurements on $\mathrm{UO}_{2}$ that the agreement between the differences calculated and those measured directly was always within $0.02 \mu \mathrm{v}$ and, most often, $0.01 \mu \mathrm{v}$. This agreement, together with the fact that differential emf measurements at temperatures above $600^{\circ} \mathrm{C}$ were hindered by the apparent high-resistance shorting of the differential thermocouple junctions, prompted the adoption of this simplified data-acquisition procedure.

Figure I.2 shows the companion set of data on Armco iron taken with power applied to the core heater and the controllers reset to give the same average specimen temperature. The dc voltage and current were measured both before and after the thermocouple emf's were determined, and the averages were used to calculate the power dissipated by the 3 -in. center section of the core heater. The averages of the groups of thermocouples were calculated, and from these, the average differences. The previously determined isothermal corrections (Fig. I.1) were algebraically applied to yield the corrected differentials. The thermocouple sensitivity at the average specimen temperature was obtained from the computer-generated set of tables described in the text. Since the $\Delta T$ was so small in these experiments, the error introdiced by the use of the sensitivity corresponding to the average temperature is less than $0.01 \%$. The " $X$ " appearing in the table and in the equation for $k$ is unique to the particular specimen and is equal to $\ln \left(r_{2} / r_{1}\right) / 2 \pi L$. The radii to the centers of the holes in the Armco specimen and the calculations yielding the " $X$ " values are:

\begin{tabular}{|c|c|c|}
\hline & Top Plure (inr:) & Ronttnm Plane (in:) \\
\hline$I_{1}$ & 0.1980 & 0.5001 \\
\hline$I_{2}$ & 0.5002 & 0.5000 \\
\hline$I_{3}$ & 0.5001 & 0.5002 \\
\hline$I_{a v}$ & 0.5001 & 0.5001 \\
\hline $\ln I_{a v}$ & $-0.69294 \% 2$ & $-0.6929472-\ln e_{1}$ \\
\hline$o_{1}$ & 1.3124 & 1.3126 \\
\hline $\mathrm{O}_{2}$ & 1.3126 & 1.3125 \\
\hline$O_{3}$ & 1.3126 & 1.3127 \\
\hline$O_{\mathrm{av}}$ & 1.3125 & 1.3126 \\
\hline $\ln O_{a v}$ & 0.2719337 & $0.2720099=\ln r_{2}$ \\
\hline $\ln t_{2}-\ln r_{1}$ & 0.9648809 & $0.9649571=\ln r_{2} / s_{1}$ \\
\hline$L$ & \multicolumn{2}{|c|}{$3.00 \mathrm{in.} \times 2.54 \mathrm{~cm} / \mathrm{in}$} \\
\hline$\frac{\ln r_{2} / r_{1}}{2 \pi L}$ & 0.0201 .53 & $0.020154=X$ \\
\hline
\end{tabular}


It may be noted that the logarithms of the average radii are taken rather than the average of the logarithms of the radii. It is not clear exactly which average should be used, but the difference is only $1 \mathrm{ppm}$ and is therefore insignificant.

The thermal conductivity, $k$, uncorrected for the thermal expansion of the core heater, is calculated using the tabulated data for each of the separate planes, and the average $k$ is then obtained. This average $k$ is corrected for the expansion of the core heater by the relation

$$
k_{\text {true }}=k_{\text {measured }}(1-\alpha T) \text {, }
$$

where $\alpha$ is the coefficient of thermal expansion of Coors AD-99 $\mathrm{Al}_{2} \mathrm{O}_{3}$, and $T$ is the core-heater temperature. As a matter of convenience, all of the results were corrected after the conclusion of the experiment through the use of correction charts and graphs.

This sample calculation represents the result shown on line 7 , run 1, of Table E.1. 


\section{THIS PAGE}

\section{WAS INTENTIONALLY LEFT BLANK}




\section{INTERNAL DISTRIBUTION}

1. Biology Library

2. Reactor Division Library

3-5. Central Research Library

6-7. ORNL - Y-12 Technical Library

Document Reference Section

8-201. Laboratory Records Department

202. Laborotory Records, ORNL R.C.

203. R. E. Adams

204. C. D. Baumann

205. R. J. Beaver

206. C. Brandon

207. N. H. Briggs

208. W. H. Cook

209. J. W. Cooke

210. J. H. Crawford

211. J. E. Cunningham

212. P. B. Denee

213. W. S. Ernst, Jr.

214. J. I. Federer

215. J. H Frye, Jr.

216. W. Fulkerson

217. H. W. Godbee

218. T. G. Godfrey

219. W. O. Harms

220-224. M. R. Hill

225. G. W. Keilholtz
226. T. G. Kollie

227. C. E. Larson

228. G. H. Llewellyn

229. H. G. MacPherson

230-259. D. L. McElroy

260. C. J. McHargue

261. H. A. McLain

262. J. P. Moore

263-264. R. B. Parker

265. S. A. Rabin

266. M. W. Rosenthal

267. G. Samuels

268. O. Sismon

269. M. J. Skinner

270. J. A. Swartout

271. W. C. Thurber

272-292. D. B. Trauger

293. G. M. Watson

294. A. M. Weinberg

295. W. J. Werner

296. G. C. Williams

297. A. A. Burr (consultant)

298. J. R. Johnson (consultant)

299. C. S. Smith (consultant)

300. R. Smoluchowski (consultant

\section{EXTERNAL DISTRIBUTION}

301. Research and Development Division, ORO

302. C. M. Adams, Jr., Massachusetts Institute of Technology

303-304. David F. Cope, Oak Ridge Operations

305-306. General Electric, Hanford (1 copy each to D. E. Baker and Ersel Evans)

307. J. L. Gregg, Cornell University

308-309. AEC, Washington (1 copy each to J. Simons and Donald K. Stevens)

310. E. E. Stansbury, University of Tennessee

311. Lawrence M. Slifkin, University of North Carolina

312-885. Given distribution as shown in TID-4500 (29th ed.) under Metals, Ceramics, and Materials category (75 copies - OTS) 